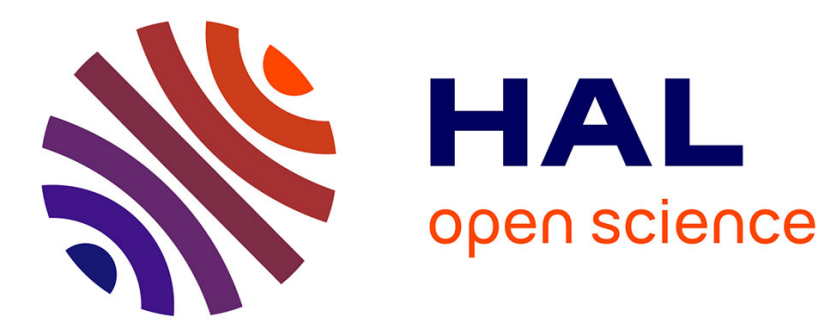

\title{
1D-coupled photochemical model of neutrals, cations and anions in the atmosphere of Titan
}

\author{
M. Dobrijevic, J.C. Loison, Kevin Hickson, G. Gronoff
}

\section{To cite this version:}

M. Dobrijevic, J.C. Loison, Kevin Hickson, G. Gronoff. 1D-coupled photochemical model of neutrals, cations and anions in the atmosphere of Titan. Icarus, 2016, 268, pp.313-339. 10.1016/j.icarus.2015.12.045 . hal-03107467

\section{HAL Id: hal-03107467 \\ https://hal.science/hal-03107467}

Submitted on 12 Jan 2021

HAL is a multi-disciplinary open access archive for the deposit and dissemination of scientific research documents, whether they are published or not. The documents may come from teaching and research institutions in France or abroad, or from public or private research centers.
L'archive ouverte pluridisciplinaire HAL, est destinée au dépôt et à la diffusion de documents scientifiques de niveau recherche, publiés ou non, émanant des établissements d'enseignement et de recherche français ou étrangers, des laboratoires publics ou privés. 


\title{
1D-coupled photochemical model of neutrals, cations and anions in the atmosphere of Titan
}

\author{
M. Dobrijevic ${ }^{\mathrm{a}, \mathrm{b}}$ J.C. Loison ${ }^{\mathrm{c}, \mathrm{d}}$ K.M. Hickson ${ }^{\mathrm{c}, \mathrm{d}}$ G. Gronoff ${ }^{\mathrm{e}}$

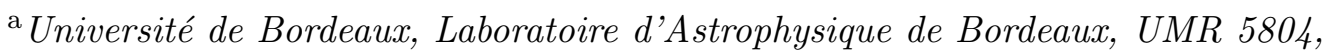 \\ F-33270 Floirac, France \\ ${ }^{\mathrm{b}}$ CNRS, Laboratoire d'Astrophysique de Bordeaux, UMR 5804, F-33270, Floirac, \\ France \\ ${ }^{\mathrm{c}}$ Université de Bordeaux, Institut des Sciences Moléculaires, UMR 5255, F-33400 \\ Talence, France \\ ${ }^{\mathrm{d}}$ CNRS, Institut des Sciences Moléculaires, UMR 5255, F-33400 Talence, France \\ e SSAI/NASA LaRC, Hampton, Va, USA
}

Number of pages: 50

Number of tables: 3

Number of figures: 27

Michel Dobrijevic

Laboratoire d'Astrophysique de Bordeaux

2 rue de l'observatoire, Floirac, F-33271, France.

Email: Michel.Dobrijevic@obs.u-bordeaux1.fr

Phone: +33-5-5777-6124

\section{Introduction}

Numerous models have been published that simulate the chemical processes at work in Titan's stratosphere and ionosphere. Keller et al. (1998) first included a rather detailed ionospheric chemistry. Banaszkiewicz et al. (2000) and Wilson and Atreya (2004) proposed the first coupled models of neutral species and ions. The study of Titan's ionosphere expanded rapidly with the Cassini mission. INMS ion data was first reported by Cravens et al. (2006) followed by numerous studies (see for instance De La Haye et al. (2008); Vuitton et al. 
(2009); Lavvas et al. (2011); Krasnopolsky (2014)). A detailed review on Titan's ionosphere is given in Galand et al. (2014). Mandt et al. (2012) listed the main photochemical models of Titan's ionosphere that had been published at that time, presenting what they considered as the main strengths and limitations of these models. Following Mandt et al. (2012), some of the most relevant features which are important for modeling Titan's ionosphere are the following:

- Detailed ion and neutral chemistry. A thorough evaluation of ion chemistry is required to improve models.

- A careful sensitivity study of uncertainty propagation in ion chemistry models. Such investigations are required to evaluate the level of predictivity of these models and to pinpoint important chemical processes.

- The way neutral densities are determined. Many models use partially or completely uncoupled neutral abundances leading to an absence of chemical feedback between ions and neutrals. Such fixed-neutral profile models allow the richness of heavy ion chemistry to be explored due to a lower computational time that makes it possible to include many more ions compared to ion-neutral coupled 1D models.

- The use of suitable cross-sections and quantum yields for photo-absorptions. In particular, several studies (Lavvas et al., 2011; Mandt et al., 2012; LuspayKuti et al., 2015) highlighted the need to use high resolution cross-sections for $\mathrm{N}_{2}$.

- A study of vertical and horizontal transport including diurnal and seasonal variations. 2D-3D photochemical models are computationally time consuming and require a reduced chemical scheme.

We (and others) have developed during the last few years a methodology to improve chemical schemes for Titan's atmosphere based on two complementary tasks (see Hébrard et al. (2009) and Loison et al. (2015) for details on the methodology): (1) the determination of key reactions through uncertainty propagation studies and global sensitivity analyses and (2) the completeness of the chemical scheme. Since the papers of Hébrard et al. (2006) and Hébrard et al. (2007) for neutral species and Carrasco et al. (2007a) for ions, we see that this methodology improves the agreement between model results and observations by comparison with Loison et al. (2015) and the present paper. Also, uncertainties on model results, at least for $\mathrm{C}_{2} \mathrm{H}_{x}$ and some nitrogen species like $\mathrm{HCN}$, have significantly decreased. We think that an improvement on the knowledge of the chemistry of Titan's atmosphere is a prerequisite for constraining many physical parameters. The aim of the present study is to develop a new photochemical model of Titan's atmosphere following this methodology, combining the strengths of several previous models. In particular:

- We propose a detailed chemical scheme that improves previous works. Following the recent papers of Hébrard et al. (2012); Hébrard et al. (2013); Do- 
brijevic et al. (2014); Hickson et al. (2014) and Loison et al. (2015), we continue in the present paper to improve the chemistry of Titan's atmosphere with thorough evaluations and updates, especially for neutral chemistry, the dissociative recombination of positive ions and negative ion chemistry.

- We develop a 1D photochemical model with vertical transport coupling neutral species with positive and negative ions. Since the production of ions is likely to be strongly related to the density of neutrals, our model computes abundance profiles from the surface up to $1500 \mathrm{~km}$ to be as consistent as possible with the various neutral species that have been observed in the lower and middle stratosphere and in the ionosphere.

- Most of the chemical rate constants have relatively large uncertainties. It is therefore important to study how these uncertainties propagate into the model and to determine the most influential chemical processes affecting the results. A global sensitivity analysis is performed to pinpoint the key reactions and to determine the importance of feedback between neutral and ion species.

In Section 2, we present our model, highlighting the main chemical processes that have been taken into account for the ion chemistry and the major modifications compared to the model of Loison et al. (2015) for neutral species. Our results, comparisons with Cassini/INMS data and the propagation of uncertainties are presented in section 3, with a particular emphasis on ion species. Specific points are discussed in section 4 before concluding in section 5 .

\section{Model}

\subsection{Neutral species}

Details of the model (eddy diffusion coefficient, boundary conditions, UV absorption by haze, condensation, etc) are given in Loison et al. (2015). Only major modifications are outlined in the following. The chemical scheme of neutral species is similar to the one presented in Loison et al. (2015) with some minor changes. To reduce the computational time of our full 1D-coupled model, we have limited the chemistry of hydrocarbons to $\mathrm{C}_{4}$-species and therefore do not consider $\mathrm{C}_{6} \mathrm{H}_{x}$ species. We have excluded some nitriles with high molecular mass $\left(\mathrm{HC}_{5} \mathrm{~N}, \mathrm{C}_{3} \mathrm{H}_{5} \mathrm{CN}, \mathrm{C}_{3} \mathrm{H}_{7} \mathrm{CN}\right.$, etc) because our previous model (Loison et al., 2015) shows that these compounds have very low abundances. We include $\mathrm{CH}_{3} \mathrm{C}_{3} \mathrm{~N}$ because the same model predicts it to have a relatively high abundance. We consider isomers only for $\mathrm{C}_{3} \mathrm{H}$ (linear and cyclic), $\mathrm{C}_{3} \mathrm{H}_{4}$ (methylacetylene and allene) and $\mathrm{CH}_{3} \mathrm{CN}$ (considering also $\mathrm{CH}_{2} \mathrm{NCH}$ ) as they have notably different reactivities. In the case of $\mathrm{C}_{3} \mathrm{H}_{2}$ we check that the use of only one isomer (the cyclic one) is enough to describe the chemistry in 
the present model as the main reactions of the two less stable $\mathrm{C}_{3} \mathrm{H}_{2}$ isomers (the carbene: $\mathrm{H}_{2} \mathrm{CCC}$ and the linear one: $\mathrm{HCCCH}$ ) should be with hydrogen atoms leading to the most stable cyclic isomer (Hébrard et al., 2013). Also, we do not consider reactions with very small fluxes (such as the $\mathrm{CH}+\mathrm{CH}$ reaction for instance). Consequently, we obtained a much smaller number of chemical reactions (137 neutral bimolecular reactions instead of 801, and 73 neutral termolecular reaction instead of 168). The complete list of reactions considered in the present study is given in appendix A (available in the supplementary material). We carefully checked that the omission of these chemical reactions has very little, if any, effect on the species considered in the model. The chemical scheme has been slightly updated, particularly for $\mathrm{C}_{4} \mathrm{H}_{x}$ species. Sulfur chemistry (Hickson et al., 2014) is not included in the present model since no sulfur-bearing species have been detected so far. The chemical scheme includes 74 neutral species, which are listed in Table 1. Our model includes vertical transport (eddy and vertical diffusion) for neutral species from the surface up to $1500 \mathrm{~km}$. We use the high resolution $(\Delta \lambda=0.004 \mathrm{~nm})$ solar spectrum of Curdt et al. (2001, 2004) between $67 \mathrm{~nm}$ and $160 \mathrm{~nm}$. This spectrum is scaled to the solar spectrum (at the solar minimum) of Thuillier et al. (2004) using the continuum at $150 \mathrm{~nm}$. For the Monte-Carlo procedure, we use global-mean photolysis rates which are calculated using a Solar Zenith Angle (SZA) of about $60^{\circ}$ and a diurnally averaged solar flux half of that at Saturn's distance from the Sun.

The high resolution absorption cross sections for $\mathrm{N}_{2}$ at $150 \mathrm{~K}$ (Heays, A.N, personal communication) between $84 \mathrm{~nm}$ and $100 \mathrm{~nm}$ are included in the present model. The high resolution (HR) cross sections of $\mathrm{N}_{2}(\Delta \lambda=0.004$ $\mathrm{nm}$ ) are presented in Figure 1 and are compared to the low resolution (LR) cross sections $(\Delta \lambda=1 \mathrm{~nm})$ of $\mathrm{N}_{2}, \mathrm{CH}_{4}$ and $\mathrm{H}_{2}$. The use of $\mathrm{HR}$ could have a noticeable effect on the calculation of the photodissociation rate of $\mathrm{N}_{2}, \mathrm{CH}_{4}$ and $\mathrm{H}_{2}$ due to the existence of many lines in the $\mathrm{HR}$ cross sections of $\mathrm{N}_{2}$ (for the wavelength range considered here).

The photolysis pathways considered in the present study are the following (see also appendix $\mathrm{A}$, available in the supplementary material):

$\mathrm{N}_{2}+\mathrm{h} \nu \rightarrow \mathrm{N}\left({ }^{2} \mathrm{D}\right)+\mathrm{N}\left({ }^{4} \mathrm{~S}\right) \lambda>89.1 \mathrm{~nm}$ and $\lambda<102.1 \mathrm{~nm}$

$\mathrm{N}_{2}+\mathrm{h} \nu \rightarrow \mathrm{N}\left({ }^{2} \mathrm{P}\right)+\mathrm{N}\left({ }^{4} \mathrm{~S}\right) \lambda>85.4 \mathrm{~nm}$ and $\lambda>89.1 \mathrm{~nm}$

$\mathrm{N}_{2}+\mathrm{h} \nu \rightarrow \mathrm{N}\left({ }^{2} \mathrm{D}\right)+\mathrm{N}\left({ }^{2} \mathrm{D}\right) \lambda<85.4 \mathrm{~nm}$

and we assume that $\mathrm{N}\left({ }^{2} \mathrm{P}\right)$ is rapidly converted to $\mathrm{N}\left({ }^{2} \mathrm{D}\right)$ (Lavvas et al., 2011).

According to Chen and $\mathrm{Wu}$ (2004), the absorption features of $\mathrm{CH}_{4}$ between $120 \mathrm{~nm}$ and $142.5 \mathrm{~nm}$ exhibit broad diffuse bands. So, they concluded that continuum absorption should be independent of instrumental resolution in this spectral range. As a consequence, we do not consider the high resolution absorption cross section of $\mathrm{CH}_{4}$ in the present study. 
Table 1

List of the 74 neutrals included in the model

\begin{tabular}{c}
$\mathrm{C}, \mathrm{CH},{ }^{1} \mathrm{CH}_{2},{ }^{3} \mathrm{CH}_{2}, \mathrm{CH}_{3}, \mathrm{CH}_{4}$ \\
${ }^{1} \mathrm{C}_{2},{ }^{3} \mathrm{C}_{2}, \mathrm{C}_{2} \mathrm{H}, \mathrm{C}_{2} \mathrm{H}_{2}, \mathrm{C}_{2} \mathrm{H}_{3}, \mathrm{C}_{2} \mathrm{H}_{4}, \mathrm{C}_{2} \mathrm{H}_{5}, \mathrm{C}_{2} \mathrm{H}_{6}$ \\
$\mathrm{C}_{3}, \mathrm{cC}_{3} \mathrm{H}, 1 \mathrm{C}_{3} \mathrm{H}, \mathrm{C}_{3} \mathrm{H}_{2}, \mathrm{C}_{3} \mathrm{H}_{3}, \mathrm{CH}_{2} \mathrm{CCH}_{2}, \mathrm{CH}_{3} \mathrm{C}_{2} \mathrm{H}, \mathrm{C}_{3} \mathrm{H}_{5}, \mathrm{C}_{3} \mathrm{H}_{6}, \mathrm{C}_{3} \mathrm{H}_{7}, \mathrm{C}_{3} \mathrm{H}_{8}$ \\
$\mathrm{C}_{4} \mathrm{H}, \mathrm{C}_{4} \mathrm{H}_{2}, \mathrm{C}_{4} \mathrm{H}_{3}, \mathrm{C}_{4} \mathrm{H}_{4}, \mathrm{C}_{4} \mathrm{H}_{5}, \mathrm{C}_{4} \mathrm{H}_{6}, \mathrm{C}_{4} \mathrm{H}_{7}, \mathrm{C}_{4} \mathrm{H}_{8}, \mathrm{C}_{4} \mathrm{H}_{9}, \mathrm{C}_{4} \mathrm{H}_{10}$ \\
$\mathrm{CN}, \mathrm{C}_{2} \mathrm{~N}, \mathrm{C}_{2} \mathrm{~N}_{2}, \mathrm{C}_{3} \mathrm{~N}$ \\
$\mathrm{HCN}, \mathrm{HNC}, \mathrm{H}_{2} \mathrm{CN}, \mathrm{HCCN}, \mathrm{CH}_{2} \mathrm{CN}, \mathrm{CH}_{2} \mathrm{NCH}, \mathrm{CH}_{3} \mathrm{CN}, \mathrm{HC}_{3} \mathrm{~N}, \mathrm{H}_{2} \mathrm{C}_{3} \mathrm{~N}, \mathrm{C}_{2} \mathrm{H}_{3} \mathrm{CN}, \mathrm{C}_{2} \mathrm{H}_{4} \mathrm{CN}_{2} \mathrm{C}_{2} \mathrm{H}_{5} \mathrm{CN}_{1} \mathrm{HC}_{4} \mathrm{~N}, \mathrm{CH}_{2} \mathrm{C}_{3} \mathrm{~N}, \mathrm{CH}_{3} \mathrm{C}_{3} \mathrm{~N}$ \\
$\left.\mathrm{~N}\left({ }^{2} \mathrm{D}\right), \mathrm{N}^{4} \mathrm{~S}\right), \mathrm{N}_{2}$ \\
$\mathrm{NH}, \mathrm{NH}_{2}, \mathrm{NH}_{3}$ \\
$\mathrm{CH}_{2} \mathrm{NH}, \mathrm{CH}_{3} \mathrm{NH}, \mathrm{CH}_{3} \mathrm{NH}_{2}$ \\
$\mathrm{O}\left({ }^{3} \mathrm{P}\right), \mathrm{O}\left({ }^{1} \mathrm{D}\right), \mathrm{OH}, \mathrm{H}_{2} \mathrm{O}, \mathrm{CH}_{3} \mathrm{O}, \mathrm{CO}, \mathrm{HCO}, \mathrm{H}_{2} \mathrm{CO}, \mathrm{CO}_{2}$ \\
\hline
\end{tabular}

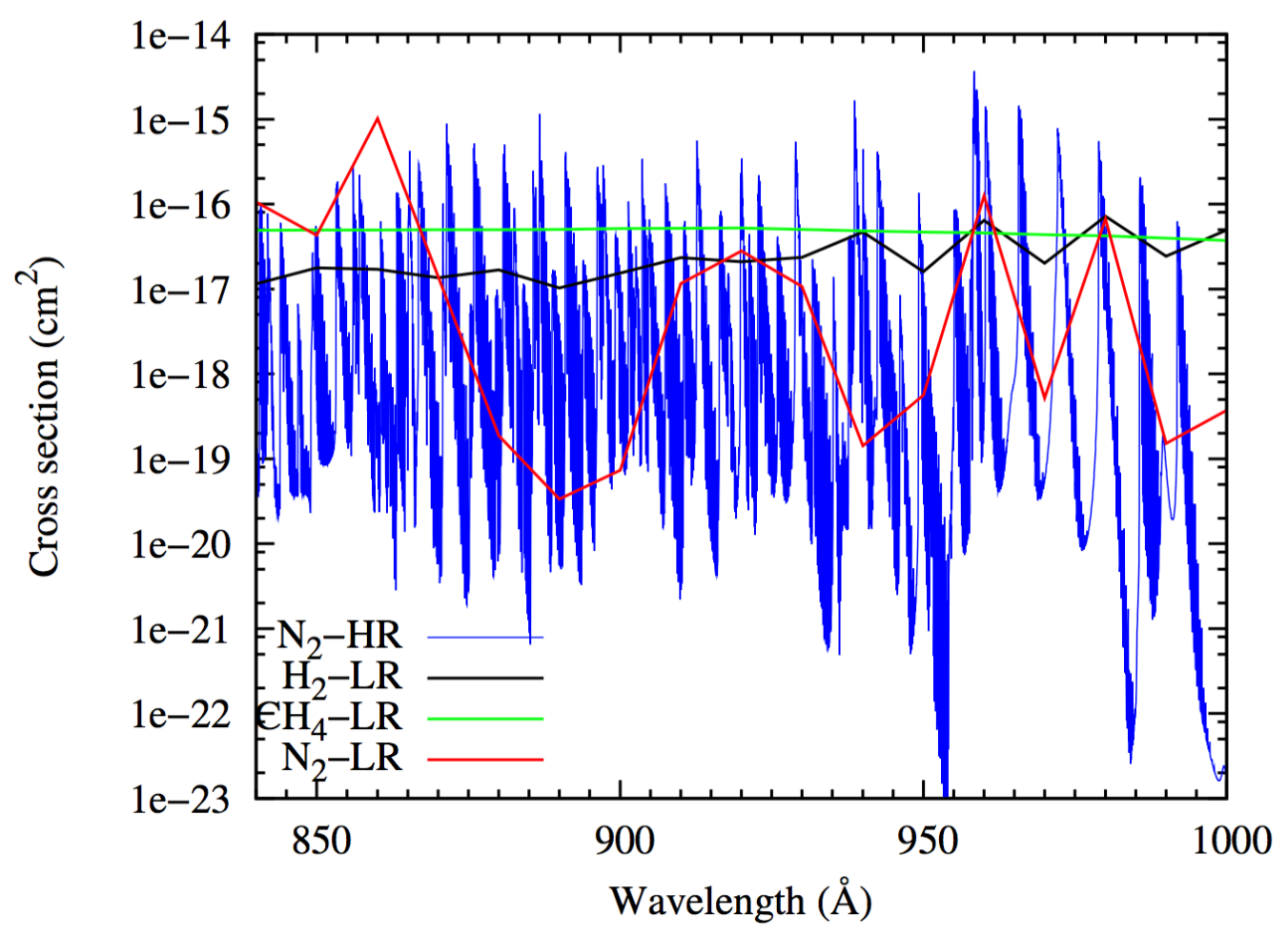

Fig. 1. Absorption cross sections of $\mathrm{N}_{2}, \mathrm{CH}_{4}$ and $\mathrm{H}_{2}$ at low resolution (LR: $\Delta \lambda=1$ $\mathrm{nm}$ ) and high resolution (HR: $\Delta \lambda=0.004 \mathrm{~nm}$ ).

\subsection{Positive and negative ions}

Ambipolar diffusion and the escape of ions are neglected in the present study. According to Westlake et al. (2012), vertical transport for the main ions is not important below $1300 \mathrm{~km}$ and might not be important between $1300 \mathrm{~km}$ and $1500 \mathrm{~km}$, so this process is not considered in the present study (which also reduces the computation time for the Monte-Carlo procedure). The model includes 47 positive ions and 7 negative ions (including electrons). A list of the positive and negative ions included in the model is given in Table 2. The list of reactions is given in appendix A (available in the supplementary material). 
In the following section, we compare our results mainly with the INMS data analyzed by Mandt et al. (2012). Fourteen Titan passes have been included in their analysis from T5 (April 2005) to T59 (July 2009). Most of these flybys have been performed between 2007 and 2009 corresponding to the minimum of the solar cycles 23-24. We also compare our results with Westlake et al. (2012) who presented the density profiles of many ions for the T40 flyby (January 2008). For this reason, we use a solar spectrum corresponding to a minimum of the solar activity.

\subsubsection{Positive ion chemistry}

Table 2

List of the 54 ions (cations et anions) included in the model

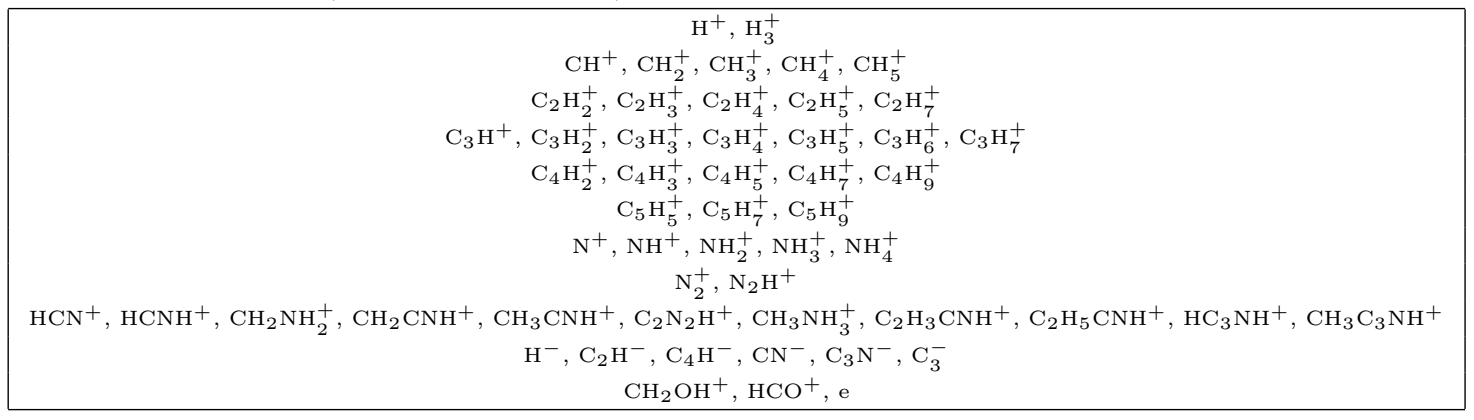

The methodology we used to build our ion chemical scheme is similar to the one presented in Loison et al. (2015). However, in contrast to our recent approach towards neutral chemistry, which has been substantially updated in recent works (Hébrard et al., 2012; Hébrard et al., 2013; Dobrijevic et al., 2014; Hickson et al., 2014; Loison et al., 2015), we did not significantly change the ionic chemistry. The ion processes used here are very similar to the ones of Carrasco et al. (2007b, 2008) and Vuitton et al. (2007). However, using recent work, we changed some Dissociative Recombination (DR) reaction branching ratios (Vigren et al., 2009, 2010a,b, 2012a,b; Plessis et al., 2010; Plessis et al., 2012; Reiter and Janev, 2010) and most of the cross sections of the Dissociative Electron Attachment (DEA) reactions (Rawat et al., 2008; May et al., 2010; Gilmore and Field, 2015; Graupner et al., 2006; May et al., 2008). Moreover, as our neutral chemical scheme is notably different (with the presence of $\mathrm{C}_{3}$ for example), we adjusted the ionic scheme using the review articles of Anicich $(1993,2003)$ and Anicich et al. (2006). Since one of the main aims of this study is to estimate the uncertainties in the model results, we used a limited chemical network to lower the computational time in our uncertainty propagation study (see 2.1). Indeed, the size of the ion network depends on the size of the neutral network. However, as already shown by Vuitton et al. (2007) and Westlake et al. (2012), hydrocarbon ion formation, up to $\mathrm{C}_{9} \mathrm{H}_{11}^{+}$, is mainly driven by the reactions of ions with $\mathrm{CH}_{4}, \mathrm{C}_{2} \mathrm{H}_{2}$ and $\mathrm{C}_{2} \mathrm{H}_{4}$. Consequently, we include $\mathrm{C}_{5} \mathrm{H}_{x}^{+}$ions even if we do not consider neutral $\mathrm{C}_{5} \mathrm{H}_{x}$. We do not include higher mass ions to reduce the computational time. This limitation has little 
influence on our neutral chemistry as the DR reactions of $\mathrm{C}_{6} \mathrm{H}_{x}^{+}$and $\mathrm{C}_{7} \mathrm{H}_{x}^{+}$ are thought to produce mainly benzene compounds (Hamberg et al., 2011), which are not included in this study. Moreover, since higher mass ions have lower abundances, they should have little effect on neutral chemistry up to $\mathrm{C}_{4} \mathrm{H}_{x}$. The main chemical pathways in Titan's ion chemistry are developed in section 3.5. We use the temperature dependency of ion-dipole reactions to account for the low temperature of Titan's atmosphere.

\subsubsection{Electron production}

The computation of electron production profiles from magnetospheric electrons and galactic cosmic rays (GCR) follows the model used in Gronoff et al. (2009a,b, 2011). The magnetospheric electron spectra measured by Cassini during the T27 transit is used as an input for the Aeroplanets model (Gronoff et al., 2012; Gronoff et al., 2012) which computes their transport in the ionosphere and the subsequent ionizations. The T27 spectrum has been used for its relatively average conditions, the precipitation of electrons has been considered as vertical to consider an average precipitation case. For the production by GCRs, the planetocosmics model (Desorgher et al., 2005) is used with the GCR spectrum from the Bahdwar O'Neill model (Badhwar and O'Neill, 1992) as in Gronoff et al. (2011); Norman et al. (2014); Gronoff et al. (2015). Figure 2 shows the production rate of photoelectrons obtained from our model and the production rate of electrons from magnetospheric electrons and GCRs obtained from the Aeroplanets model using the peak of photoelectron production around $1100 \mathrm{~km}$ as an input.

The Aeroplanets model is used with the latest values from the Atmociad database (Gronoff et al., 2012) and a very fine energy grid to allow the computation of the energy flux with a resolution less than $1 \mathrm{eV}$ for electron energies lower than $100 \mathrm{eV}$ at all altitudes. Figure 3 shows the energy flux of electrons for various altitudes that have been computed at 14 points between $1500 \mathrm{~km}$ and $600 \mathrm{~km}$. Our model results are in a quite good agreement with CAPS-ELS data obtained during the T40 flyby at $1020 \mathrm{~km}$ and with the model of Richard et al. (2015b).

\subsubsection{Electron temperature}

Many studies using Cassini data from the Radio and Plasma Wave ScienceLangmuir Probe (RPWS-LP) instrument have been published these last few years to infer the electron temperature in the ionosphere of Titan. Agren et al. (2009) analyzed data from 17 flybys (from T16 to T42), with closest approaches below $1200 \mathrm{~km}$ of altitude, corresponding to various Solar Zenith Angles (SZA) ranging from $20^{\circ}$ to $165^{\circ}$. They found that the electron tem- 


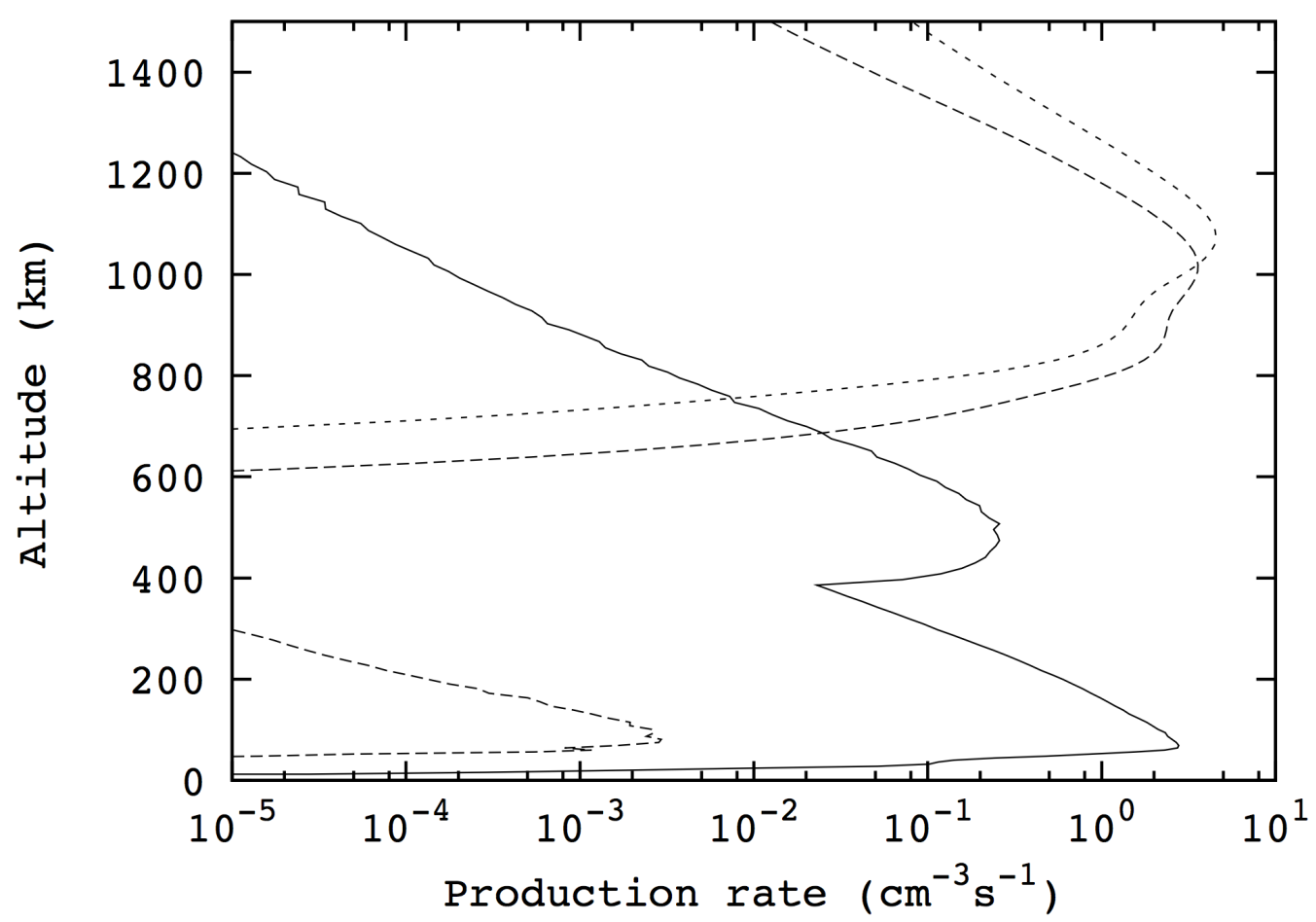

Fig. 2. Production rate of photoelectrons (short dashed line), electrons from secondary and magnetospheric electrons (long dashed line) and Galactic Cosmic Rays (solid line).

perature at the ionospheric peaks does not depend on SZA with values which lie between $350 \mathrm{~K}$ and $700 \mathrm{~K}$, whereas the ionospheric peak altitudes are quite scattered (between 1000 and $1250 \mathrm{~km}$ ). Robertson et al. (2009) analyzed RPWS-LP data from T17 and T18 flybys and obtained electron temperatures between $400 \mathrm{~K}$ and $600 \mathrm{~K}$ at $1000 \mathrm{~km}$ and observed a roughly linear increase with altitude reaching values between $1200 \mathrm{~K}$ and $1500 \mathrm{~K}$ at $1500 \mathrm{~km}$ of altitude. This linear evolution is in quite good agreement with T5 data analysis from Ågren et al. (2007). Vigren et al. (2013) derived the electron temperature $\left(T_{e}\right)$ from LP measurements for T40, T41, T42 and T48 flybys and obtained similar values $(500 \mathrm{~K}$ at $1000 \mathrm{~km}$ and $1100 \mathrm{~K}$ at $1400 \mathrm{~km})$. The electron temperature used in the present study is based on these results. We consider that the electron temperature is equal to $500 \mathrm{~K}$ at $1000 \mathrm{~km}$ and follows a linear relation with the altitude $z$ given by $T_{e}(z)=1 / 0.715 \times(z-642.5)(z$ in $\mathrm{km}$, $T_{e}$ in $\mathrm{K}$ ), in both the dayside and the nightside of the Titan's ionosphere. Below $1000 \mathrm{~km}, T_{e}$ decreases to reach the temperature of the neutral atmosphere (148 $\mathrm{K}$ at about $750 \mathrm{~km}$ ) in agreement with the model of Richard et al. (2011). Below $750 \mathrm{~km}$, we use a constant $T_{e}$ value of $148 \mathrm{~K}$. 


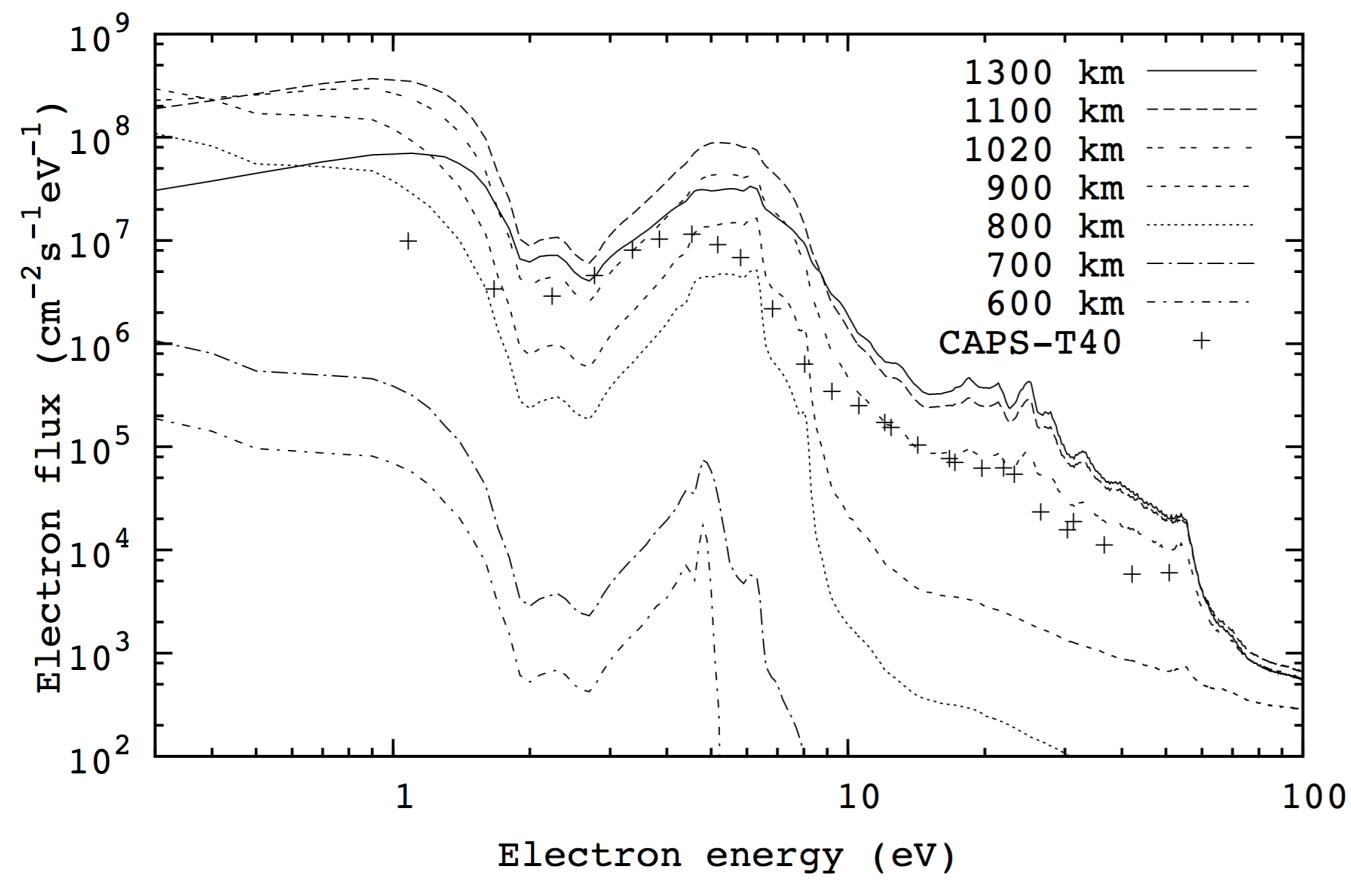

Fig. 3. Energetic electron fluxes at several altitudes. Our model at $1020 \mathrm{~km}$ is compared to CAPS-ELS data obtained during the T40 flyby for the same altitude (Richard et al., 2015b).

\subsubsection{Negative ion chemistry}

The various primary electron-induced processes leading to negative ion formation in Titan's atmosphere have been reviewed by Vuitton et al. (2009). The three processes leading to negative ions are electron attachment (either radiative or through termolecular processes), dissociative electron attachment (DEA) and ion-pair formation from photoionisation. The most important processes for Titan's atmosphere involve DEA. They are endothermic for most species and require supra-thermal electrons.

The important DEA reactions for Titan's atmospheric chemistry have been (re)measured recently. The various cross sections for DEA reactions are presented in Figure 4. Among them, the $\mathrm{CH}_{4}$ DEA (Rawat et al., 2008) has been shown to be 10 times more efficient than the previous measurements from Sharp and Dowell (1967), and the DEA for HCN (May et al., 2010) has been shown to be 10 times less efficient than the previous measurements from Inoue (1966). As a result, in contrast to the study of Vuitton et al. (2009), the main production of anions in Titan's atmosphere is the DEA of $\mathrm{CH}_{4}$ leading mainly to $\mathrm{H}^{-}$. In our model, the only compound for which the DEA has various competitive exit pathways is $\mathrm{HC}_{3} \mathrm{~N}$. The branching ratios for the $\mathrm{HC}_{3} \mathrm{~N}$ DEA are presented in Figure 5.

Ion-pair formation from photoionisation is not an efficient process in the con- 


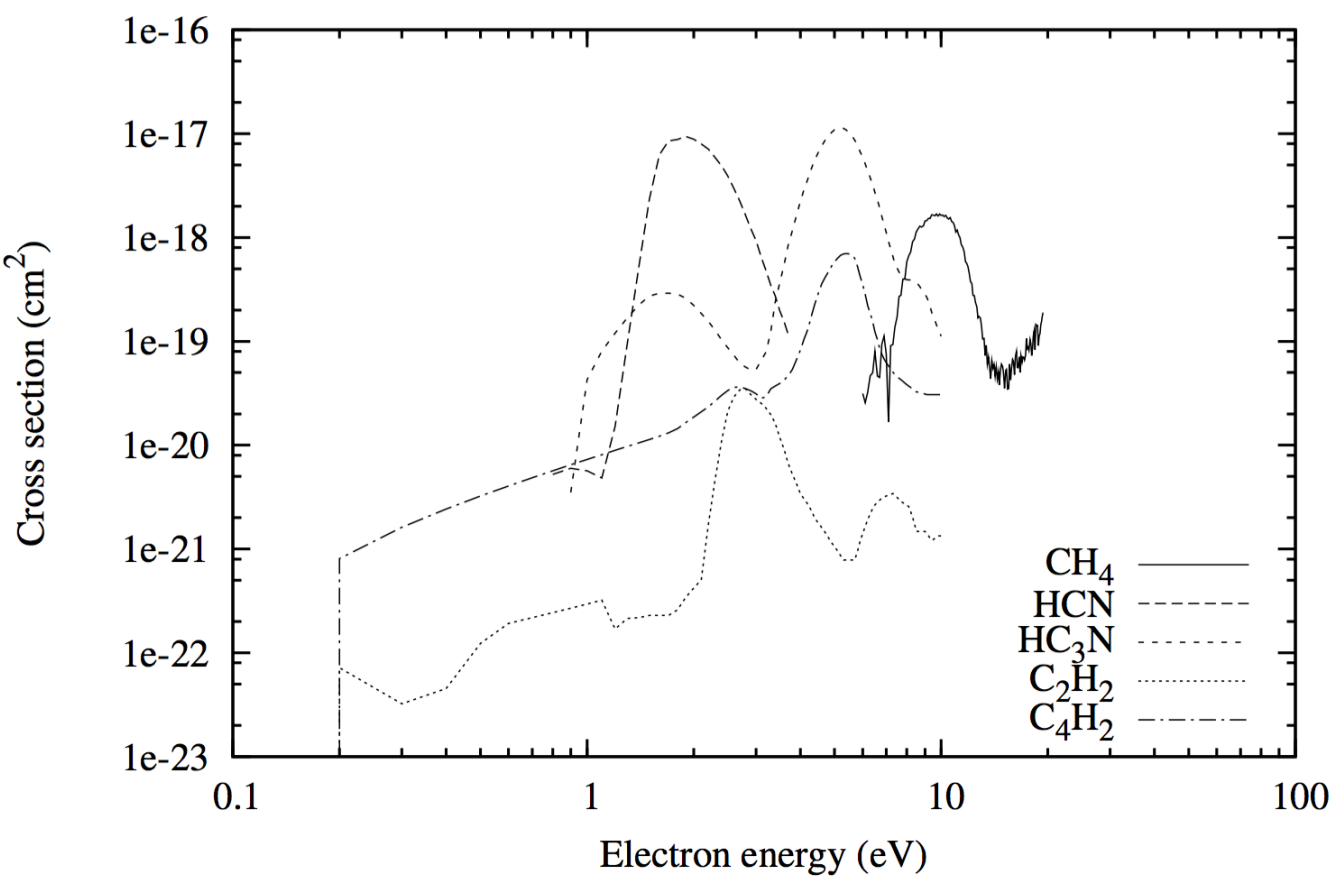

Fig. 4. Cross sections for Dissociative Electron Attachment included in the present model $\left(\mathrm{CH}_{4}\right.$ : Rawat et al. (2008), $\mathrm{HCN}$ : May et al. (2010), $\mathrm{C}_{2} \mathrm{H}_{2}$ and $\mathrm{C}_{4} \mathrm{H}_{2}$ : May et al. (2008), $\mathrm{HC}_{3} \mathrm{~N}$ : Gilmore and Field (2015)).

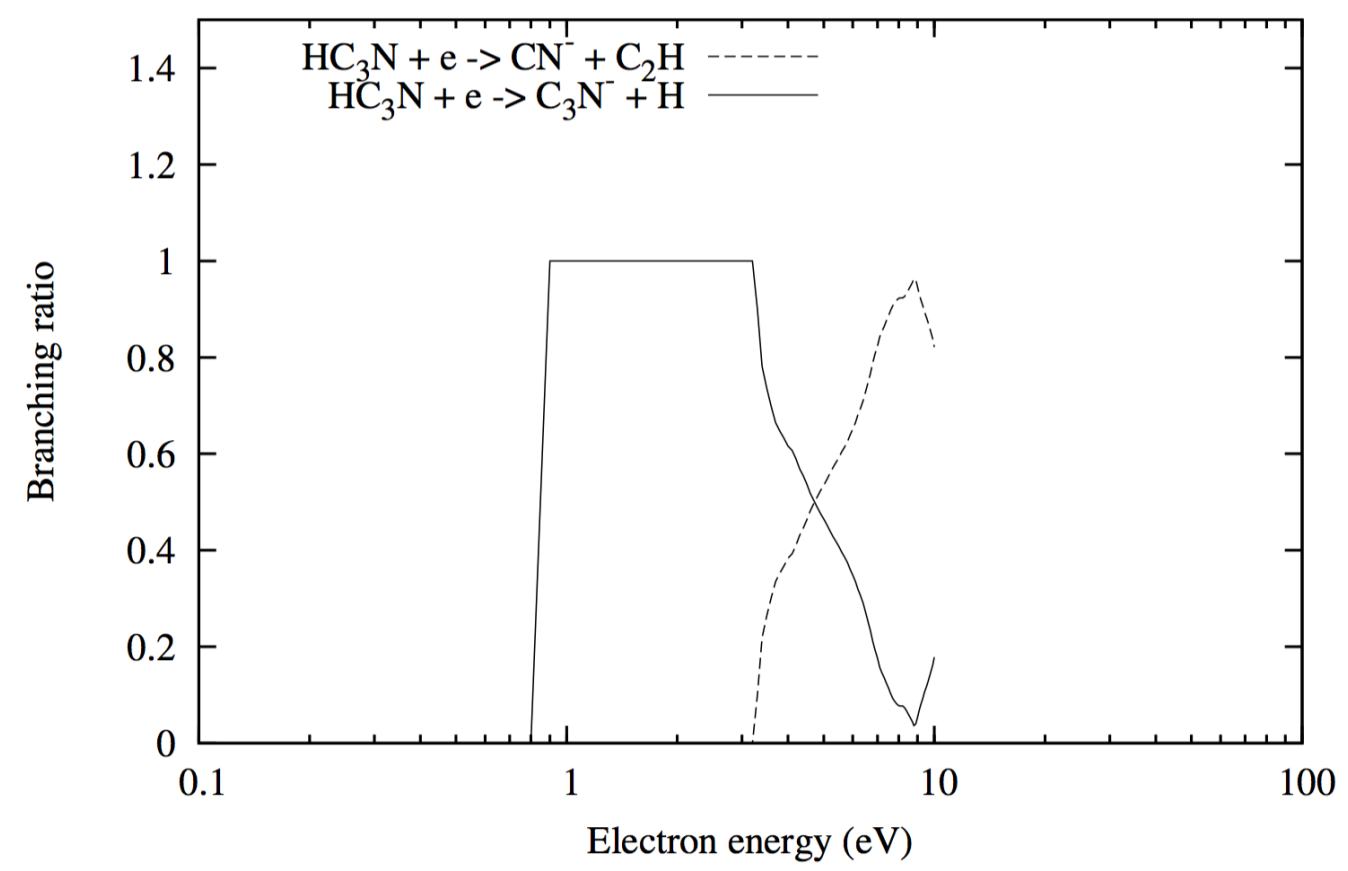

Fig. 5. Branching ratios for $\mathrm{HC}_{3} \mathrm{~N}$ Dissociative Electron Attachment as a function of electron energy (Gilmore and Field, 2015; Graupner et al., 2006). 
text of Titan's atmosphere. Therefore, we only consider the $\mathrm{CH}_{4}+\mathrm{h} \nu \rightarrow \mathrm{H}^{-}$ $+\mathrm{CH}_{3}^{+}$process using the Rogers et al. (2010) study and verified that its flux is very low.

For electron attachment we only consider radiative processes even if termolecular processes may play a role at low altitude where the pressure increases. No radiative electron attachment process has ever been studied experimentally and we use the theoretical rates from Herbst and Osamura (2008) deduced from statistical theory for radiative electron attachment. This process is indeed relatively inefficient in the context of Titan's atmosphere because it either involves abundant radicals $\left(\mathrm{CH}_{3}\right)$ associated with a very low rate constant (the electron affinity (EA) of $\mathrm{CH}_{3}$ is equal to $0.08 \mathrm{eV}$ and the lifetime of $\mathrm{CH}_{3}^{-* *}$ is much too short to be efficiently stabilized by photon emission) or involves radicals with low concentrations $\left(\mathrm{C}_{4} \mathrm{H}, \mathrm{C}_{3} \mathrm{~N}\right)$. Even for $\mathrm{C}_{3}$, an abundant species in our model with a relatively large EA equal to $1.995 \mathrm{eV}$ (Rienstra-Kiracofe et al., 2002), the radiative electron attachment rate constant is too low to play an important role.

\subsection{Propagation of uncertainties}

It has been demonstrated in several studies that uncertainties on rate constants have noticeable effects on photochemical model results (see for instance Hébrard et al. (2012); Hébrard et al. (2013); Dobrijevic et al. (2014); Loison et al. (2015) for neutrals and Carrasco et al. (2007b, 2008); Plessis et al. (2012) for ions). In these studies, the propagation of uncertainties was performed on the neutral chemistry alone, or on the ion chemistry neglecting the direct coupling between ions and neutrals. The present study improves on these previous works by accounting for the coupling between neutrals and ions to study how uncertainties on rate constants propagate into the model. The propagation of uncertainties for the neutral chemical rate constants follows the methodology presented in Loison et al. (2015) (and related papers) and it is not repeated here. For photoionization, electron ionization and dissociative electron attachment, we follow the same procedure as for photodissociation processes and we consider that the uncertainty factors on the rate constants are equal to 1.2, 1.2 and 1.4 respectively (see below). For ion-neutral reactions and dissociative recombinations, we use Dirichlet distributions to account for the fact that the sum of branching ratio for a given reaction has to be equal to 1 during the Monte-Carlo procedure (see Carrasco and Pernot (2007); Carrasco et al. (2007b)). We performed 480 Monte-Carlo runs to obtain statistically significant results while limiting the computational time.

As a result, for each compound we obtain a statistical set of mole fraction profiles as a function of altitude. Since the distributions of these profiles are 
not always normal or lognormal for a given altitude, we use the 5th and 15th 20-quantiles and the 1st and 19th 20-quantiles (which represent the intervals containing respectively $50 \%$ and $90 \%$ of the mole fraction profiles) to represent the results in a simple way. The nominal profile corresponds to the result of the model using the unperturbed rate constants. For some compounds, the mean profile can be different from the nominal profile because their distributions are bimodal (or multimodal).

All rate constants, including photolysis rates, are calculated in advance by the Monte-Carlo process which are then used as inputs in the photochemical model. This allows us to study statistically the distributions of rate constants prior to their use in the model. These distributions are available upon request so that they could be used by other modelers. For this reason, when considering the propagation of uncertainties, the photolysis rates are not reevaluated during the photochemical calculation as this is performed for the nominal model only. However, this has little effect on the results since all photolysis rates are computed using the relative abundances of species from the nominal model at steady state as inputs.

The evaluation of uncertainties on many chemical parameters is a difficult task. When several measurements exist with the preferred rate (used as the nominal rate) not significantly different from the average value, the uncertainty on the nominal rate is the statistical deviation (this is the case for most of the known ion-molecule reactions, see Anicich $(1993,2003))$. When there is no measurement but a precise theoretical calculation, we use an uncertainty factor $(F)$ ranging from 1.6 and 2.0 depending on the calculation method. When there are ab-initio or DFT calculations to determine the height of the barrier in the entrance valley but without a precise RRKM calculation that includes the tunnelling effect, we consider a $F$ value between 2 and 3 for bimolecular rate constants and 10 to 30 for termolecular and radiative association rate constants. When there is no information but only a general rule we use a $F$ value ranging from 3 and 10 depending on the system. Globally we consider that we use in the present study a relatively optimistic value of $F$ for most of the reaction rates. Important sources of uncertainties in photochemical models lie in the determination of photodissociation and photolysis rates, ionisation rates by electrons, dissociative electron attachment and photodetachment rates. All these quantities require specific models to compute the actinic and electron (thermal and supra-thermal) fluxes as a function of energy and altitude. Moreover, many data are lacking or are quite imprecise regarding cross sections and quantum yields at low temperature. Indeed, the determination of the uncertainty on each of these rates requires in depth studies beyond the scope of the present paper. To account for the uncertainties, we consider for simplicity that all the photolysis rates have an uncertainty factor of 1.2 and equal to 1.4 for DEA. Using a low value for these uncertainty factors allows us to lower the importance of these rates in our uncertainties propagation model and to 
pinpoint the key reactions from our global sensitivity analysis. However, it is important to keep in mind that the uncertainties presented in the following are undoubtedly quite optimistic for kinetic rate constants and significantly underestimated for photolysis processes.

\section{$3 \quad$ Results}

\subsection{Neutral species}

In this section, we present the mole fraction profiles of the main neutral species obtained by our 1D neutral-ion coupled model, which differ slightly from the ones presented in Loison et al. (2015). The eddy diffusion coefficient (not shown here) has been constrained from comparisons with $\mathrm{CH}_{4}, \mathrm{H}_{2}, \mathrm{C}_{2}-\mathrm{C}_{3}$ hydrocarbons and $\mathrm{H}_{2} \mathrm{O}$ profiles gathered from various observations in the higher atmosphere down to the lower stratosphere (see Dobrijevic et al. (2014) and Loison et al. (2015) for details). Density profiles of $\mathrm{N}_{2}, \mathrm{CH}_{4}$ and $\mathrm{H}_{2}$ obtained with our global-mean model are presented in Figure 6. They are in good agreement with the Waite et al. (2013) recommended profiles.

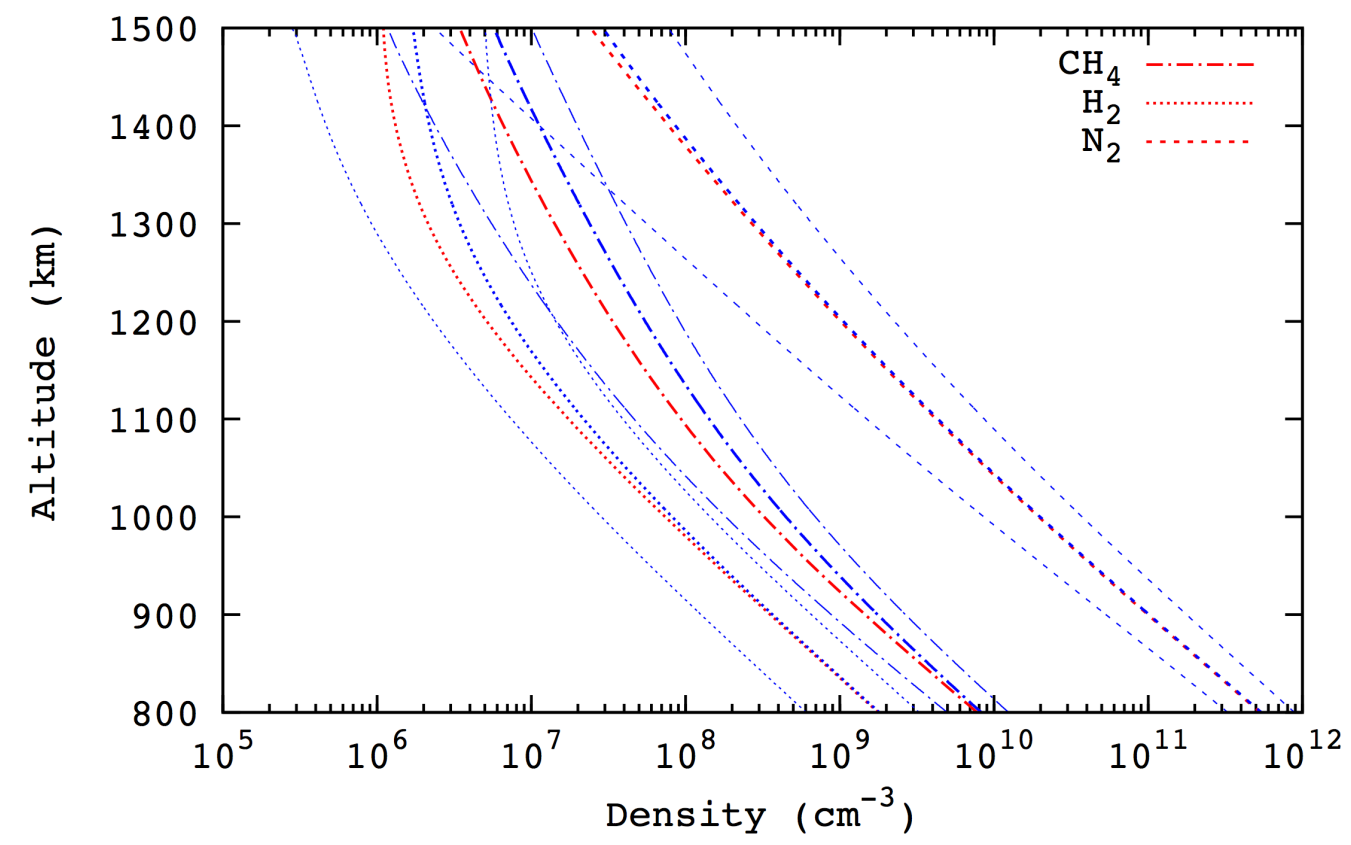

Fig. 6. Model densities of $\mathrm{N}_{2}, \mathrm{CH}_{4}$ and $\mathrm{H}_{2}$ (in red) and comparison with recommended profiles from Waite et al. (2013) (nominal, minimum and maximum profiles in blue). Model uncertainties for these 3 compounds are very low and are not depicted.

As we can see in Figures 7 and 8, the main hydrocarbons that have been 
observed so far are in very good agreement with our model throughout the atmosphere (except for $\mathrm{C}_{2} \mathrm{H}_{4}$ in the lower atmosphere, see Loison et al. (2015) for a discussion on that point). We favored data gathered by the same instrument and analyzed at the same time for this comparison. Our model closely matches CIRS data in the lower atmosphere and INMS data in the ionosphere. For INMS data, we mainly use the data analyses made by Magee et al. (2009) and Cui et al. (2009) for comparison with our model and we adopt the correction suggested by Teolis et al. (2015). The differences in neutral mole fractions obtained from Cassini/INMS data analysis by Magee et al. (2009) and Cui et al. (2009) are quite low except for $\mathrm{C}_{2} \mathrm{H}_{2}, \mathrm{C}_{2} \mathrm{H}_{4}$ and $\mathrm{C}_{3} \mathrm{H}_{8}$. For that reason, data from Cui et al. (2009) for these three compounds are given in Figures 7 and 8 in addition to the ones of Magee et al. (2009).

For $\mathrm{C}_{2} \mathrm{H}_{2}$, the agreement with the Cui et al. (2009) value is good, but the mole fraction obtained with our model is about two times lower than the value of Magee et al. (2009). For $\mathrm{C}_{3} \mathrm{H}_{8}$, Cui et al. (2009) gave only an upper limit on its density, which is more in agreement with our results. The value inferred by Magee et al. (2009) is more than 10 times higher than expected by our model and also greater that the value observed in the lower stratosphere. Such a high value at $1000 \mathrm{~km}$ would imply that the mole fraction of $\mathrm{C}_{3} \mathrm{H}_{8}$ increases with altitude from the stratosphere whereas we find that it should decrease.

Our results are also in good agreement with the main nitrogen species comparing with INMS data, except for $\mathrm{HC}_{3} \mathrm{~N}$, which is 5 times greater in our model. In the lower atmosphere, our model overestimates the mole fractions of many nitriles, especially $\mathrm{HC}_{3} \mathrm{~N}$ and $\mathrm{C}_{2} \mathrm{H}_{5} \mathrm{CN}$; a point that was discussed in Loison et al. (2015). The coupling between neutrals and ions does not significantly change conclusions drawn in that paper for $\mathrm{HC}_{3} \mathrm{~N}$ but ion chemistry affects the $\mathrm{C}_{2} \mathrm{H}_{5} \mathrm{CN}$ abundance. Indeed, as $\mathrm{C}_{2} \mathrm{H}_{5} \mathrm{CN}$ has a high proton affinity, it is easily protonated and since the dissociative recombination of $\mathrm{C}_{2} \mathrm{H}_{5} \mathrm{NH}^{+}$does not give back $\mathrm{C}_{2} \mathrm{H}_{5} \mathrm{CN}$ with a yield of $100 \%$, ion chemistry results in a net loss of $\mathrm{C}_{2} \mathrm{H}_{5} \mathrm{CN}$. Despite this effect, our model still overestimates $\mathrm{C}_{2} \mathrm{H}_{5} \mathrm{CN}$ in the lower atmosphere. It should be noted that the $\mathrm{C}_{2} \mathrm{H}_{5} \mathrm{CN}$ mole fraction of our model is in good agreement with the INMS measurement indicating that our chemical scheme for this species, at least in the ionosphere, is probably good.

\subsection{Positive ions}

Recently, Teolis et al. (2015) pointed out that INMS measurements yield neutral and ion densities systematically lower, by factors of approximately 2 to 3 , than estimates from several other spacecraft systems. They conducted a new analysis of the data and the INMS ion densities were revised upward by a constant detector sensitivity correction factor of $1.55 \pm 0.33$ and the neutral 


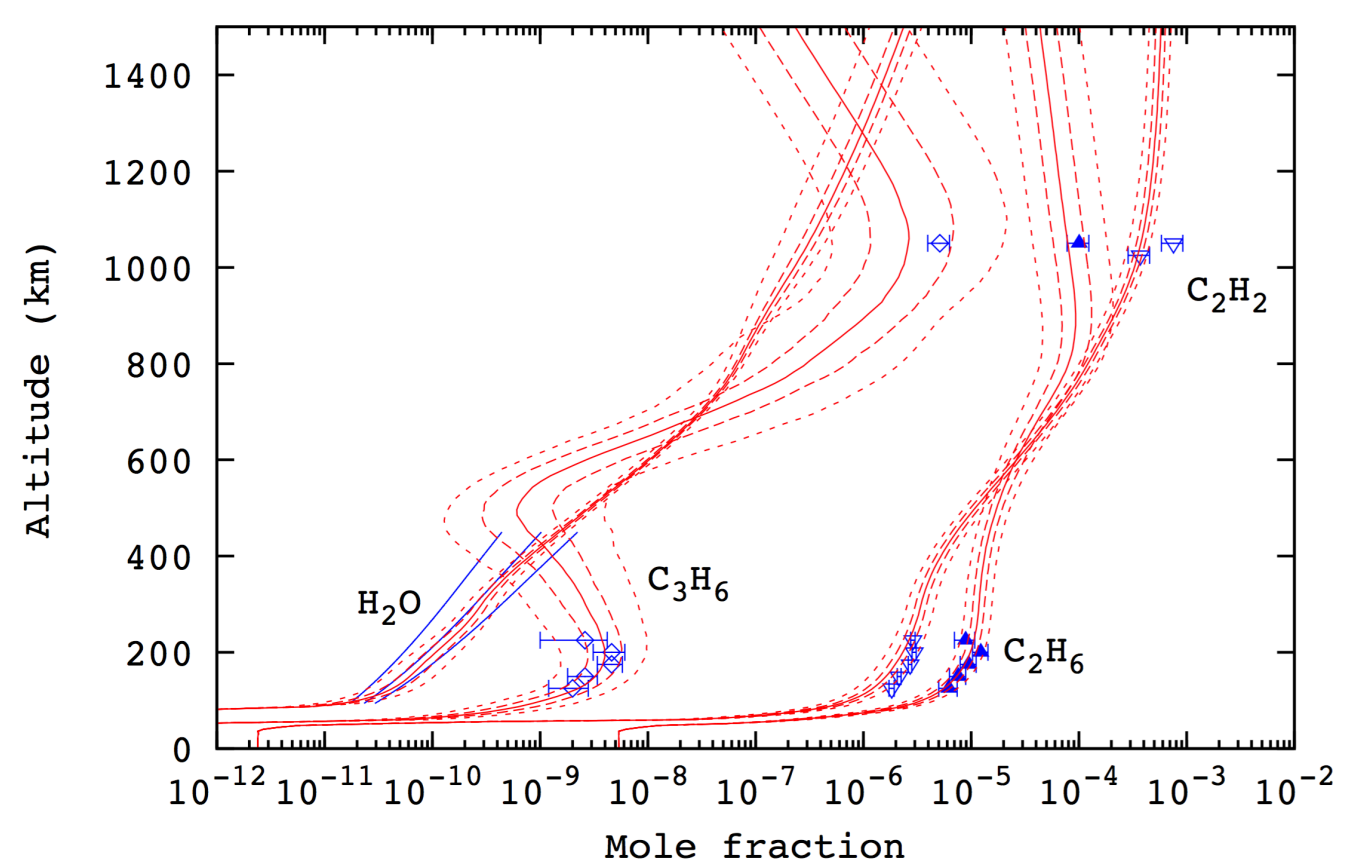

Fig. 7. Mole fraction profiles of $\mathrm{H}_{2} \mathrm{O}, \mathrm{C}_{2} \mathrm{H}_{2}, \mathrm{C}_{2} \mathrm{H}_{6}$ and $\mathrm{C}_{3} \mathrm{H}_{6}$ (in red). Solid line: Mean profile. Dashed lines and dotted lines give the intervals containing respectively $50 \%$ and $90 \%$ of the abundance profiles. Observations in blue. Water: $\mathrm{H}_{2} \mathrm{O}$ profile derived from Herschel observations (Moreno et al., 2012). Hydrocarbons: Cassini/CIRS observations (Nixon et al., 2013) for the lower stratosphere and Cassini/INMS data (Magee et al., 2009) for the higher atmosphere $(1050 \mathrm{~km})$. For $\mathrm{C}_{2} \mathrm{H}_{2}$, the INMS value inferred from Cui et al. (2009) (at $1025 \mathrm{~km}$ ) is also given. A correction for INMS data by a factor of $2.2 \pm 0.5$ has been applied (Teolis et al., 2015).

densities by a constant factor of $2.2 \pm 0.5$, which are applicable to all previously published INMS results. As a consequence, all INMS results presented in the following have been corrected accordingly.

\subsubsection{Density profiles}

We first show the density profiles of some of the main positive ions obtained from our global mean model with model uncertainties derived from our MonteCarlo procedure (see Figure 11). The main density peak is located around 1100 $\mathrm{km}$ and a secondary peak is present around $500 \mathrm{~km}$ corresponding to the peaks of electron production. As there are various measurements of ion density, we compare the results of our photochemical model with observations not only in global mean conditions but also for specific flybys in the daytime.

Westlake et al. (2012) and Mandt et al. (2012) presented the density profiles of some species as a function of altitude for specific flybys, which allow us to compare the results of our photochemical model with observations. They 


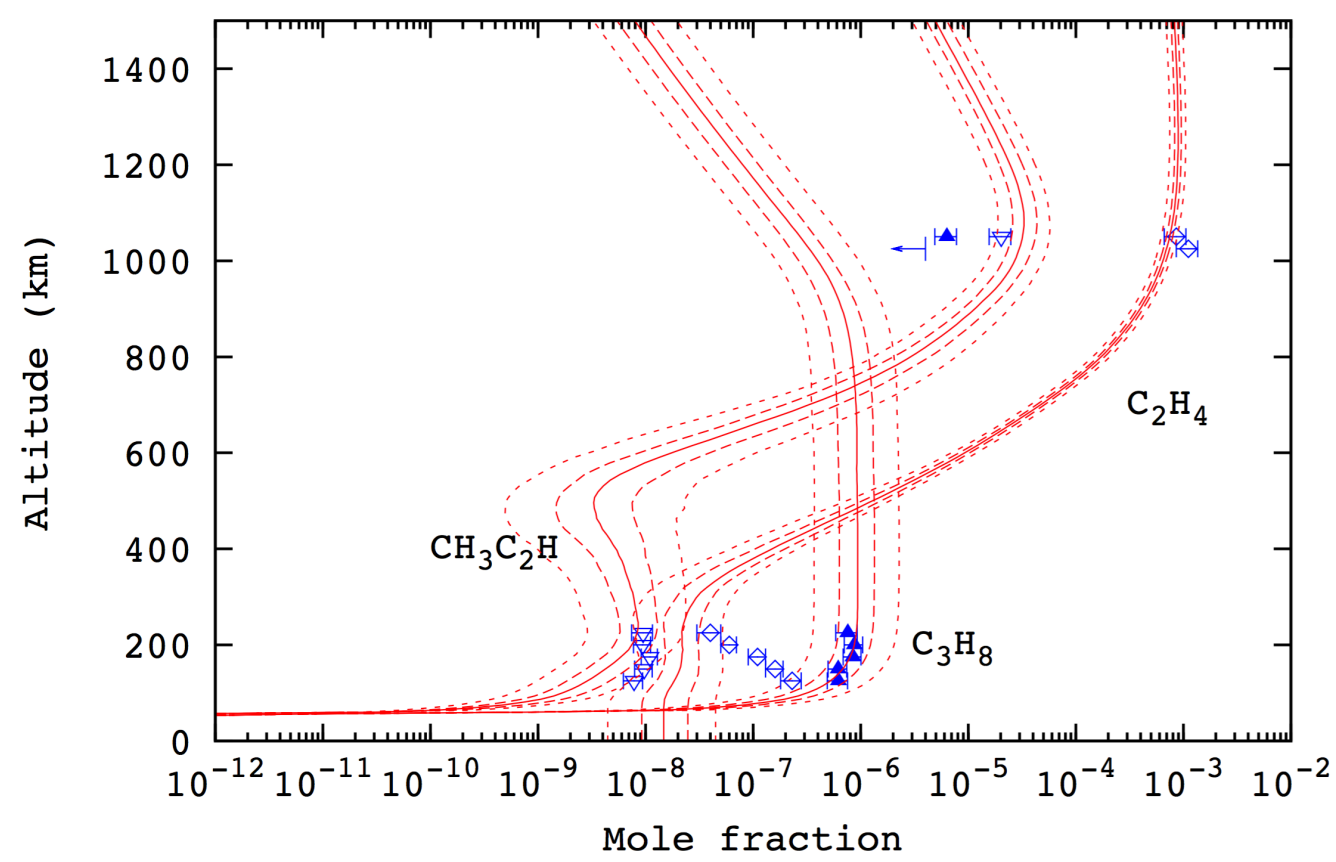

Fig. 8. Mole fraction profiles of $\mathrm{C}_{2} \mathrm{H}_{4}, \mathrm{C}_{3} \mathrm{H}_{8}, \mathrm{C}_{3} \mathrm{H}_{4}$ (in red). Solid line: Mean profile. Dashed lines and dotted lines give the intervals containing respectively $50 \%$ and $90 \%$ of the abundance profiles. Observations in blue. Comparison with Cassini/CIRS observations (Nixon et al., 2013) for the lower stratosphere and Cassini/INMS data Magee et al. (2009) for the higher atmosphere $(1050 \mathrm{~km})$. For $\mathrm{C}_{2} \mathrm{H}_{4}$, the INMS value inferred from Cui et al. (2009) (at $1025 \mathrm{~km}$ ) is also given. For $\mathrm{C}_{3} \mathrm{H}_{8}$, Cui et al. (2009) gives only an upper limit. A correction for INMS data by a factor of $2.2 \pm 0.5$ has been applied (Teolis et al., 2015).

chose T40 and T48 flybys which correspond respectively to Solar Zenith Angles (SZA) of $37.2^{\circ}$ and $25.4^{\circ}$, and consequently to the dayside of Titan's ionosphere. To compare our model to these data, we ran our model in dayside mode, meaning that the solar flux is not divided by a factor of 2 to account for the night side as done in the global mean mode presented below.

Westlake et al. (2012) presented the density profiles of many ions for the T40 flyby (see also the recent analysis of Richard et al. (2015b,a)). In Figure 11, we present the data for $\mathrm{HCNH}^{+}, \mathrm{C}_{2} \mathrm{H}_{5}^{+}$and $\mathrm{CH}_{5}^{+}$, which are considered to be important due to their relatively high abundances and their influence on the chemistry of other ions. Our model is in quite good agreement with $\mathrm{HCNH}^{+}$ and $\mathrm{C}_{2} \mathrm{H}_{5}^{+}$since the uncertainty factors for these 2 compounds (only calculated in the global mean mode) are respectively 1.41 and 1.36 at $1150 \mathrm{~km}$ (around the maximum of their peak density). For $\mathrm{CH}_{5}^{+}$, the uncertainty factor is equal to 1.40 (in the global mean mode), so our nominal model overpredicts its density. The number of reactions controlling the $\mathrm{CH}_{5}^{+}$abundance is small $\left(\mathrm{N}_{2} \mathrm{H}^{+}+\mathrm{CH}_{4}, \mathrm{CH}_{5}^{+}+\mathrm{C}_{2} \mathrm{H}_{4}, \mathrm{C}_{2} \mathrm{H}_{2}\right.$ and $\left.\mathrm{HCN}\right)$, and the uncertainties on these reactions, mainly taken from Anicich (1993) and Anicich (2003), are 


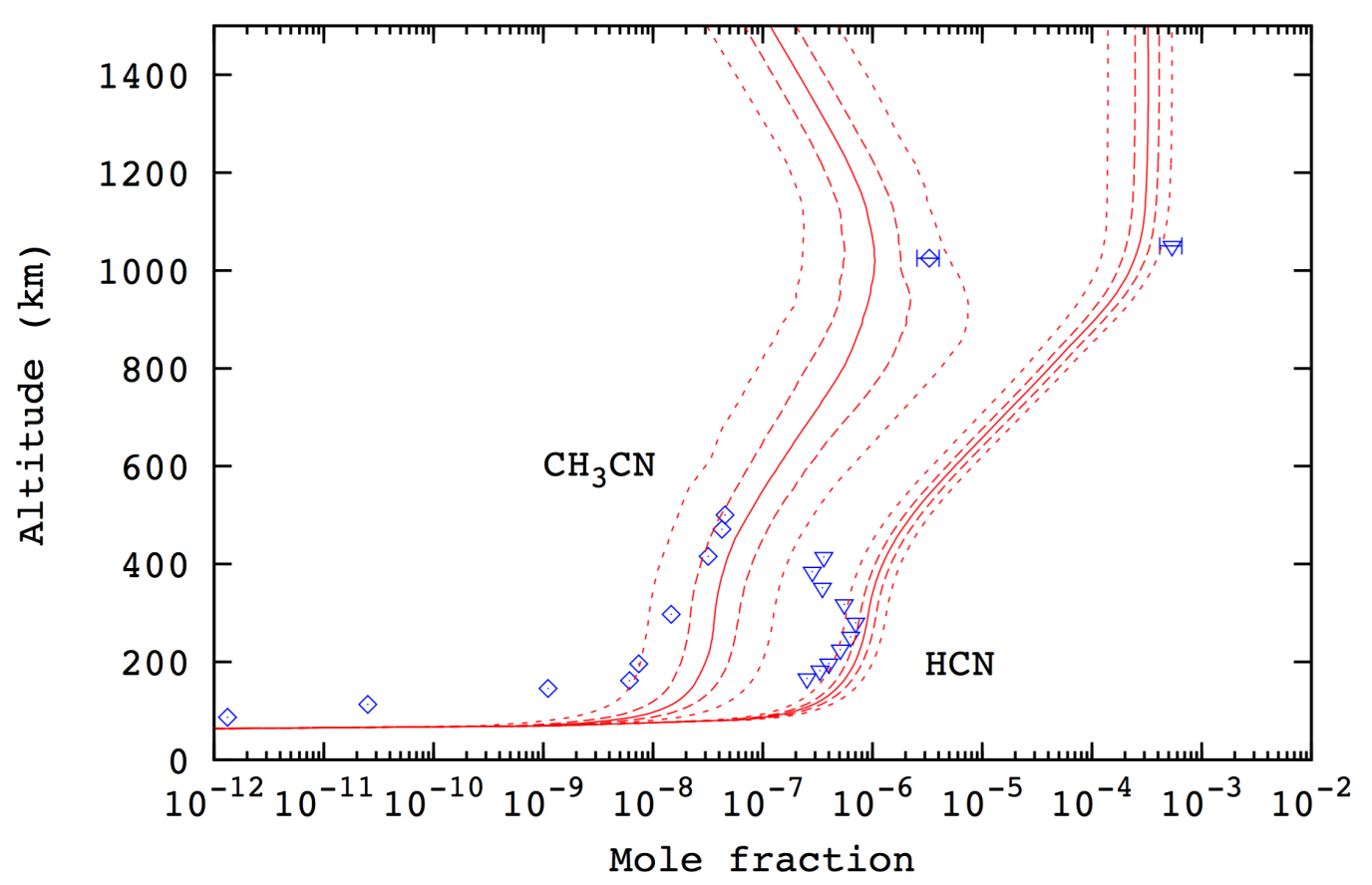

Fig. 9. Mole fraction profiles of $\mathrm{HCN}$ and $\mathrm{CH}_{3} \mathrm{CN}$ (in red). Solid line: Mean profile. Dashed lines and dotted lines give the intervals containing respectively $50 \%$ and $90 \%$ of the abundance profiles. Observations in blue. Comparison with Cassini/CIRS observations (Vinatier et al., 2010) for $\mathrm{HCN}$ and $\mathrm{CH}_{3} \mathrm{CN}$ millimetric observations (Marten et al., 2002) for the lower stratosphere and Cassini/INMS data for HCN (1050 km, Magee et al. (2009) and $\mathrm{CH}_{3} \mathrm{CN}(1025 \mathrm{~km}$, Cui et al. (2009)) for the higher atmosphere. A correction for INMS data by a factor of $2.2 \pm 0.5$ has been applied (Teolis et al., 2015).

probably underestimated (see section 2.3). So, we cannot preclude that our model underestimates the uncertainty on the density of this compound. For $\mathrm{HCNH}^{+}, \mathrm{C}_{2} \mathrm{H}_{5}^{+}$and $\mathrm{CH}_{5}^{+}$, it is noticeable that the shapes of the profiles are well reproduced by our model. In Figure 12, we present the density profiles in the day-side mode of some heavier ions: $\mathrm{C}_{3} \mathrm{H}_{3}^{+}, \mathrm{HC}_{3} \mathrm{NH}^{+}$and $\mathrm{CH}_{3} \mathrm{CNH}^{+}$. Our model is in quite good agreement with these three ions considering that the uncertainty factors for these 3 compounds are respectively 1.75, 1.8, and 2.2. in the global-mean mode.

In this study, we do not consider the reactions of $\mathrm{HCNH}^{+}$with $\mathrm{H}_{2}, \mathrm{C}_{2} \mathrm{H}_{2}$ and $\mathrm{C}_{2} \mathrm{H}_{4}$ as suggested by Westlake et al. (2012) following Adams and Smith (1977) (for $\mathrm{HCNH}^{+}+\mathrm{H}_{2}$ ). The value suggested by Adams and Smith (1977) for the radiative association reaction $\mathrm{HCNH}^{+}+\mathrm{H}_{2} \rightarrow \mathrm{CH}_{2} \mathrm{NH}_{2}^{+}+\mathrm{h} \nu$ was an upper limit considering that there is no barrier for this reaction. However, considering the low reactivity of $\mathrm{HCNH}^{+}$with saturated molecules $\left(\mathrm{CH}_{4}, \mathrm{C}_{2} \mathrm{H}_{6}, \mathrm{~N}_{2}\right.$, etc. see Anicich (2003)) there is very likely to be a barrier for the $\mathrm{HCNH}^{+}+\mathrm{H}_{2}$ reaction. For the reaction of $\mathrm{HCNH}^{+}$with $\mathrm{C}_{2} \mathrm{H}_{2}$ and $\mathrm{C}_{2} \mathrm{H}_{4}$, Milligan et al. (2001) showed that they lead only to addition without precise identification 


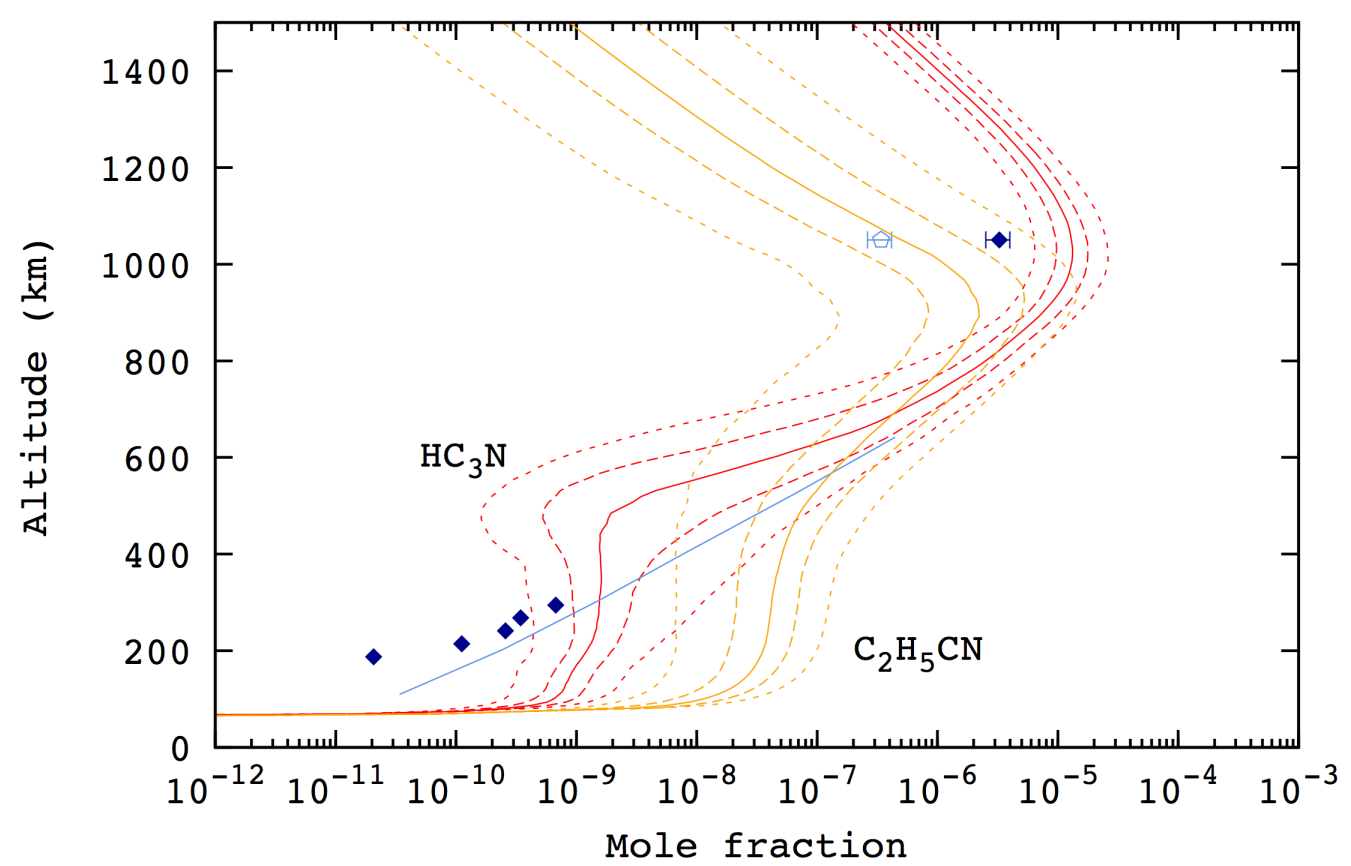

Fig. 10. Mole fraction profiles of $\mathrm{HC}_{3} \mathrm{~N}$ (in red) and $\mathrm{C}_{2} \mathrm{H}_{5} \mathrm{CN}$ (in orange). Solid line: Mean profile. Dashed lines and dotted lines give the intervals containing respectively $50 \%$ and $90 \%$ of the abundance profiles. Observations of $\mathrm{HC}_{3} \mathrm{~N}$ (dark blue) and $\mathrm{C}_{2} \mathrm{H}_{5} \mathrm{CN}$ (light blue). Lower atmosphere: Comparison with Cassini/CIRS observations (Vinatier et al., 2010) for $\mathrm{HC}_{3} \mathrm{~N}$ and ALMA observations (straight line, Cordiner et al. (2015) for $\mathrm{C}_{2} \mathrm{H}_{5} \mathrm{CN}$. Higher atmosphere $(1050 \mathrm{~km})$ : Cassini/INMS data (Magee et al., 2009). A correction for INMS data by a factor of $2.2 \pm 0.5$ has been applied (Teolis et al., 2015).

of the various product isomers. As these reactions are less important than the DR reaction of $\mathrm{HCNH}^{+}$(Milligan et al., 2001), and as the isomers are not clearly identified and might not be the most stable ones (for example the $\mathrm{C}_{3} \mathrm{H}_{6} \mathrm{~N}^{+}$adduct ion formed from $\mathrm{HCNH}^{+}+\mathrm{C}_{2} \mathrm{H}_{4}$ is supposed to be the four-membered covalently bound cyclic $\mathrm{CH}_{2} \mathrm{CH}_{2} \mathrm{CHNH}^{+}$species), we do not consider these reactions even if they may play a non-negligible role in nitrile chemistry.

Our model result for $\mathrm{HCNH}^{+}$agrees better with INMS data than the model results of Westlake et al. (2012), Mandt et al. (2012) and Richard et al. (2015b). One of the key reactions for $\mathrm{HCNH}^{+}$(see section 3.6.1) is $\mathrm{N}\left({ }^{2} \mathrm{D}\right)+\mathrm{HCN} \rightarrow$ $\mathrm{CH}+\mathrm{N}_{2}$ (introduced for the first time in the neutral photochemical model of Hébrard et al. (2013)), which is not included in other ionospheric models. Since, this reaction efficiently consumes $\mathrm{HCN}$, this probably explains why the production of $\mathrm{HCNH}^{+}$(mainly via the reaction of $\mathrm{HCN}$ with $\mathrm{C}_{2} \mathrm{H}_{5}^{+}$) is lower in our model than in the previous models.

Mandt et al. (2012) presented the density profiles of $\mathrm{N}^{+}, \mathrm{CH}_{4}^{+}$and $\mathrm{CH}_{3}^{+}$for 

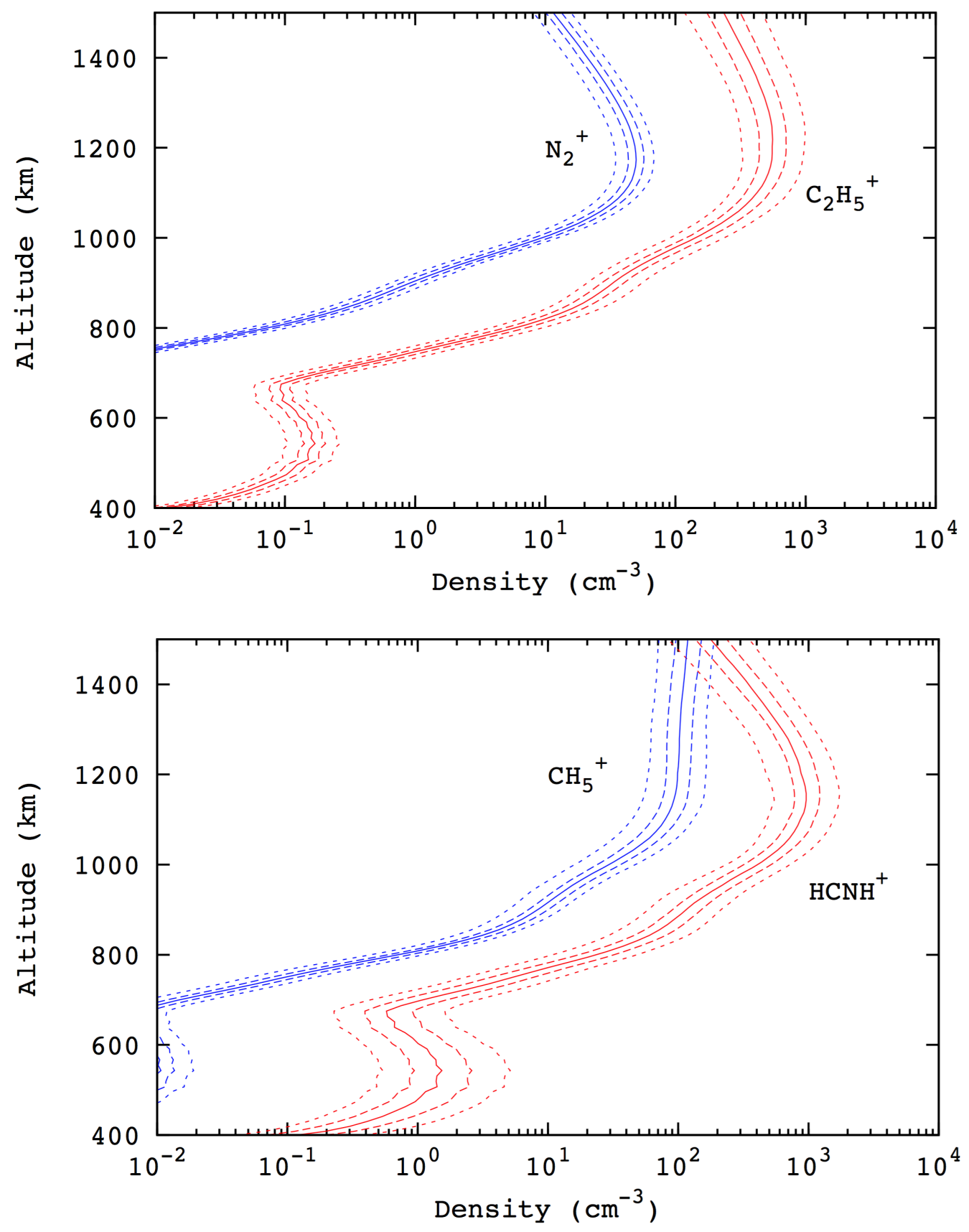

Fig. 11. Global mean density profiles of $\mathrm{C}_{2} \mathrm{H}_{5}^{+}$(red) and $\mathrm{N}_{2}^{+}$(blue) (top) and $\mathrm{HCNH}^{+}$(red) and $\mathrm{CH}_{5}^{+}$(blue) (bottom). Solid line: Mean profile. Dashed lines and dotted lines give the intervals containing respectively $50 \%$ and $90 \%$ of the density profiles.

the T40 and T48 flybys. These data highlight the variability of ion densities inferred from the INMS instrument from one flyby to another in roughly similar SZA conditions. $\mathrm{N}^{+}$and $\mathrm{CH}_{4}^{+}$are the two primary products of $\mathrm{N}_{2}$ and $\mathrm{CH}_{4}$ photoionization that INMS can measure and $\mathrm{CH}_{3}^{+}$is also a good tracer of $\mathrm{N}_{2}$ photoionization since $\mathrm{N}_{2}^{+}$reacts with $\mathrm{CH}_{4}$ to produce $\mathrm{CH}_{3}^{+}$. So, these 

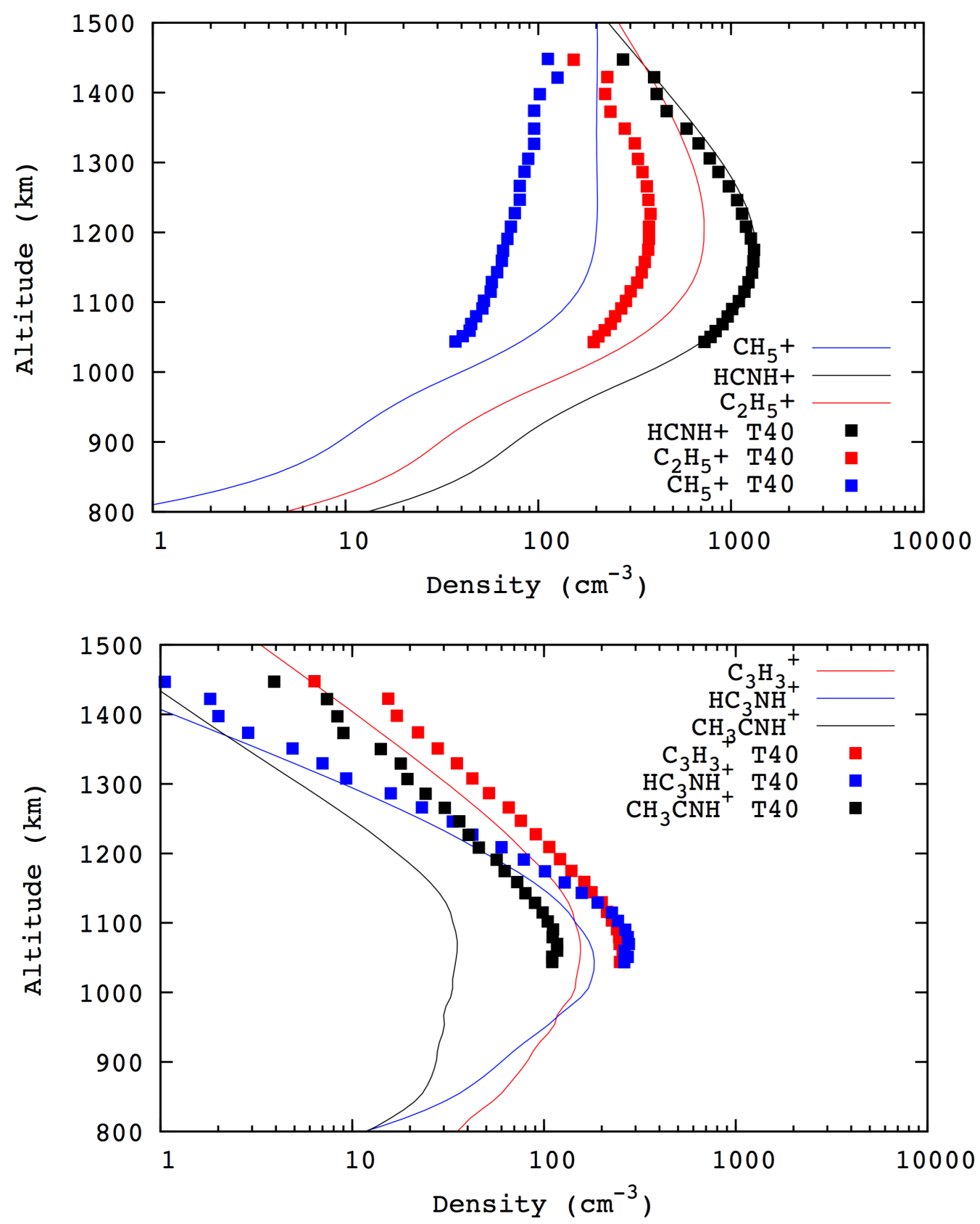

Fig. 12. Densities of $\mathrm{HCNH}^{+}, \mathrm{C}_{2} \mathrm{H}_{5}^{+}$and $\mathrm{CH}_{4}^{+}$(top) and $\mathrm{C}_{3} \mathrm{H}_{3}^{+}, \mathrm{HC}_{3} \mathrm{NH}^{+}$and $\mathrm{CH}_{3} \mathrm{CNH}^{+}$(bottom) as a function of altitude derived from INMS T40 flyby from Westlake et al. (2012). The Solar Zenith Angle corresponds to $37.2^{\circ}$ for this flyby. Our model has been used in dayside mode (the solar flux is not divided by a factor of 2 to account for night side). For clarity, uncertainties on INMS data and model results are not depicted. These data have been corrected following the analysis of Teolis et al. (2015). 
three compounds are good tracers of the initial steps of Titan's ionospheric chemistry. The uncertainty factors for $\mathrm{N}^{+}, \mathrm{CH}_{4}^{+}$and $\mathrm{CH}_{3}^{+}$(calculated in the global mean mode) are respectively $1.7,1.35$ and 1.35 at the peak densities (and roughly constant in the ionosphere). Our model is in quite good agreement with INMS data (see Figure 13). We slightly overpredict the density of $\mathrm{CH}_{3}^{+}$, which may be due to the fact that $\mathrm{CH}_{3}^{+}$is formed through the $\mathrm{N}_{2}^{+}+$ $\mathrm{CH}_{4}$ reaction and is not thermalized before reacting with $\mathrm{CH}_{4}$. Then the rate constant may be greater than the one determined under equilibrium conditions. Consequently, we conclude that the initial steps of Titan's ionospheric chemistry are relatively well reproduced by our model.

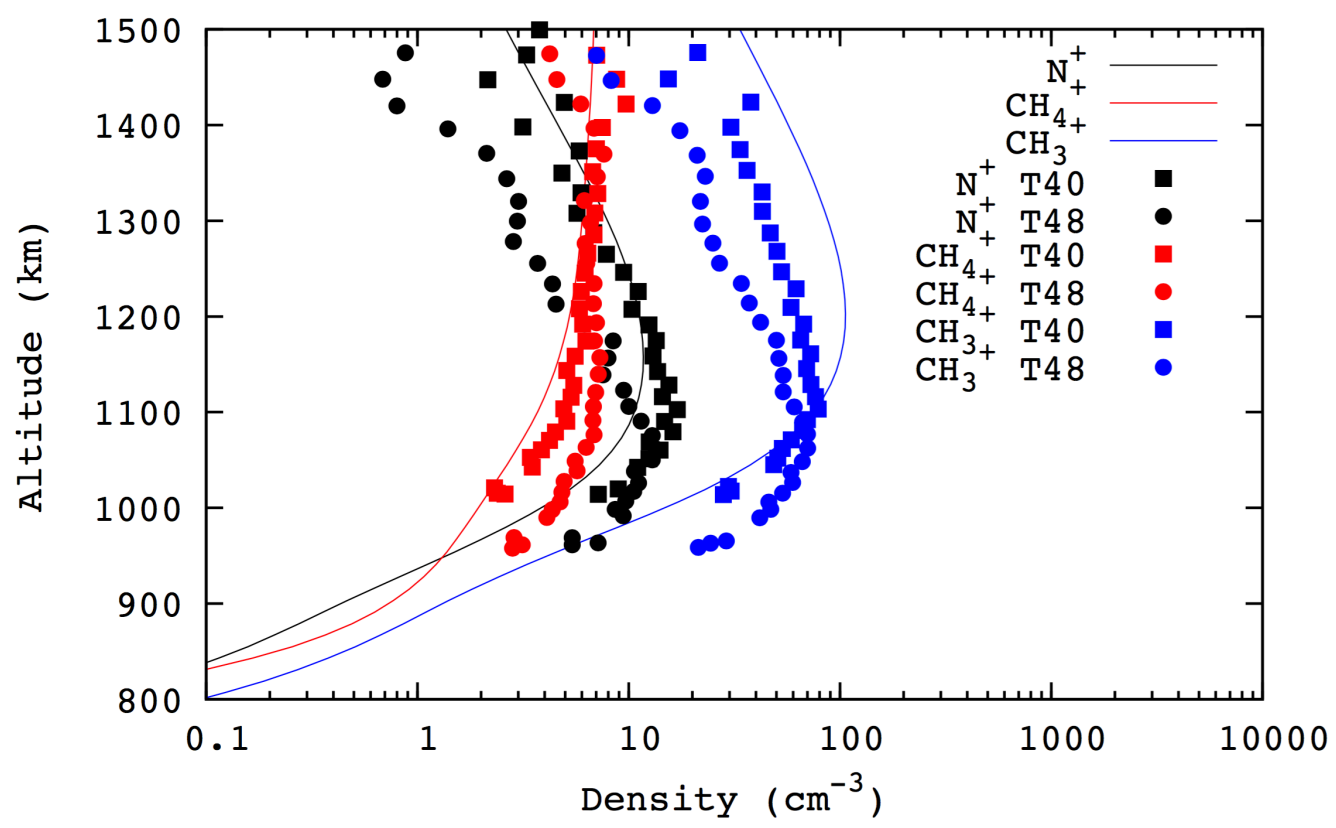

Fig. 13. Densities of $\mathrm{N}^{+}, \mathrm{CH}_{4}^{+}$and $\mathrm{CH}_{3}^{+}$as a function of altitude derived from INMS T40 and T48 flybys from Mandt et al. (2012). The Solar Zenith Angles correspond to $37.2^{\circ}$ and $25.4^{\circ}$ for these flybys respectively. Our model has been used in dayside mode (the solar flux is not divided by a factor of 2 to account for night side). For clarity, uncertainties on INMS data are not depicted. These data have been corrected following Teolis et al. (2015) analysis.

\subsubsection{Mass spectrum}

In the following, we compare our model results with ion mass spectra densities derived from the Cassini INMS instrument. Mandt et al. (2012) conducted an analysis of ground and in-flight calibration to constrain the instrument response to ion energy. They derived total ion densities with this method for a set of 14 flybys of Titan corresponding to different altitudes, latitudes and local solar times. To compare the results of our global-mean model with INMS data, we first constructed, from an analysis of Mandt et al. (2012), 
global-mean INMS ion densities averaged over their mean densities in the dayside, nightside, morning and evening terminators. We then extracted ion densities from our model results and averaged them over altitudes (between 1075 and $1125 \mathrm{~km}$ ) to be in agreement with the Mandt et al. (2012) analysis. The results are presented in Figure 14.

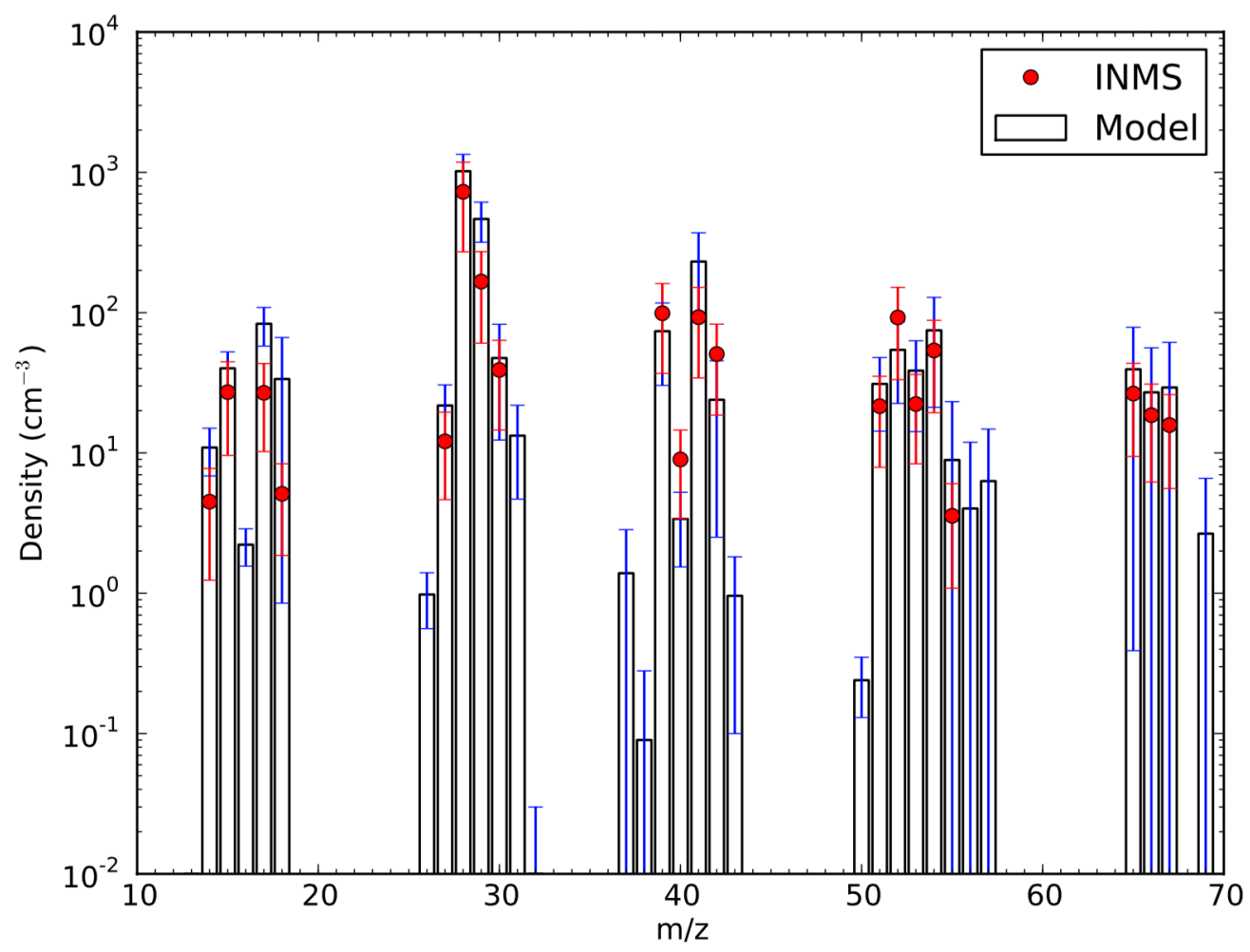

Fig. 14. Mass spectra comparing mean INMS data from Mandt et al. (2012) and our global-mean model results for altitudes between 1075 and $1125 \mathrm{~km}$ (see text). 1- $\sigma$ model uncertainties are shown in blue for each mass.

Mandt et al. (2012) and Westlake et al. (2012) pointed out that several important ion densities are over-predicted by their photochemical model. We draw a different conclusion from our study. We see on Figure 14 that for $\mathrm{HCNH}^{+}$ (peak 28) and $\mathrm{C}_{2} \mathrm{H}_{5}^{+}$(peak 29) the agreement between our model and INMS observations is very good taking uncertainties on both observations and the model into account. For several peaks, the nominal value derived from our model is significantly greater than the nominal value inferred from INMS data. However, for all of these peaks, model uncertainties are large so that the modeled and observed densities agree within the combined uncertainties. These results highlight the need to improve our knowledge of some chemical processes, which are responsible for high model uncertainties (see section 3.6 below).

Several ions could in principle contribute to each peak of the modeled mass spectrum. The propagation of uncertainties we performed can change the rel- 

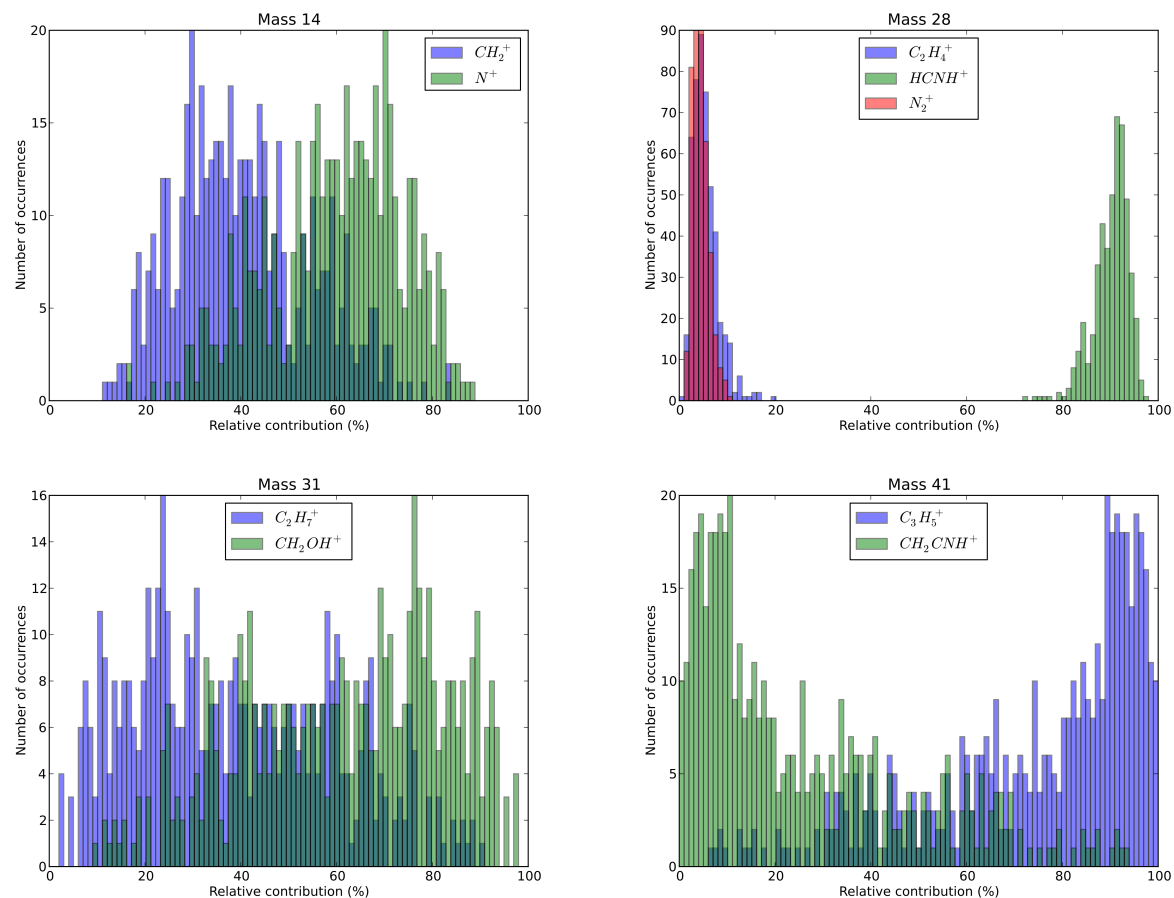

Fig. 15. Relative contribution of the different species densities to some specific masses $(14,28,31$ and 41 uma) of the spectrum shown in Figure 14. For each of these masses, the number of occurrences over the 480 Monte-Carlo runs used in our uncertainty propagation model is given for the relative contribution to the mass peak ranging from 0 to $100 \%$. This highlights the evolution of the relative importance of each species density to the mass spectrum from one run to another.

ative importance of the different species in each peak. Many peaks have one major contributor (even if for some hydrocarbon ions such as $\mathrm{C}_{4} \mathrm{H}_{3}^{+}, \mathrm{C}_{4} \mathrm{H}_{7}^{+}$and $\mathrm{C}_{5} \mathrm{H}_{5}^{+}$, several isomers exist) : mass $15 \rightarrow \mathrm{CH}_{3}^{+}, 16 \rightarrow \mathrm{CH}_{4}^{+}, 17 \rightarrow \mathrm{CH}_{5}^{+}, 18 \rightarrow$ $\mathrm{NH}_{4}^{+}, 27 \rightarrow \mathrm{C}_{2} \mathrm{H}_{3}^{+}, 28 \rightarrow \mathrm{HCNH}^{+}$(with minor $\mathrm{N}_{2}^{+}$and $\mathrm{C}_{2} \mathrm{H}_{4}^{+}$contributions), $29 \rightarrow \mathrm{C}_{2} \mathrm{H}_{5}^{+}, 30 \rightarrow \mathrm{CH}_{2} \mathrm{NH}_{2}^{+}, 39 \rightarrow \mathrm{C}_{3} \mathrm{H}_{3}^{+}, 40 \rightarrow \mathrm{C}_{3} \mathrm{H}_{4}^{+}, 42 \rightarrow \mathrm{CH}_{3} \mathrm{CNH}^{+}, 51$ $\rightarrow \mathrm{C}_{4} \mathrm{H}_{3}^{+}, 52 \rightarrow \mathrm{HC}_{3} \mathrm{NH}^{+}, 54 \rightarrow \mathrm{C}_{2} \mathrm{H}_{3} \mathrm{CNH}^{+}, 55 \rightarrow \mathrm{C}_{4} \mathrm{H}_{7}^{+}, 65 \rightarrow \mathrm{C}_{5} \mathrm{H}_{5}^{+}, 66$ $\rightarrow \mathrm{CH}_{3} \mathrm{C}_{3} \mathrm{NH}^{+}, 67 \rightarrow \mathrm{C}_{5} \mathrm{H}_{7}^{+}$. An example is shown in Figure 15 for mass 28, which is dominated by $\mathrm{HCNH}^{+}$despite uncertainties on the rate constants. In contrast, some peaks have 2 major contributors that can change according to the rate constants used for their formation and destruction reactions (using values within their uncertainty factors). This is the case for masses 14, 31 and 41. For the nominal model, the peak corresponding to the mass 14 is dominated by $\mathrm{N}^{+}(60 \%)$. From our uncertainty propagation study we see that this peak may, in fact, be dominated either by $\mathrm{CH}_{2}^{+}$or $\mathrm{N}^{+}$. For mass 31 , in the nominal model, $\mathrm{CH}_{2} \mathrm{OH}^{+}$contributes $65 \%$ to the peak. $\mathrm{C}_{2} \mathrm{H}_{7}^{+}$could also be a major contributor to this peak. For mass 41, in the nominal model, $\mathrm{C}_{3} \mathrm{H}_{5}^{+}$contributes $85 \%$ to the peak and seems to be the only contributor. However, our global sensitivity analysis shows that $\mathrm{CH}_{2} \mathrm{CNH}^{+}$(formed through the $\mathrm{HCNH}^{+}$ $+\mathrm{CH}_{2} \mathrm{CN}$ reaction; we calculate that the proton affinity of $\mathrm{CH}_{2} \mathrm{CN}$ is equal 
to $757 \mathrm{~kJ} / \mathrm{mol}$ ) may contribute and even dominate (albeit with a lower probability) to this peak. The source of this behaviour lies in the uncertainties on the key reactions associated with these species (see section 3.6 for details).

\subsection{Electron density profile}

Shebanits et al. (2013) used data from 47 flybys of the Cassini spacecraft Radio and Plasma Wave Science Langmuir Probe (RPWS-LP) to measure the electron number densities as a function of altitude (between 880 and 1400 $\mathrm{km}$ ) and SZA. They obtained densities of about 3500-4000 $\mathrm{cm}^{-3}$ around 1100 $\mathrm{km}$ and a SZA between $15^{\circ}$ and $45^{\circ}$. At $60^{\circ}$, corresponding to our global-mean conditions, their density is about 2000-3000 $\mathrm{cm}^{-3}$ at the peak (around 1000 $\mathrm{km}$ ). Our global-mean electron density profile and its uncertainty is shown in Figure 16. The electron peak density we obtain is in quite good agreement with these data but our model slightly over-predicts the number density at the peak.

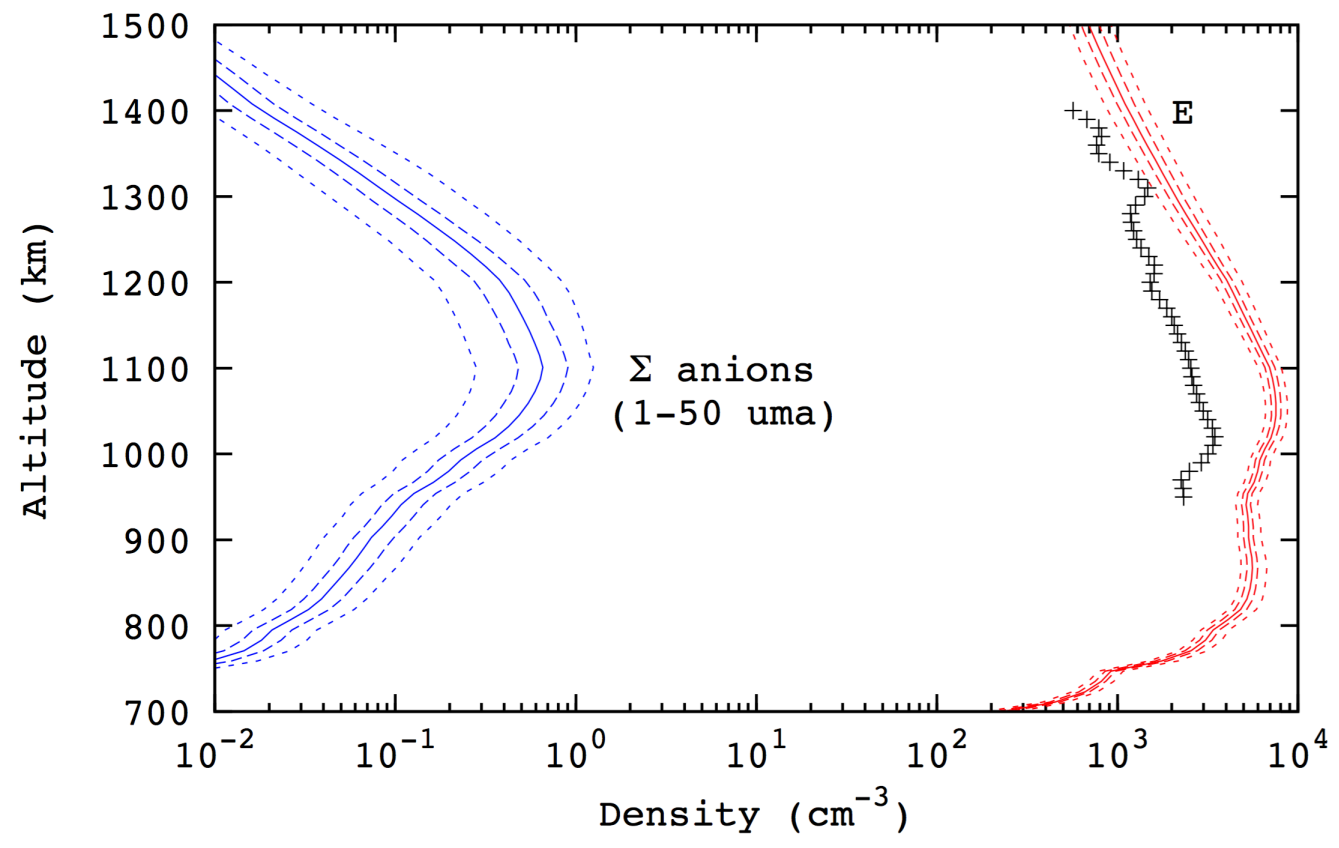

Fig. 16. Global-mean number density profiles of electrons (in red) and the sum of anions for masses between 1 and 50 uma (blue). Solid line: Mean profile. Dashed lines and dotted lines give the intervals containing respectively $50 \%$ and $90 \%$ of the density profiles. The electron density profile (black crosses) derived at a solar zenith angle of $60^{\circ} \mathrm{S}$ from the Cassini RPWS-LP instrument is also shown for comparison (Shebanits et al., 2013). 


\subsection{Negative ions}

The density profiles of the 6 negative ions included in the present model are given in Figure 17 with the distributions obtained from our Monte-Carlo procedure which highlight the uncertainties on model results. The peak density is around $1100 \mathrm{~km}$ and the two most abundant negative ions in our model are $\mathrm{CN}^{-}$and $\mathrm{C}_{3} \mathrm{~N}^{-}$, in agreement with Vuitton et al. (2009). However, compared to Vuitton et al. (2009), our mean $\mathrm{CN}^{-}$density at the peak is about 2 times lower and the density profiles of the other ions are very different. For instance, $\mathrm{C}_{2} \mathrm{H}^{-}$is about 10 times greater at the peak and the density profile of $\mathrm{C}_{4} \mathrm{H}^{-}$ depends strongly on altitude in our model. The density of $\mathrm{C}_{4} \mathrm{H}^{-}$is about 100 times lower in our model at $700 \mathrm{~km}$. We also note that uncertainties on $\mathrm{C}_{4} \mathrm{H}^{-}$ and $\mathrm{C}_{3}^{-}$especially are very large (see section 3.6.2). These differences compared with the model of Vuitton et al. (2009) arise mainly from the fact that we use more recent cross section values for the dissociative electron attachment of $\mathrm{CH}_{4}$ and $\mathrm{HCN}$, leading mainly to $\mathrm{H}^{-}$production rather than $\mathrm{CN}^{-}$ production. However, $\mathrm{H}^{-}$is quickly transformed into $\mathrm{C}_{2} \mathrm{H}^{-}$and $\mathrm{CN}^{-}$(but not into $\mathrm{C}_{2} \mathrm{H}_{3}^{-}$since the reaction $\mathrm{H}^{-}+\mathrm{C}_{2} \mathrm{H}_{4} \rightarrow \mathrm{H}_{2}+\mathrm{C}_{2} \mathrm{H}_{3}^{-}$is endothermic) and $\mathrm{C}_{2} \mathrm{H}^{-}$reacts quickly with $\mathrm{HCN}$ also leading to $\mathrm{CN}^{-}$. $\mathrm{CN}^{-}$is the most abundant anion in our model because, even if it reacts quickly with $\mathrm{HC}_{3} \mathrm{~N}$ leading to $\mathrm{C}_{3} \mathrm{~N}^{-}$, the $\mathrm{HC}_{3} \mathrm{~N}$ abundance is much smaller than the $\mathrm{HCN}$ abundance and steady state favors $\mathrm{CN}^{-}$versus $\mathrm{C}_{3} \mathrm{~N}^{-}$. In our model we do not consider $\mathrm{HC}_{5} \mathrm{~N}$ and $\mathrm{C}_{6} \mathrm{H}_{2}$; very minor species which are as yet undetected in Titan's atmosphere. Consequently, we neglect the formation of $\mathrm{C}_{5} \mathrm{~N}^{-}$and $\mathrm{C}_{6} \mathrm{H}^{-}$. In contrast to Vuitton et al. (2009), we do not consider either $\mathrm{CH}_{3}^{-}$or $\mathrm{CH}_{2}^{-}$. $\mathrm{CH}_{3}^{-}$in Vuitton et al. (2009) is mainly formed through radiative association. However, the formation of $\mathrm{CH}_{3}^{-}$by radiative association of $\mathrm{CH}_{3}$ is likely to be very inefficient, as explained earlier. The rate constant used by Vuitton et al. (2009) is estimated from CN radiative electron attachment but the EA of $\mathrm{CN}$ is equal to $3.8 \mathrm{eV}$. As a result, the radiative electron attachment of $\mathrm{CH}_{3}$ is probably significantly overestimated in Vuitton et al. (2009). $\mathrm{CH}_{2}^{-}$is a very minor product of the dissociative electron attachment of $\mathrm{CH}_{4}$ (Rawat et al., 2008). Moreover, it also has a low EA $(0.65 \mathrm{eV})$ and will not play a major role in Titan's atmosphere. Furthermore, its reactivity with molecules is almost unknown. The radiative electron attachment of $\mathrm{C}_{3} \mathrm{~N}$ involves low fluxes because in our model we use the recently measured rate constant for the $\mathrm{C}_{3} \mathrm{~N}+\mathrm{CH}_{4}$ reaction $\left(k=3.010^{-11} \mathrm{~cm}^{3} \mathrm{~s}^{-1}\right.$ for $T \in[150,300] \mathrm{K}$ and $F \approx 1.6$ )(Fournier et al., 2015) leading to low $\mathrm{C}_{3} \mathrm{~N}$ densities. It should be noted that the fluxes of anion + cation reactions are always very low and the fluxes for photodetachment (Millar et al., 2007) are low except for $\mathrm{H}^{-}$which has a much lower EA than other anions considered here. In general, the effect of anions on neutral species is very low as the anion reactions involve low fluxes. 

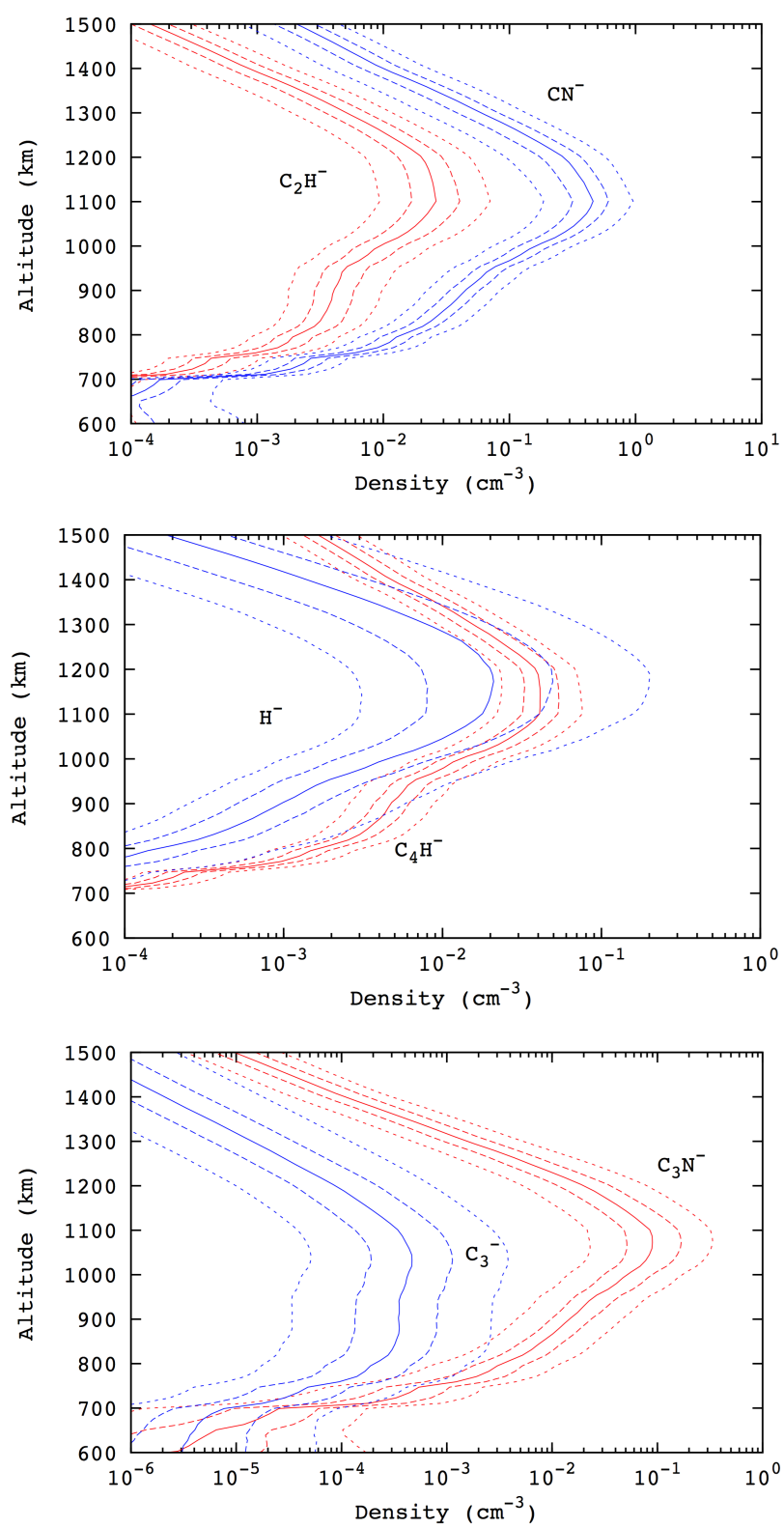

Fig. 17. Top: Global-mean number density profiles of $\mathrm{C}_{2} \mathrm{H}^{-}$(red) and $\mathrm{CN}^{-}$(blue). Middle: Density profiles of $\mathrm{C}_{3}^{-}$(blue) and $\mathrm{C}_{3} \mathrm{~N}^{-}$(red). Bottom: Density profiles of $\mathrm{H}^{-}$(red) and $\mathrm{C}_{4} \mathrm{H}^{-}$(blue). Solid line: Mean profile. Dashed lines and dotted lines give the intervals containing respectively $50 \%$ and $90 \%$ of the density profiles.

Wellbrock et al. (2013) presented a summary of numerous observations performed with the Electron Spectrometer sensor of the Cassini Plasma Spectrometer (CAPS-ELS). From 34 Titan encounters, they obtained negative ion density trends of different mass groups with altitude (between 950 and 1400 $\mathrm{km}$ ). The heaviest ions observed so far have masses up to 13,800 amu/q. Densities of a few $\mathrm{cm}^{-3}$ up to a maximum density around $200 \mathrm{~cm}^{-3}$ have been recorded for masses in the 12-55 range. The peak average altitude for masses from 12 to $55 \mathrm{amu} / \mathrm{q}$ is around $1060 \mathrm{~km}$ (see Table 3). The altitude of peak 
densities we obtained is consistent with these data but we predict much fewer negative ions since the total integrated density of the negative ions in the 12-55 range is around $1 \mathrm{~cm}^{-3}$ in our model (see Figure 16). However, such a comparison could be unrealistic. According to Wellbrock et al. (2013), a fraction of the processed counts they used to derive the negative ion densities may be due to background electrons or inter-anode scaling uncertainties. As already noted, the uncertainties on DEA reactions are difficult to estimate and are likely to be underestimated in this study. Moreover, the uncertainty on the energetic electron fluxes will also play a role. Then, the uncertainty on our negative ion calculations may be underestimated, even if a factor of 200 seems unlikely.

Table 3

Negative ion densities from Wellbrock et al. (2013). Model species are the main negative ions in our model expected to contribute in the corresponding mass range.

\begin{tabular}{cccc}
\hline Mass range $(\mathrm{amu} / \mathrm{q})$ & Model species & Density range $\left(\mathrm{cm}^{-3}\right)$ & Peak average altitude $(\mathrm{km})$ \\
\hline $12-30$ & $\mathrm{CN}^{-} ; \mathrm{C}_{2} \mathrm{H}^{-}$ & $5.3-112$ & 1066 \\
$30-55$ & $\mathrm{C}_{3}^{-} ; \mathrm{C}_{3} \mathrm{~N}^{-} ; \mathrm{C}_{4} \mathrm{H}^{-}$ & $3.5-92$ & 1061 \\
\hline
\end{tabular}

\subsection{Main chemical pathways in ion chemistry}

The main pathways of our chemical network are presented in Figures 18, 20, 21 and 22 for neutral species and positive and negative ions. For hydrocarbons, we show separately the chemistry in the ionosphere and in the lower atmosphere (altitude range) as they are notably different.

\subsubsection{Hydrocarbon chemistry}

The main chemical pathways of hydrocarbon chemistry are presented in Figure 18. This flowchart has been constructed using the integrated column rates given in Appendix B (available in the supplementary material). The main changes with respect to our previous models for hydrocarbon chemistry is the update of $\mathrm{C}_{4} \mathrm{H}_{x}$ chemistry and some rate constants for $\mathrm{C}_{2} \mathrm{H}_{3}$ reactions. These modifications have no significant effect on the abundances of most of the hydrocarbons presented here except for $\mathrm{C}_{4} \mathrm{H}_{10}$ which now reaches an abundance level similar to $\mathrm{C}_{3} \mathrm{H}_{8}$ and might therefore be detectable. It should be noted that only one isomer for $\mathrm{C}_{4} \mathrm{H}_{10}$ was considered here. The abundance profiles of stable $\mathrm{C}_{4} \mathrm{H}_{x}$ species are presented in Figure 19. Our $\mathrm{C}_{4} \mathrm{H}_{2}$ profile is in good agreement with disk averaged data in the stratosphere from Coustenis et al. (2013). According to our model, $\mathrm{C}_{4} \mathrm{H}_{2}$ (diacetylene), $\mathrm{C}_{4} \mathrm{H}_{4}$ (vinylacetylene: $\mathrm{H}_{2} \mathrm{C}=\mathrm{CH}-\mathrm{CCH}$ ) and $\mathrm{C}_{4} \mathrm{H}_{6}$ (butadiene: $\mathrm{H}_{2} \mathrm{C}=\mathrm{CH}-\mathrm{CH}=\mathrm{CH}_{2}$ ) should all be relatively abundant in the higher atmosphere. 


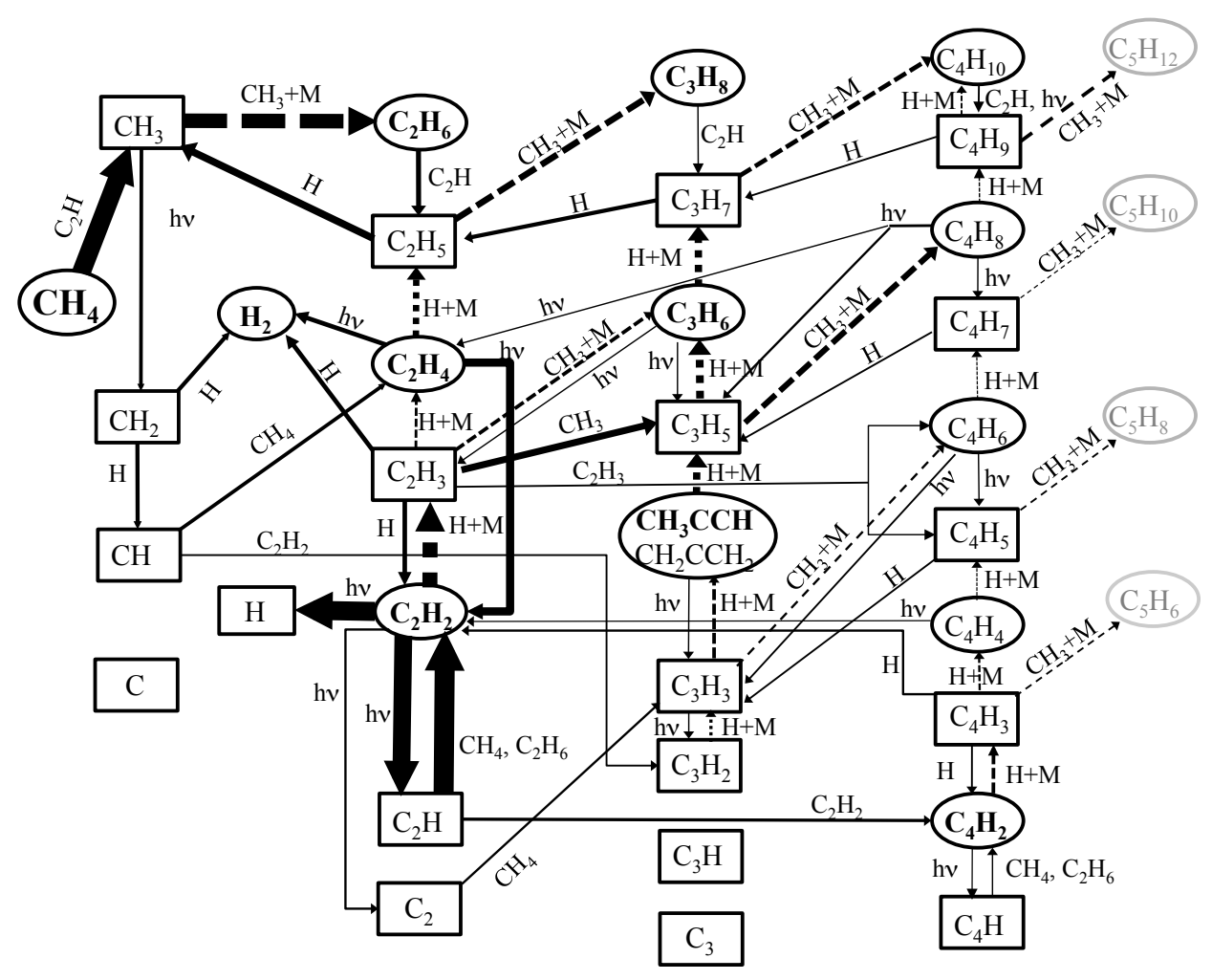

Fig. 18. Schematic diagram highlighting the important pathways for hydrocarbon production in the lower atmosphere (only neutral species are important in this case). The thickness of each arrow represents the integrated total production. Dashed lines correspond to termolecular processes, which are efficient only in the lower atmosphere. Species in grey are not considered in this study. Compounds that have been detected are highlighted in bold. $\mathrm{C}, \mathrm{C}_{3}$ and $\mathrm{C}_{3} \mathrm{H}$ species are formed only in the upper atmosphere (see Figure 20). For atomic hydrogen we show only its formation since its destruction involves reactions already present in the scheme (almost half of the reactions).

\subsubsection{Hydrocarbon-ion chemistry}

Hydrocarbon-ion chemistry is initiated by photoionization of $\mathrm{N}_{2}$ leading mainly to the formation of $\mathrm{CH}_{3}^{+}$through the $\mathrm{N}_{2}^{+}+\mathrm{CH}_{4}$ reaction, and then to $\mathrm{C}_{2} \mathrm{H}_{5}^{+}$ through the $\mathrm{CH}_{3}^{+}+\mathrm{CH}_{4}$ reaction. One of the main reactions of $\mathrm{C}_{2} \mathrm{H}_{5}^{+}$is with $\mathrm{HCN}$ leading to $\mathrm{C}_{2} \mathrm{H}_{4}$ and $\mathrm{HCNH}^{+}$. This ionic chemistry is therefore an important production pathway for $\mathrm{C}_{2} \mathrm{H}_{4}$ in the upper atmosphere, in addition to the main neutral pathway, the $\mathrm{CH}+\mathrm{CH}_{4}$ reaction. $\mathrm{C}_{2} \mathrm{H}_{5}^{+}$is also an important source of $\mathrm{C}_{2} \mathrm{H}_{3}$ through $\mathrm{DR}$ (which also produces $\mathrm{C}_{2} \mathrm{H}_{4}$ ). The $\mathrm{C}_{2} \mathrm{H}_{3}$ production is similar in magnitude to its production from $\mathrm{C}_{2} \mathrm{H}_{4}$ dissociation in the lower atmosphere (induced by cosmic rays). Apart from reacting with $\mathrm{HCN}$ and electrons, $\mathrm{C}_{2} \mathrm{H}_{5}^{+}$also reacts with $\mathrm{C}_{2} \mathrm{H}_{2}$ and $\mathrm{C}_{2} \mathrm{H}_{4}$ initiating efficient hydrocarbon cation formation, eventually leading to $\mathrm{C}_{9} \mathrm{H}_{11}^{+}$(Anicich et al., 2006; Westlake et al., 2014). These processes are therefore a major source of neutral 

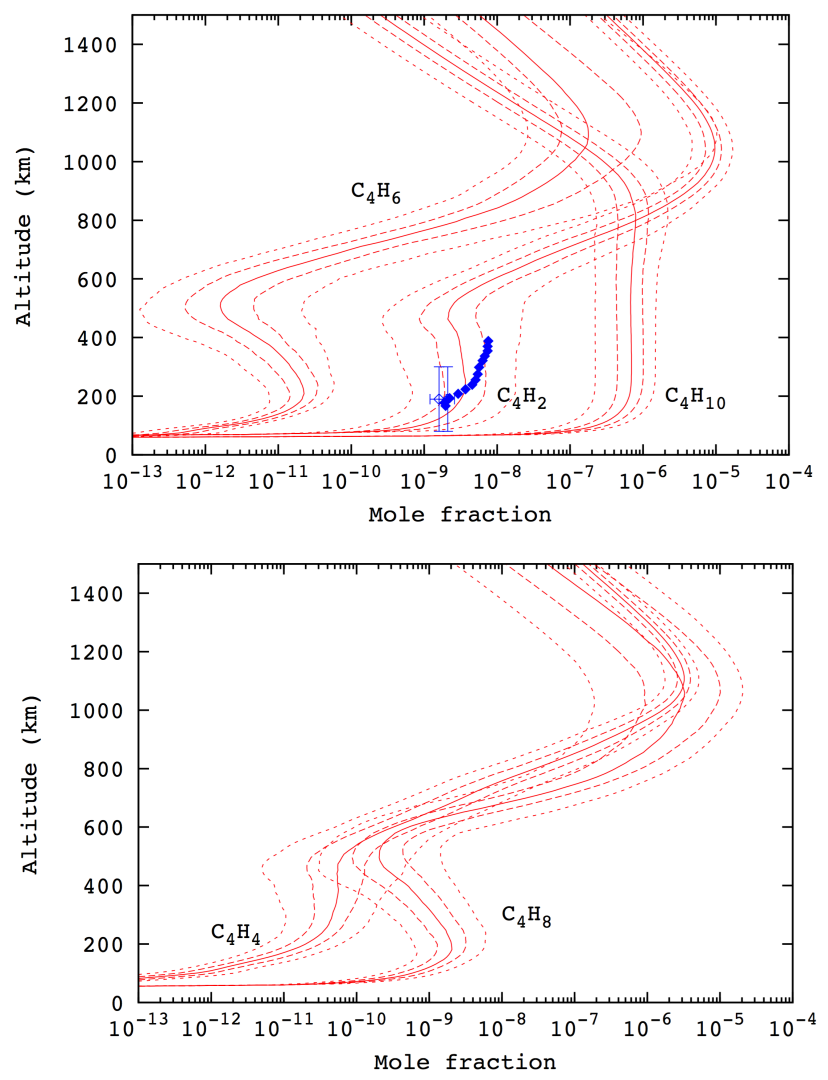

Fig. 19. Mole fraction profiles of $\mathrm{C}_{4} \mathrm{H}_{2}, \mathrm{C}_{4} \mathrm{H}_{6}, \mathrm{C}_{4} \mathrm{H}_{10}$ (top) and $\mathrm{C}_{4} \mathrm{H}_{4}, \mathrm{C}_{4} \mathrm{H}_{8}$ (bottom). Solid line: Mean profile. Dashed lines and dotted lines give the intervals containing respectively $50 \%$ and $90 \%$ of the abundance profiles. The new analysis from Coustenis et al. (2013) of IRIS/Voyager 1 and ISO disk averaged data and CIRS observations of Vinatier et al. (2010) at $5^{\circ} \mathrm{N}$ for $\mathrm{C}_{4} \mathrm{H}_{2}$ are depicted in blue.

hydrocarbons in the ionosphere through DR. In general, hydrocarbons do not lead efficiently to ions through proton transfer due to low proton affinity except in two cases: $\mathrm{C}_{4} \mathrm{H}_{2}$ and $\mathrm{C}_{3}$, which lead to $\mathrm{C}_{4} \mathrm{H}_{3}^{+}$and $\mathrm{C}_{3} \mathrm{H}^{+}$. In the case of $\mathrm{C}_{3} \mathrm{H}^{+}$, this acts as an important loss process for $\mathrm{C}_{3}$ as $\mathrm{C}_{3} \mathrm{H}^{+}$reacts quickly with $\mathrm{CH}_{4}$. It should be noted that the peak of the $\mathrm{C}_{3} \mathrm{H}^{+}$abundance is in relatively good agreement with INMS observations (Vuitton et al., 2007) and is the only indirect evidence of the presence of $\mathrm{C}_{3}$ in Titan's upper atmosphere. No other models consider $\mathrm{C}_{3}$, even if it is known to be the main product of the $\mathrm{C}+\mathrm{C}_{2} \mathrm{H}_{2}$ reaction (Costes et al., 2009; Chastaing et al., 2001; Bergeat and Loison, 2001; Guadagnini et al., 1998; Mebel et al., 2007) and is also likely to be a product of $\mathrm{C}_{3} \mathrm{H}_{2}$ photodissociation and the $\mathrm{C}_{3} \mathrm{H}_{3}^{+}$DR reaction. There is no $\mathrm{C}_{3}$ peak in the neutral INMS spectrum but the $\mathrm{C}_{3}^{+}$spectrum after ionization at $70 \mathrm{eV}$ is unknown and may lead mainly to fragmentation, forming $\mathrm{C}^{+}$ $+\mathrm{C}_{2}$ and $\mathrm{C}+\mathrm{C}_{2}^{+}$. It should be noted that the mass spectra of $\mathrm{C}_{3} \mathrm{H}, \mathrm{C}_{3} \mathrm{H}_{2}$, $\mathrm{C}_{3} \mathrm{H}_{3}, \mathrm{C}_{3} \mathrm{H}_{5}, \mathrm{C}_{3} \mathrm{H}_{7}$ after ionization at $70 \mathrm{eV}$ are also unknown and probably lead to many fragments. 


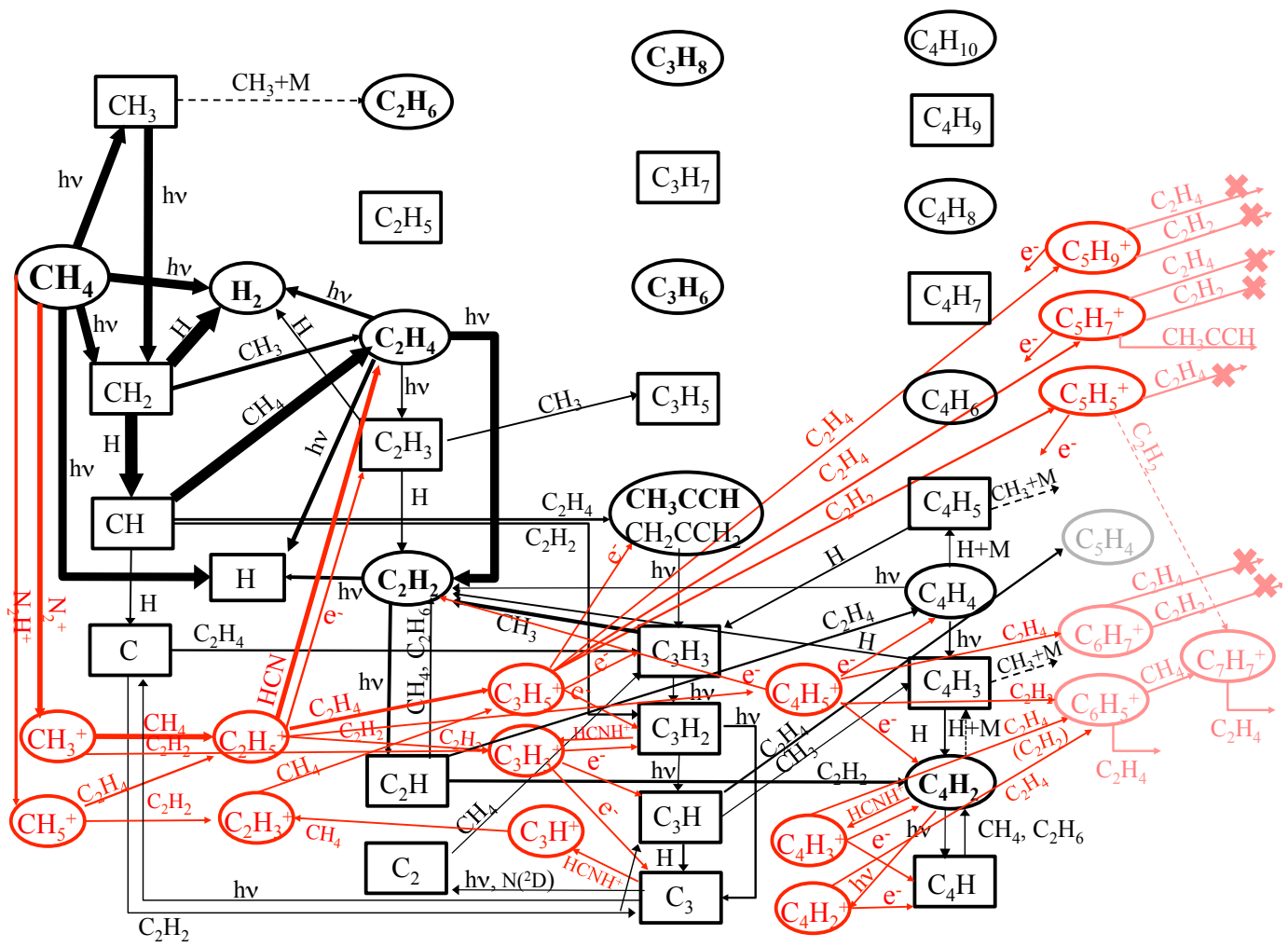

Fig. 20. Schematic diagram highlighting the important neutral (black) and ionic (red) pathways for the production of hydrocarbons in the ionosphere. The thickness of each arrow represents the integrated total production. Dashed lines correspond to the few termolecular processes which are non-negligible in the ionosphere. Species and arrows in grey and light red are not considered in this study. Compounds that have been detected are highlighted in bold.

\subsubsection{Nitrogen-ion chemistry}

The schematic diagram highlighting the important neutral and ionic pathways for the production of nitriles, amines and imines is shown in Figure 21. Since the main effect of UV photons on $\mathrm{N}_{2}$ is either photodissociation or photoionization and because $\mathrm{N}_{2}^{+}$leads mainly to $\mathrm{CH}_{3}^{+}$through the $\mathrm{N}_{2}^{+}+\mathrm{CH}_{4}$ reaction, ionic chemistry has little effect on nitrile production. $\mathrm{N}_{2}$ dissociative photoionization however, acts as a secondary source of $\mathrm{HCN}$ and $\mathrm{HNC}$ through the $\mathrm{N}^{+}+\mathrm{CH}_{4}$ reaction followed by the $\mathrm{DR}$ of $\mathrm{HCNH}^{+}$and $\mathrm{HCNH}^{+}$ reactions with neutrals having high proton affinities. As already noted by several authors, nitriles can efficiently accept $\mathrm{H}^{+}$because they have high proton affinities. Since the DR of protonated nitriles does not form nitriles $+\mathrm{H}$ with a $100 \%$ yield, but also other products, these reactions act as loss processes for large nitriles (partly transformed into $\mathrm{HCN}$ and $\mathrm{HNC}$ ). This is particularly true for $\mathrm{C}_{2} \mathrm{H}_{5} \mathrm{CN}$ since its high $\mathrm{PA}$ prevents $\mathrm{H}^{+}$transfer toward other molecules (except $\mathrm{CH}_{2} \mathrm{NH}$ and $\mathrm{NH}_{3}$ ). It should be noted than the observed $\mathrm{CH}_{3} \mathrm{CN}$ and $\mathrm{C}_{2} \mathrm{H}_{5} \mathrm{CN}$ abundances in the lower atmosphere $(150-300 \mathrm{~km})$ are 
hardly compatible with the $\mathrm{CH}_{3} \mathrm{CNH}^{+}$and $\mathrm{C}_{2} \mathrm{H}_{5} \mathrm{CNH}^{+}$INMS measurements in the current state of the photochemical network. As $\mathrm{CH}_{3} \mathrm{CN}$ and $\mathrm{C}_{2} \mathrm{H}_{5} \mathrm{CN}$ have very low reactivity and are not easily photodissociated (similar to $\mathrm{HCN}$ ) their profiles are dominated by diffusion. The fact that the tropospheric values are overestimated in our model compared to the observations for $\mathrm{CH}_{3} \mathrm{CN}$, $\mathrm{C}_{2} \mathrm{H}_{5} \mathrm{CN}$ and $\mathrm{HC}_{3} \mathrm{~N}$ strongly suggests that additional physical loss processes at low altitude are involved. Such effects may be Hadley cell-type transport affecting differently the species as a function of their saturated vapour pressure, or sticking on (charged) grains with an efficiency function related to the dipole moment and the dispersion coefficient.

In the upper atmosphere, $\mathrm{CH}_{2} \mathrm{NH}$ is relatively abundant and has a high $\mathrm{PA}$ (higher than $\mathrm{C}_{2} \mathrm{H}_{5} \mathrm{CN}$ ). Then, since the $\mathrm{DR}$ reaction of $\mathrm{CH}_{2} \mathrm{NH}_{2}^{+}$may not lead back entirely to $\mathrm{CH}_{2} \mathrm{NH}$, ionic chemistry may act as a strong sink for $\mathrm{CH}_{2} \mathrm{NH}$. Additionally, DR of $\mathrm{CH}_{2} \mathrm{NH}_{2}^{+}$may lead to $\mathrm{CH}_{2}+\mathrm{NH}_{2}$ (Yelle et al., 2010). This acts not only as a sink for $\mathrm{CH}_{2} \mathrm{NH}$ but also as a source of $\mathrm{NH}_{2}$. Then $\mathrm{NH}_{2}$ reaches a relatively high concentration in the ionosphere reacting mainly with $\mathrm{N}$ atoms (Loison et al., 2015) and also with $\mathrm{H}_{2} \mathrm{CN}$ leading to $\mathrm{NH}_{3}$ (Yelle et al., 2010). It should be noted that considering its PA $(773 \mathrm{~kJ} / \mathrm{mol}$ (Hunter and Lias, 1998)), $\mathrm{NH}_{2}$ should react rapidly with $\mathrm{C}_{2} \mathrm{H}_{5}^{+}$and $\mathrm{HCNH}^{+}$leading to $\mathrm{NH}_{3}^{+}$and then to $\mathrm{NH}_{4}^{+}$(through the $\mathrm{NH}_{3}^{+}+\mathrm{CH}_{4}$ reaction), which will be an additional important source of $\mathrm{NH}_{3}$ in Titan's ionosphere. Ionic chemistry does not appear to be the main source of nitriles or imines in Titan's ionosphere, which are produced mainly through neutral chemistry. However the coupled neutral-ionic chemistry is the main source of amines.

\subsubsection{Negative ion chemistry}

The schematic diagram of negative ion chemistry considered in the present model is presented in Figure 22 and the chemistry has been discussed in paragraph 3.5. In our model, the main source of anions is the $\mathrm{CH}_{4}$ dissociative electron attachment, with two secondary sources, HCN dissociative electron attachment and radiative attachment to $\mathrm{C}_{4} \mathrm{H}$ and $\mathrm{C}_{3}$. The most thermodynamically favored anion is $\mathrm{C}_{3} \mathrm{~N}^{-}$, but as $\mathrm{HCN}$ is much more abundant than $\mathrm{HC}_{3} \mathrm{~N}, \mathrm{CN}^{-}$is more abundant at steady state (see section 3.4).

\subsection{Propagation of uncertainties and key reactions}

In order to determine the key reactions in our chemical scheme, i.e. the reactions that have a significant influence on the uncertainties of modeled species densities, we performed a global sensitivity analysis based on the calculation of Rank Correlation Coefficients (RCCs) between compounds of interest and 


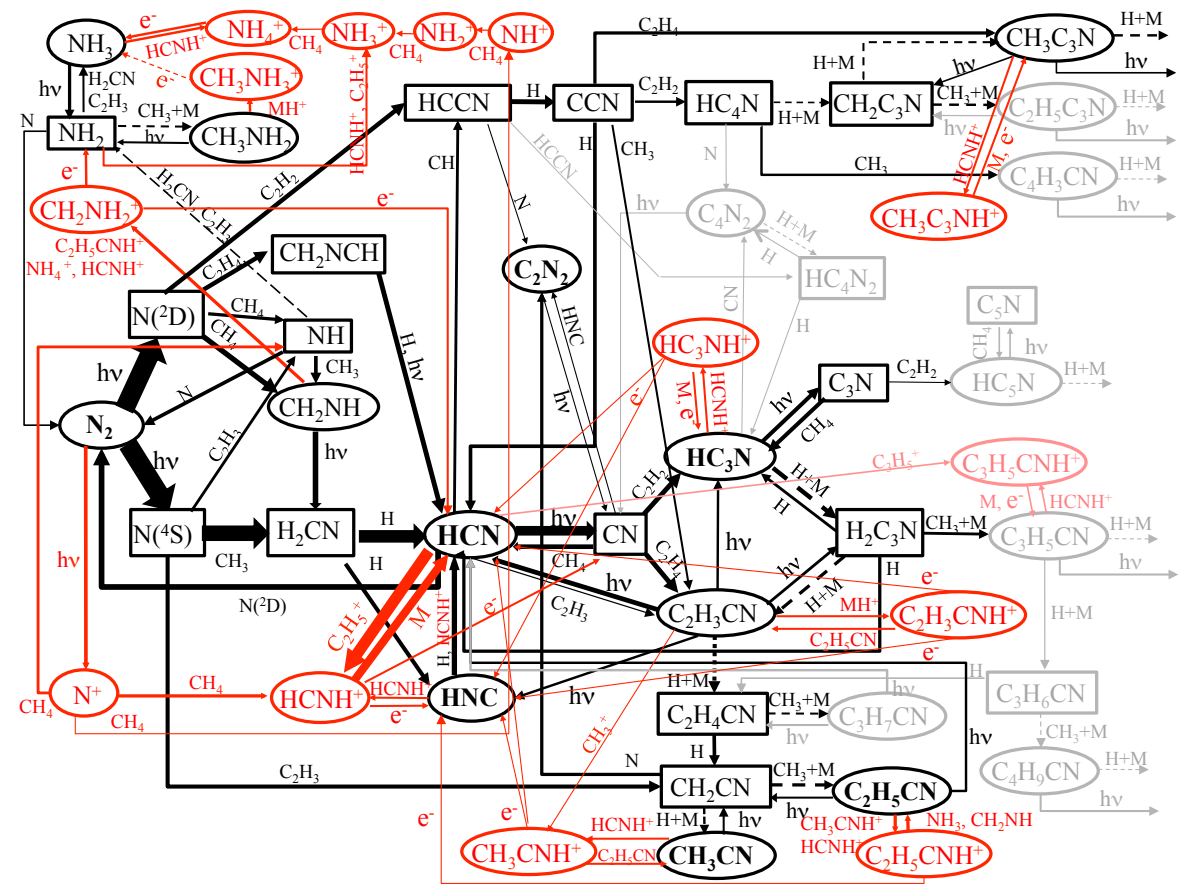

Fig. 21. Schematic diagram highlighting the important neutral (black) and ionic (red) pathways for the production of nitriles, amines and imines. The thickness of each arrow represents the integrated total production (however the thicknesses are not the same as for hydrocarbon chemistry, the $\mathrm{N}_{2}$ photodissociation flux being 110 times smaller than the $\mathrm{C}_{2} \mathrm{H}_{2}$ photodissociation flux). Dashed lines correspond to termolecular processes, which are efficient only in the lower atmosphere. Species and arrows in grey are not considered in this study. Compounds that have been detected are highlighted in bold.

all rate constants as a function of altitude (see for instance Hébrard et al. (2009) for details of the methodology). Note that these key reactions are not necessarily the reactions that have the most important relative production rates (or loss rates) for a given compound. This methodology has succeeded in allowing us to identify the key reactions for the photochemistry of neutral compounds, leading to a subsequent improvement in the prediction of hydrocarbon abundances in Titan's atmosphere. We clearly see these improvements by comparing the studies of Hébrard et al. (2007) and Loison et al. (2015). The chemical scheme published in Loison et al. (2015) provides a better agreement between the model results and observations and a noticeable reduction of uncertainties on model results. We adopt here the same methodology for ions (see Dobrijevic et al. (2014) and Loison et al. (2015) for neutral species). 


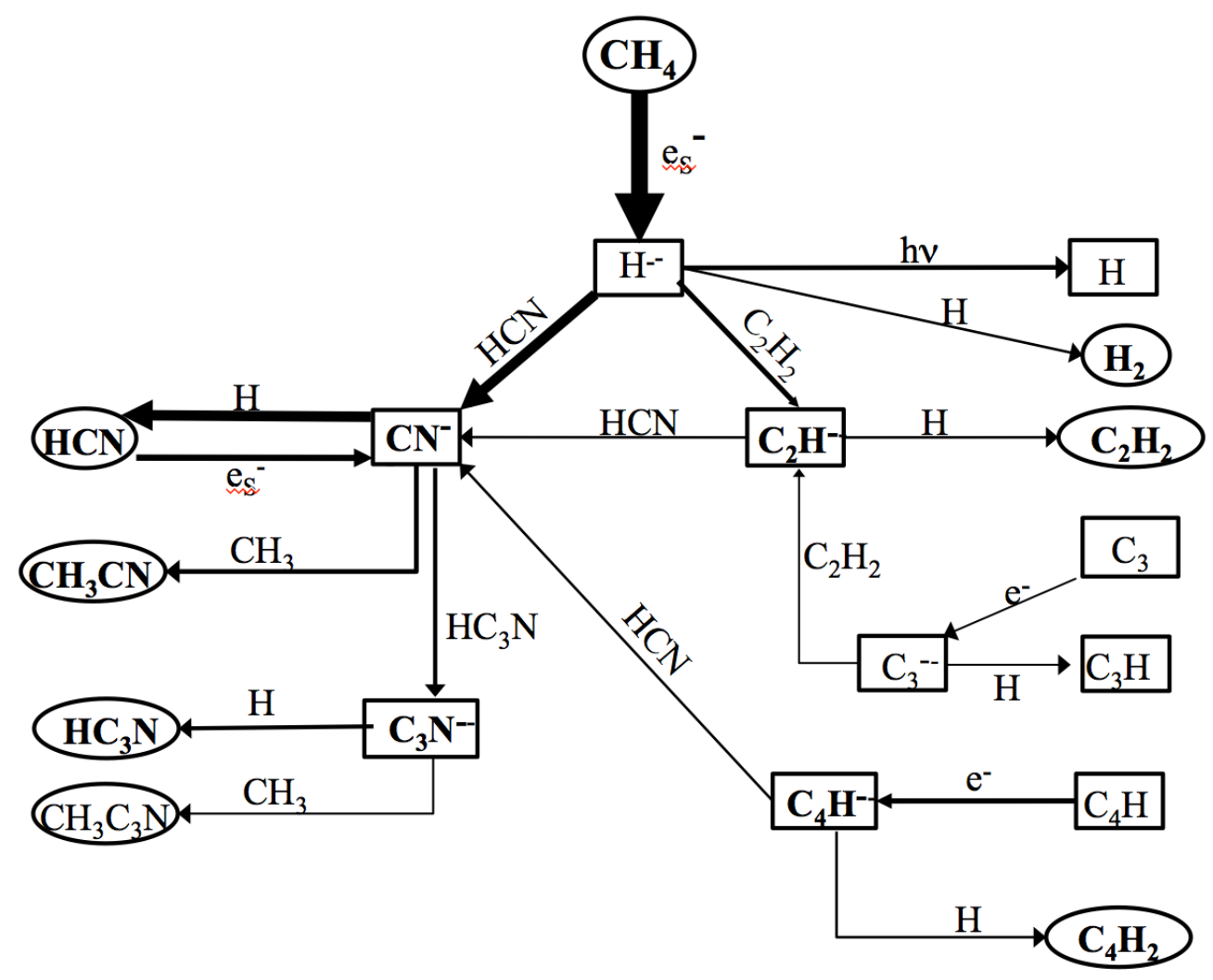

Fig. 22. Schematic diagram highlighting the important pathways for the production of anions. The thickness of each arrow represents the integrated total production (however the thicknesses are not the same as for hydrocarbon and nitrile chemistry, the fluxes involved being much smaller). Compounds that have been detected are highlighted in bold.

\subsubsection{Positive ions}

Since many ions have relative 1- $\sigma$ uncertainties greater than $100 \%$, we defined density uncertainty factors $F_{i}$ by $\log \left(n_{i}\right)=\overline{\log \left(n_{i}\right)} \pm \log \left(F_{i}\right)$ (where $n_{i}$ is the number density of species $i$ ) for all ion species at $1100 \mathrm{~km}$ (which correspond approximately to the maximum of ion production). These uncertainty factors are plotted in Figure 23. We see a general trend in this plot: the higher the mass, the greater the uncertainty factor. This result confirms the results of Peng et al. (2010) who studied the predictivity of photochemical models, obtaining an increase of model result uncertainties with molecular mass. Moreover, there is no evident difference between hydrocarbons and nitrogen compounds in terms of uncertainty as a function of molecular mass: both ion families have similar uncertainties despite the fact that their chemistry is notably different.

The uncertainties on the densities of many compounds (including the most 


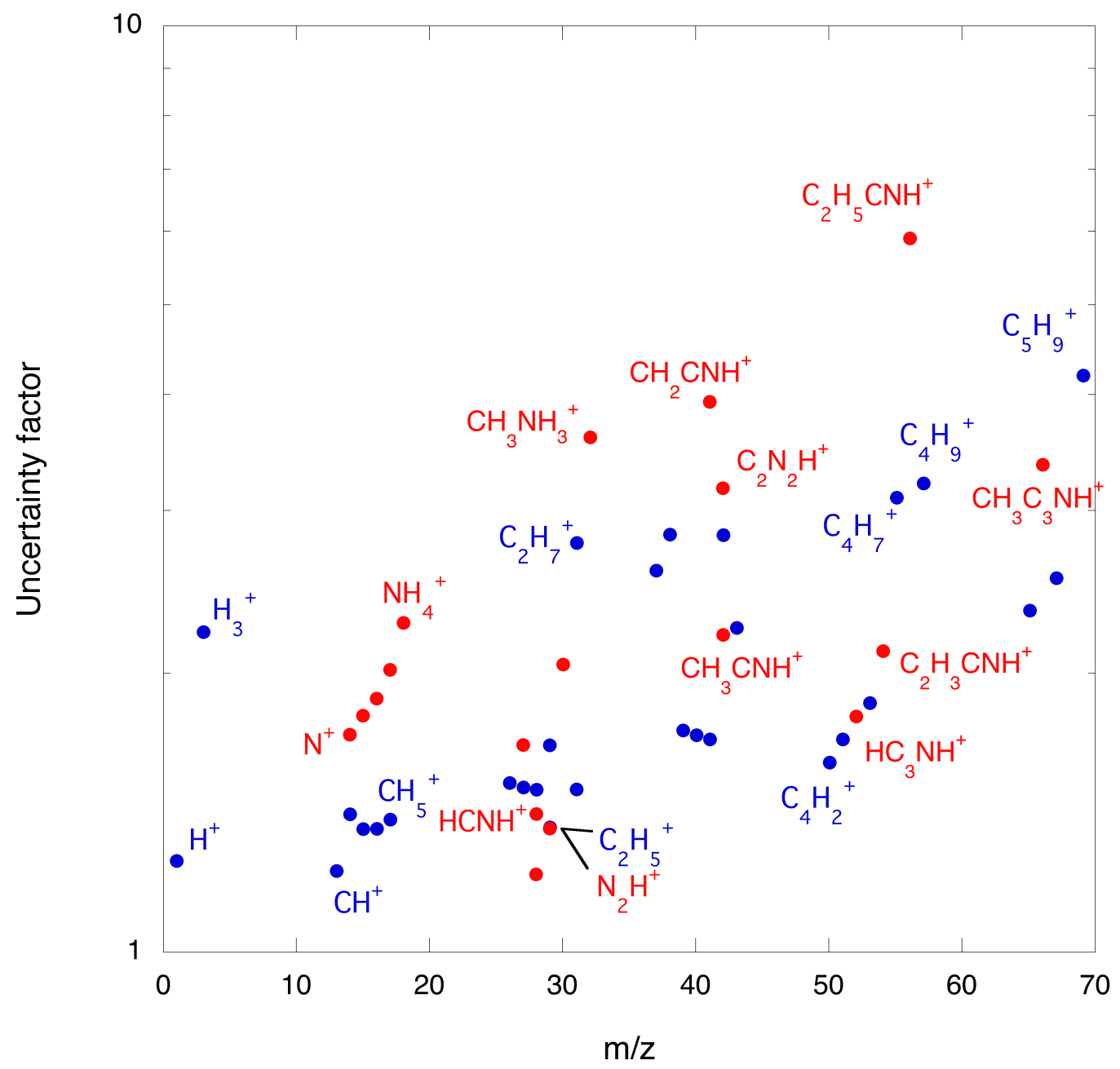

Fig. 23. Uncertainty factors of positive ion densities at $1100 \mathrm{~km}$ of altitude as a function of mass (uma). In red: species containing nitrogen atoms. In blue: other species. For clarity, we label only certain ions with high density and/or high uncertainty factors.

abundant ones) are lower than a factor of 2 in the current model. The uncertainty factor reaches a maximum of about 6 for $\mathrm{C}_{2} \mathrm{H}_{5} \mathrm{CNH}^{+}$. It is important to note that these factors are very likely to be underestimated (see section 2.3).

Our model allows us to determine the key reactions for each species. In the following, we only present some specific results (the complete list of key reactions is available upon request).

Uncertainty in the attribution of mass 14. We have seen previously that both $\mathrm{N}^{+}$and $\mathrm{CH}_{2}^{+}$can contribute significantly to mass 14 peak in the INMS spectra at $1100 \mathrm{~km}$ when taking uncertainties on rate constants into account. For $\mathrm{CH}_{2}^{+}$, some of the main key reactions (and the associated RCC 
and uncertainty factors $F$ ) are:

\begin{tabular}{ccc}
\hline Key reaction & RCC & $F$ \\
\hline $\mathrm{N}_{2}+\mathrm{h} \nu \rightarrow \mathrm{N}_{2}^{+}+\mathrm{e}$ & 0.41 & 1.2 \\
$\mathrm{CH}_{2}^{+}+\mathrm{CH}_{4} \rightarrow \mathrm{C}_{2} \mathrm{H}_{4}^{+}+\mathrm{H}_{2}$ & -0.40 & 1.25 \\
$\mathrm{~N}_{2}^{+}+\mathrm{CH}_{3} \rightarrow \mathrm{CH}_{2}^{+}+\mathrm{H}+\mathrm{N}_{2}$ & 0.34 & 3.0 \\
$\mathrm{~N}_{2}^{+}+\mathrm{CH}_{4} \rightarrow \mathrm{CH}_{2}^{+}+\mathrm{H}_{2}+\mathrm{N}_{2}$ & 0.42 & 1.25 \\
\hline
\end{tabular}

These last 3 reactions contribute equally to the uncertainty on $\mathrm{CH}_{2}^{+}$but their rate constants have quite low uncertainty factors, except for the $\mathrm{N}_{2}^{+}+\mathrm{CH}_{3}$ reaction. As expected, the photoionization of $\mathrm{N}_{2}$ is a key process. Uncertainties on the density of $\mathrm{N}^{+}$are mainly controlled by reactions of $\mathrm{N}^{+}$with $\mathrm{CH}_{4}$. The main key reactions are:

\begin{tabular}{ccc}
\hline Key reaction & $\mathrm{RCC}$ & $F$ \\
\hline $\mathrm{N}^{+}+\mathrm{CH}_{4} \rightarrow \mathrm{CH}_{3}++\mathrm{NH}$ & -0.95 & 2.0 \\
$\mathrm{~N}^{+}+\mathrm{CH}_{4} \rightarrow \mathrm{CH}_{4}^{+}+\mathrm{N}\left({ }^{4} \mathrm{~S}\right)$ & -0.46 & 1.25 \\
$\mathrm{~N}^{+}+\mathrm{CH}_{4} \rightarrow \mathrm{HCN}^{+}+\mathrm{H}_{2}+\mathrm{H}$ & -0.45 & 1.25 \\
$\mathrm{~N}^{+}+\mathrm{CH}_{4} \rightarrow \mathrm{HCNH}^{+}+\mathrm{H}_{2}$ & -0.94 & 2.0 \\
\hline
\end{tabular}

It is interesting to note that $\mathrm{N}^{+}$is strongly coupled to two key reactions that have uncertainty factors which are high compared to other ion-neutral reactions, according to Anicich (2003). A better determination of these rate constants will significantly lower the uncertainty on the $\mathrm{N}^{+}$density and will help to reveal which of these two species has the major contribution to mass peak 14.

Uncertainty in the attribution of mass 31. Two compounds also contribute significantly to mass peak $31: \mathrm{C}_{2} \mathrm{H}_{7}^{+}$and $\mathrm{CH}_{2} \mathrm{OH}^{+}$. In this case, one of the compounds might be the major contributor to the peak depending on the rate constants of the following key reactions. For $\mathrm{C}_{2} \mathrm{H}_{7}^{+}$, the main key reactions are: 


\begin{tabular}{ccc}
\hline Key reaction & RCC & $F$ \\
\hline $\mathrm{CH}_{5}^{+}+\mathrm{C}_{2} \mathrm{H}_{6} \rightarrow \mathrm{C}_{2} \mathrm{H}_{7}^{+}+\mathrm{CH}_{4}$ & 0.64 & 2.0 \\
$\mathrm{C}_{2} \mathrm{H}_{7}^{+}+\mathrm{HCN} \rightarrow \mathrm{HCNH}^{+}+\mathrm{C}_{2} \mathrm{H}_{6}$ & -0.35 & 2.0 \\
$\mathrm{C}_{2} \mathrm{H}_{7}^{+}+\mathrm{e} \rightarrow \mathrm{C}_{2} \mathrm{H}_{5}+\mathrm{H}+\mathrm{H}$ & -0.33 & 2.0 \\
\hline
\end{tabular}

While for $\mathrm{CH}_{2} \mathrm{OH}^{+}$, the main key reactions are the DR of $\mathrm{CH}_{2} \mathrm{OH}^{+}$:

\begin{tabular}{ccc}
\hline Key reaction & RCC & $F$ \\
\hline $\mathrm{CH}_{2} \mathrm{OH}^{+}+\mathrm{e} \rightarrow \mathrm{H}_{2} \mathrm{CO}+\mathrm{H}$ & -0.71 & 1.6 \\
$\mathrm{CH}_{2} \mathrm{OH}^{+}+\mathrm{e} \rightarrow \mathrm{HCO}+\mathrm{H}+\mathrm{H}$ & -0.71 & 1.6 \\
$\mathrm{CH}_{2} \mathrm{OH}^{+}+\mathrm{e} \rightarrow \mathrm{CO}+\mathrm{H}+\mathrm{H}_{2}$ & -0.72 & 1.6 \\
$\mathrm{CH}_{2} \mathrm{OH}^{+}+\mathrm{e} \rightarrow{ }^{1} \mathrm{CH}_{2}+\mathrm{OH}$ & -0.67 & 1.6 \\
$\mathrm{CH}_{2} \mathrm{OH}^{+}+\mathrm{e} \rightarrow{ }^{3} \mathrm{CH}_{2}+\mathrm{OH}$ & -0.65 & 1.6 \\
$\mathrm{CH}_{2} \mathrm{OH}^{+}+\mathrm{e} \rightarrow \mathrm{H}_{2} \mathrm{O}+\mathrm{CH}$ & -0.57 & 1.6 \\
\hline
\end{tabular}

Since the RCC values of all these reactions are high, a better determination of all of these rate constants, and especially those with high RCC and uncertainty factors, are necessary to reveal which compound contributes to the mass peak 31.

Uncertainty on $\mathbf{H C N H}^{+}$. The uncertainty on the $\mathrm{HCNH}^{+}$density is relatively low in our current model but $\mathrm{HCNH}^{+}$is the most abundant ion and we have probably underestimated the uncertainty factors of several chemical processes (see section 2.3). It is therefore important to identify the key reactions for this compound. The main key reactions at $1100 \mathrm{~km}$ are:

\begin{tabular}{ccc}
\hline Key reaction & $\mathrm{RCC}$ & $F$ \\
\hline $\mathrm{HCNH}^{+}+\mathrm{e} \rightarrow \mathrm{HCN}+\mathrm{H}$ & -0.55 & 1.60 \\
$\mathrm{HCNH}^{+}+\mathrm{e} \rightarrow \mathrm{HNC}+\mathrm{H}$ & -0.51 & 1.60 \\
$\mathrm{HCNH}^{+}+\mathrm{e} \rightarrow \mathrm{CN}+\mathrm{H}+\mathrm{H}$ & -0.56 & 1.60 \\
$\mathrm{~N}\left({ }^{2} \mathrm{D}\right)+\mathrm{C}_{2} \mathrm{H}_{4} \rightarrow \mathrm{CH}_{2} \mathrm{NCH}+\mathrm{H}$ & 0.30 & 2.00 \\
$\mathrm{~N}\left({ }^{2} \mathrm{D}\right)+\mathrm{HCN} \rightarrow \mathrm{CH}+\mathrm{N}_{2}$ & -0.26 & 3.00 \\
\hline
\end{tabular}

It is interesting to note that some of the most important key reactions of $\mathrm{HCNH}^{+}$are not strictly the reactions that contribute most to its production (or loss). In particular, $\mathrm{N}\left({ }^{2} \mathrm{D}\right)+\mathrm{C}_{2} \mathrm{H}_{4} \rightarrow \mathrm{CH}_{2} \mathrm{NCH}+\mathrm{H}$ is a key reaction 
because the reaction $\mathrm{CH}_{2} \mathrm{NCH}+\mathrm{H} \rightarrow \mathrm{HCN}+\mathrm{CH}_{3}$ is an important source of $\mathrm{HCN}$ with a high uncertainty factor $(F=3.0)$ and the reaction of $\mathrm{HCN}$ with $\mathrm{C}_{2} \mathrm{H}_{5}^{+}$is one of the major sources of $\mathrm{HCNH}^{+}$(see Figure 21).

Uncertainty on high mass species like $\mathbf{C}_{2} \mathbf{H}_{5} \mathbf{C N H}^{+}$. The uncertainty on the $\mathrm{C}_{2} \mathrm{H}_{5} \mathrm{CNH}^{+}$density is relatively high. This species is strongly coupled to only two key reactions, which are three-body association reactions with high uncertainty factors.

\begin{tabular}{ccc}
\hline Key reaction & RCC & $F$ \\
\hline $\mathrm{CH}_{2} \mathrm{CN}+\mathrm{CH}_{3}+\mathrm{M} \rightarrow \mathrm{C}_{2} \mathrm{H}_{5} \mathrm{CN}+\mathrm{M}$ & 0.72 & 7.1 \\
$\mathrm{C}_{2} \mathrm{H}_{3} \mathrm{CN}+\mathrm{H}+\mathrm{M} \rightarrow \mathrm{C}_{2} \mathrm{H}_{4} \mathrm{CN}+\mathrm{M}$ & 0.43 & 17.6 \\
\hline
\end{tabular}

So, the uncertainty on $\mathrm{C}_{2} \mathrm{H}_{5} \mathrm{CNH}^{+}$is directly linked to the $\mathrm{C}_{2} \mathrm{H}_{5} \mathrm{CN}$ one.

\subsubsection{Negative ions}

Vuitton et al. (2009) developed the first model of Titan's upper atmosphere to include negative ion chemistry. They notably stated that ion densities are sensitive to many chemical parameters and concluded that a global sensitivity analysis would be valuable. In our study, we couple neutral and ion chemistry and study how uncertainties on the rate constants propagate into the model to pinpoint which reactions strongly influence uncertainties on negative ion density profiles.

We find that $\mathrm{CN}^{-}$, which is the most abundant negative ion, is strongly coupled to four reactions. At $1100 \mathrm{~km}$ of altitude, the main key reactions are:

\begin{tabular}{ccc}
\hline Key reaction & $\mathrm{RCC}$ & $F$ \\
\hline $\mathrm{N}\left({ }^{2} \mathrm{D}\right)+\mathrm{HCN} \rightarrow \mathrm{CH}+\mathrm{N}_{2}$ & -0.36 & 3.00 \\
$\mathrm{CN}^{-}+\mathrm{H} \rightarrow \mathrm{HCN}+\mathrm{e}$ & -0.30 & 1.40 \\
$\mathrm{CH}_{4}+\mathrm{e}_{s} \rightarrow \mathrm{H}^{-}+\mathrm{CH}_{3}$ & 0.40 & 1.20 \\
${ }^{1} \mathrm{CH}_{2}+\mathrm{CH}_{4} \rightarrow \mathrm{CH}_{3}+\mathrm{CH}_{3}$ & -0.39 & 1.80 \\
\hline
\end{tabular}

$\mathrm{e}_{s}$ correspond to supra-thermal electrons. Since we probably underestimate the uncertainty factors of the DEA of $\mathrm{CH}_{4}$, our results point out the importance of this reaction to determine precisely the abundance of $\mathrm{CN}^{-}$.

For $\mathrm{C}_{3} \mathrm{~N}^{-}$, the second most abundant anion, the most influential key reactions are: 


\begin{tabular}{ccc}
\hline Key reaction & $\mathrm{RCC}$ & $F$ \\
\hline${ }^{1} \mathrm{CH}_{2}+\mathrm{CH}_{4} \rightarrow \mathrm{CH}_{3}+\mathrm{CH}_{3}$ & -0.47 & 1.80 \\
$\mathrm{CN}^{-}+\mathrm{HC}_{3} \mathrm{~N} \rightarrow \mathrm{HCN}+\mathrm{C}_{3} \mathrm{~N}^{-}$ & 0.38 & 2.00 \\
${ }^{1} \mathrm{CH}_{2}+\mathrm{N}_{2} \rightarrow{ }^{3} \mathrm{CH}_{2}+\mathrm{N}_{2}$ & 0.37 & 1.60 \\
\hline
\end{tabular}

The uncertainty on $\mathrm{C}_{3} \mathrm{~N}^{-}$is then partially related to the $\mathrm{CN}^{-}$one.

$\mathrm{H}^{-}$is the negative ion with the highest uncertainty. At $1100 \mathrm{~km}$, the main key reactions are:

\begin{tabular}{ccc}
\hline Key reaction & RCC & $F$ \\
\hline $\mathrm{H}^{-}+\mathrm{HCN} \rightarrow \mathrm{CN}^{-}+\mathrm{H}_{2}$ & -0.30 & 1.40 \\
$\mathrm{~N}\left({ }^{2} \mathrm{D}\right)+\mathrm{HCN} \rightarrow \mathrm{CH}+\mathrm{N}_{2}$ & 0.32 & 3.00 \\
$\mathrm{CH}_{4}+\mathrm{e}_{s} \rightarrow \mathrm{H}^{-}+\mathrm{CH}_{3}$ & 0.79 & 1.20 \\
\hline
\end{tabular}

The latter two reactions are also key reactions for $\mathrm{CN}^{-}$. As these processes play a major role in the chemistry of anion species, they should be studied in priority.

\subsubsection{Review of critical key reactions}

Concerning neutral reactions, we find from our global sensitivity analysis that the $\mathrm{N}\left({ }^{2} \mathrm{D}\right)+\mathrm{HCN}$ reaction is a key reaction contributing significantly to the uncertainties of 32 compounds, including both neutrals and ions (with an arbitrary RCC threshold of 0.2 ). This is due to the fact that it is one of very few reactions leading to $\mathrm{HCN}$ loss with a rate constant that is practically unknown. The $\mathrm{N}\left({ }^{2} \mathrm{D}\right)+\mathrm{C}_{2} \mathrm{H}_{4}$ reaction is also a major key reaction contributing to the uncertainties of 10 compounds. Indeed, even if the branching ratio of this reaction has been studied in detail recently (Balucani et al., 2012), there is still a large uncertainty on the low temperature rate constant (Sato et al., 1999). The ${ }^{1} \mathrm{CH}_{2}+\mathrm{CH}_{4}$ and ${ }^{1} \mathrm{CH}_{2}+\mathrm{N}_{2}$ reactions contribute significantly to the uncertainties of 41 and 23 compounds respectively. This is due to the fact that ${ }^{1} \mathrm{CH}_{2}$, produced by $\mathrm{CH}_{4}$ photodissociation, is an important precursor of the Titan's atmospheric chemistry through its reaction and relaxation to ground state triplet $\left({ }^{3} \mathrm{CH}_{2}\right)$ followed by reaction with $\mathrm{H}$ atoms producing $\mathrm{CH}$ radicals. Even if these rate constants have been studied experimentally over a large range of temperatures, the remaining uncertainties are still large enough to lead to major uncertainties in the model. In our model $\mathrm{C}_{2} \mathrm{~N}$ is a key species not only for the production of $\mathrm{CH}_{3} \mathrm{C}_{3} \mathrm{~N}$ but also for carbon atom chemistry as the $\mathrm{H}+\mathrm{C}_{2} \mathrm{~N}$ reaction is an important source of carbon atoms. As a result, the $\mathrm{H}+\mathrm{HCCN}$ and $\mathrm{H}+\mathrm{C}_{2} \mathrm{~N}$ reactions contribute significantly to the uncertainties 
of 8 and 10 compounds respectively. These reactions have never been studied experimentally which explains their large uncertainty factors, which should be studied in the future, as well as the $\mathrm{C}_{2} \mathrm{~N}+\mathrm{C}_{2} \mathrm{H}_{2}$ and $\mathrm{C}_{2} \mathrm{~N}+\mathrm{C}_{2} \mathrm{H}_{4}$ reactions, to increase the predictivity and the precision of the model for $\mathrm{C}_{3}$ formation (as the reaction $\mathrm{H}+\mathrm{C}_{2} \mathrm{~N} \rightarrow \mathrm{C}+\mathrm{HCN}$ is an important source of carbon atoms) and large nitriles.

For cations, the $\mathrm{N}^{+}+\mathrm{CH}_{4}$ and $\mathrm{N}_{2}^{+}+\mathrm{CH}_{4}$ reactions are some of the most critical ionic reactions contributing importantly to the uncertainties of 9 and 7 compounds respectively. Even if there are various measurements for these reactions, the uncertainties are still too large to constrain precisely the models. We find that most of the DR reactions are key reactions for the associated cations. Among them, the DR reaction of $\mathrm{C}_{2} \mathrm{H}_{5}^{+}$(linked to 13 compounds) and the one of $\mathrm{C}_{3} \mathrm{H}_{5}^{+}$(linked to 6 compounds: $\mathrm{C}_{2} \mathrm{H}_{3}, \mathrm{CH}_{3} \mathrm{C}_{2} \mathrm{H}, \mathrm{C}_{3} \mathrm{H}_{5}^{+}, \mathrm{C}_{5} \mathrm{H}_{5}^{+}$, $\mathrm{C}_{5} \mathrm{H}_{7}^{+}, \mathrm{C}_{5} \mathrm{H}_{9}^{+}$) are important key reactions. For anions, the most critical key reaction is the DEA of $\mathrm{CH}_{4}$, which is the most important source of anions. It should be noted that the uncertainty for this reaction is difficult to estimate and has been taken to be equal to an optimistic value of 1.4 in the present study.

\section{Discussion}

\subsection{Effect of the $\mathrm{HR} \mathrm{N}_{2}$ cross section}

Recently, Luspay-Kuti et al. (2015) discussed the effect of the nitrogen photoabsorption cross-section resolution on minor neutral production rates and abundances in the higher part of the atmosphere (above $600 \mathrm{~km}$ of altitude). They showed in particular that mixing ratios of $\mathrm{C}_{2} \mathrm{H}_{6}$ and $\mathrm{HCN}$ increase by $20 \%$ and $35 \%$ respectively and their production rates increase by $30 \%-70 \%$ when HR cross sections were used. They concluded that models that use LR cross sections underestimate the abundances of most neutral species but also overestimate ion densities.

We see in the $\mathrm{HR} \mathrm{N}_{2}$ absorption cross section spectrum (see Figure 1) the presence of many spectral regions where the cross sections of $\mathrm{CH}_{4}$ and $\mathrm{H}_{2}$ are greater than the one of $\mathrm{N}_{2}$. On the other hand, the LR $\mathrm{N}_{2}$ absorption cross section is mostly lower than the ones of $\mathrm{CH}_{4}$ and $\mathrm{H}_{2}$ between 84 and $100 \mathrm{~nm}$. $\mathrm{CH}_{4}$ and $\mathrm{H}_{2}$ are the most abundant species in the atmosphere that absorb in these spectral ranges. We see Figure 24 (top) that the photolysis rate of $\mathrm{N}_{2}$ is significantly modified when using the $\mathrm{HR} \mathrm{N}_{2}$ cross section, but not the ones of $\mathrm{CH}_{4}$ and $\mathrm{H}_{2}$. 

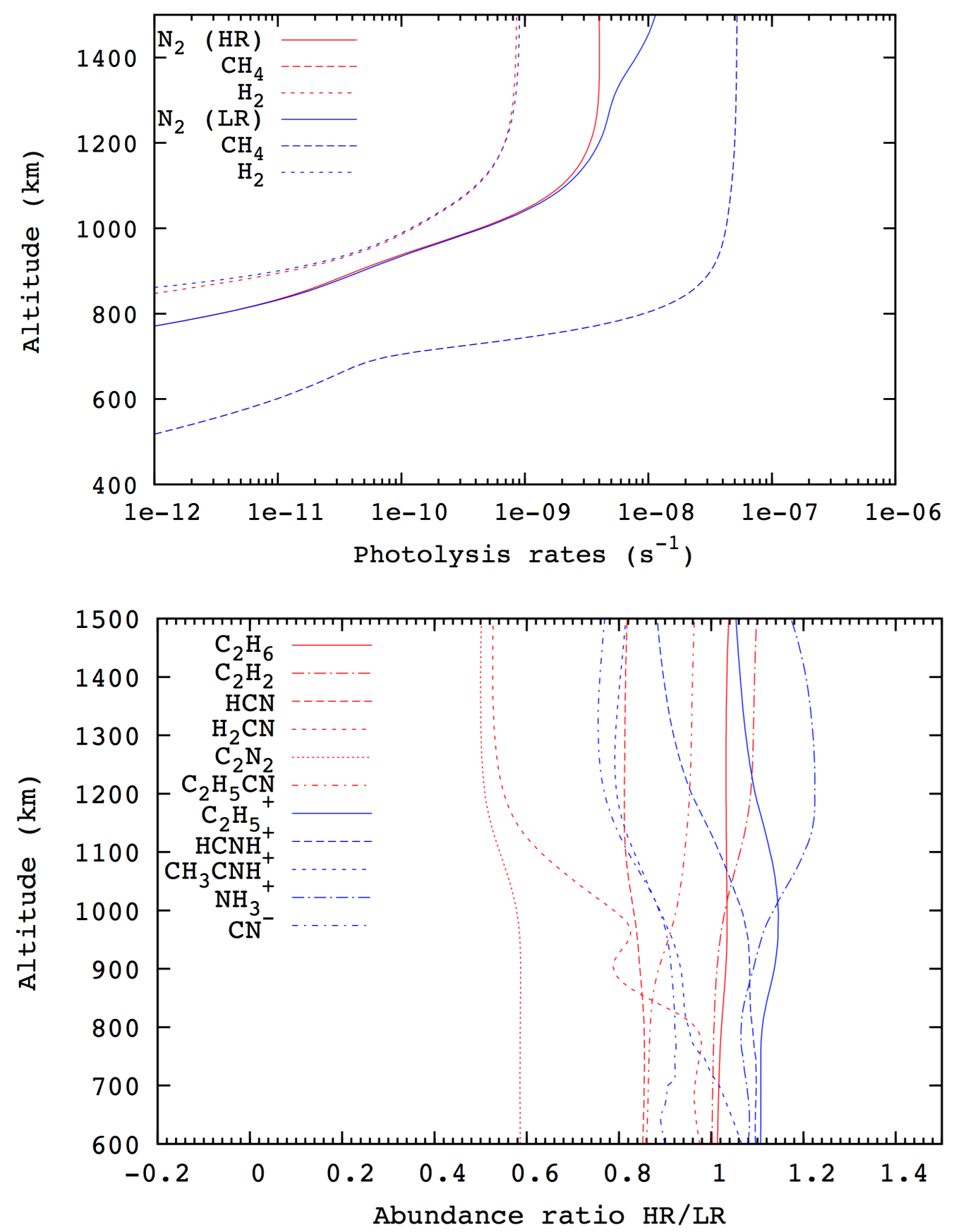

Fig. 24. Top: Photolysis rates of $\mathrm{N}_{2}, \mathrm{CH}_{4}$ and $\mathrm{H}_{2}$ as a function of altitude considering low resolution (LR) $\mathrm{N}_{2}$ absorption cross sections (blue) and high resolution (HR) $\mathrm{N}_{2}$ absorption cross sections (red). Bottom: Ratio of mole fractions of various species (neutrals and ions) obtained in our model using either low resolution (LR) or high resolution (HR) $\mathrm{N}_{2}$ absorption cross sections and the HR solar flux. Neutral species are in red, ions are in blue. 
The abundance profiles of several compounds considering low and high $\mathrm{N}_{2}$ photoabsorption cross-section resolutions are presented in Figure 24 (bottom). We confirm that there is a clear effect of nitrogen photoabsorption cross-section resolution on some minor neutral species and ion densities. However, in contrast to the study of Luspay-Kuti et al. (2015), we find that the use of HR cross sections for $\mathrm{N}_{2}$ does not have a significant effect on $\mathrm{C}_{2} \mathrm{H}_{6}$, whose abundance increases by only $4 \%$ at the maximum (in the ionosphere) and we find that HCN decreases (about 19\% at $1170 \mathrm{~km}$ ). Luspay-Kuti et al. (2015) found that $\mathrm{H}_{2} \mathrm{CN}$ is also affected by the use of $\mathrm{HR}$ cross sections with an increase of more than $50 \%$ around $900 \mathrm{~km}$, whereas we observe a decrease at this altitude. In fact, many other nitriles are more affected in our model such as $\mathrm{CH}_{3} \mathrm{C}_{3} \mathrm{~N}$, $\mathrm{C}_{2} \mathrm{~N}_{2}, \mathrm{C}_{2} \mathrm{H}_{5} \mathrm{CN}$. The disagreement between the two models is also pronounced for ions. Indeed, we find that the use of $\mathrm{LR} \mathrm{N}_{2}$ cross sections underestimates or overestimates ion densities depending on the species compared to the model results with the $\mathrm{HR} \mathrm{N}_{2}$ cross sections. Some ions (like $\mathrm{CH}_{3} \mathrm{CNH}^{+}$) are underestimated using the $\mathrm{HR} \mathrm{N}_{2}$ cross section, while other ions (like $\mathrm{C}_{2} \mathrm{H}_{5}^{+}$) are overestimated (see Figure 24 (bottom)). The main anions are affected by the use of $\mathrm{HR} \mathrm{N}_{2}$ cross sections. For instance, $\mathrm{CN}^{-}$decreases by about $22 \%$ in the ionosphere. In conclusion, the effect observed on the results of the model using HR $\mathrm{N}_{2}$ cross sections is species and altitude dependent for both neutrals and ions. This highlights the complex coupling between these two families. Consequently, the effect is then highly model dependent, which may explain the difference between our results and the study of Luspay-Kuti et al. (2015).

\subsection{Effect of coupling between neutrals and ions}

The methodology used in many studies to simulate the ionospheric chemistry of Titan's atmosphere consists of using neutral abundances derived from INMS data as a fixed background atmosphere to infer the abundances of ions for the same flyby (see for instance Westlake et al. (2012)). This methodology suffers from some limitations. In particular, the abundances of some neutral species required for the calculation of ion densities are at least rather imprecise or not known at all. The other methodology frequently considered is to use profiles published in 1D neutral photochemical models (see for instance Vuitton et al. (2009). The main limitation being that the atmospheric conditions and the chemical parameters for photoionisation and photodissociation processes are not identical in the different models. Both methods neglect the coupling between ion and neutral species. Mandt et al. (2012) obtained modeled densities of $\mathrm{N}^{+}, \mathrm{CH}_{5}^{+}, \mathrm{HCNH}^{+}$and $\mathrm{C}_{2} \mathrm{H}_{5}^{+}$too high by a factor of 2-10 depending on the species and the flyby and found results different from Westlake et al. (2012), although they used the same model (same photolysis rates, chemical scheme, etc). In particular, Mandt et al. (2012) overpredicted $\mathrm{N}^{+}$by a factor of 5 (compared to T40 INMS data) while the Westlake et al. (2012) study 
did not overpredict its density. Mandt et al. (2012) suggested that the best explanation for this discrepancy lies in the origin of the neutral densities of the minor species used in their model. They concluded that it is important to couple ion and neutral chemistry in models. We show in the following how this coupling affects both neutrals and ions.

To illustrate the importance of the coupling between neutrals and ions, we run our model in two different modes:

Mode 1. We use the coupled (nominal) model.

Mode 2. We use a decoupled model. We first run our model considering only the neutral species. We then used neutral profiles at steady state as a fixed background atmosphere for ion species.

Comparing mode 1 (coupled model) and mode 2 (decoupled model), we can see effect of the ion chemistry on neutral species from the ground to the top of the atmosphere, and highlight the importance of coupling for ion species.

Figure 25 (top) shows the profiles of several neutral species for the coupled and decoupled models. Most of the hydrocarbons are affected by ion chemistry (by a factor of 2 or more) except for some species like $\mathrm{C}_{2} \mathrm{H}_{2}$ (difference of $42 \%$ at the maximum around $1200 \mathrm{~km}$ ), and $\mathrm{C}_{2} \mathrm{H}_{6}, \mathrm{C}_{3} \mathrm{H}_{8}, \mathrm{C}_{4} \mathrm{H}_{10}$ (difference of about $15 \%$ percent). All nitriles, and evidently all amines are strongly affected by ion chemistry. Oxygen compounds are slightly affected $\left(90 \%\right.$ for $\mathrm{H}_{2} \mathrm{O}$ in the ionosphere, $30 \%$ for $\mathrm{H}_{2} \mathrm{CO}$ at $600 \mathrm{~km}$ ). Some neutral species are mainly affected in the ionosphere $\left(\mathrm{C}_{3} \mathrm{H}_{4}, \mathrm{C}_{3} \mathrm{H}_{6}, \ldots\right)$, others are affected throughout the atmosphere $\left(\mathrm{NH}_{3}, \mathrm{HNC}, \mathrm{HCN}, \ldots\right)$.

If we consider that the neutrals are fixed (decoupled model), we obtain quite different densities for many positive ions and negative ions compared to the coupled model. The more abundant positive ions are slightly different $(24 \%$ for $\mathrm{HCNH}^{+}, 7 \%$ for $\mathrm{C}_{2} \mathrm{H}_{5}^{+}, 9 \%$ for $\mathrm{CH}_{5}^{+}, 60 \%$ for $\mathrm{N}_{2}^{+}$) except for $\mathrm{N}_{2} \mathrm{H}^{+}$for which the difference is $265 \%$. Differences are more pronounced for higher mass and less abundant species like $\mathrm{NH}_{3}^{+}, \mathrm{NH}_{4}^{+}, \mathrm{C}_{4} \mathrm{H}_{3}^{+}$, etc. Figure 25 (middle) shows some of the positive ion mole fractions as a function of altitude for the coupled and decoupled models. For most species, the coupling increases the ion densities in the ionosphere (except for $\mathrm{C}_{2} \mathrm{H}_{4}^{+}, \mathrm{C}_{2} \mathrm{H}_{5}^{+}, \mathrm{CH}_{3} \mathrm{OH}^{+}, \mathrm{HCO}^{+}$and $\mathrm{H}^{-}$, which inrease by only a few percent). Among the most abundant negative ions, $\mathrm{CN}^{-}$and $\mathrm{C}_{4} \mathrm{H}^{-}$, are respectively $23 \%$ and $395 \%$ more abundant in the coupled model (see Figure 25, bottom).

\subsection{Specific points}

In the following, we discuss some specific points highlighting in particular the species for which our model is not consistent with observations or is very 

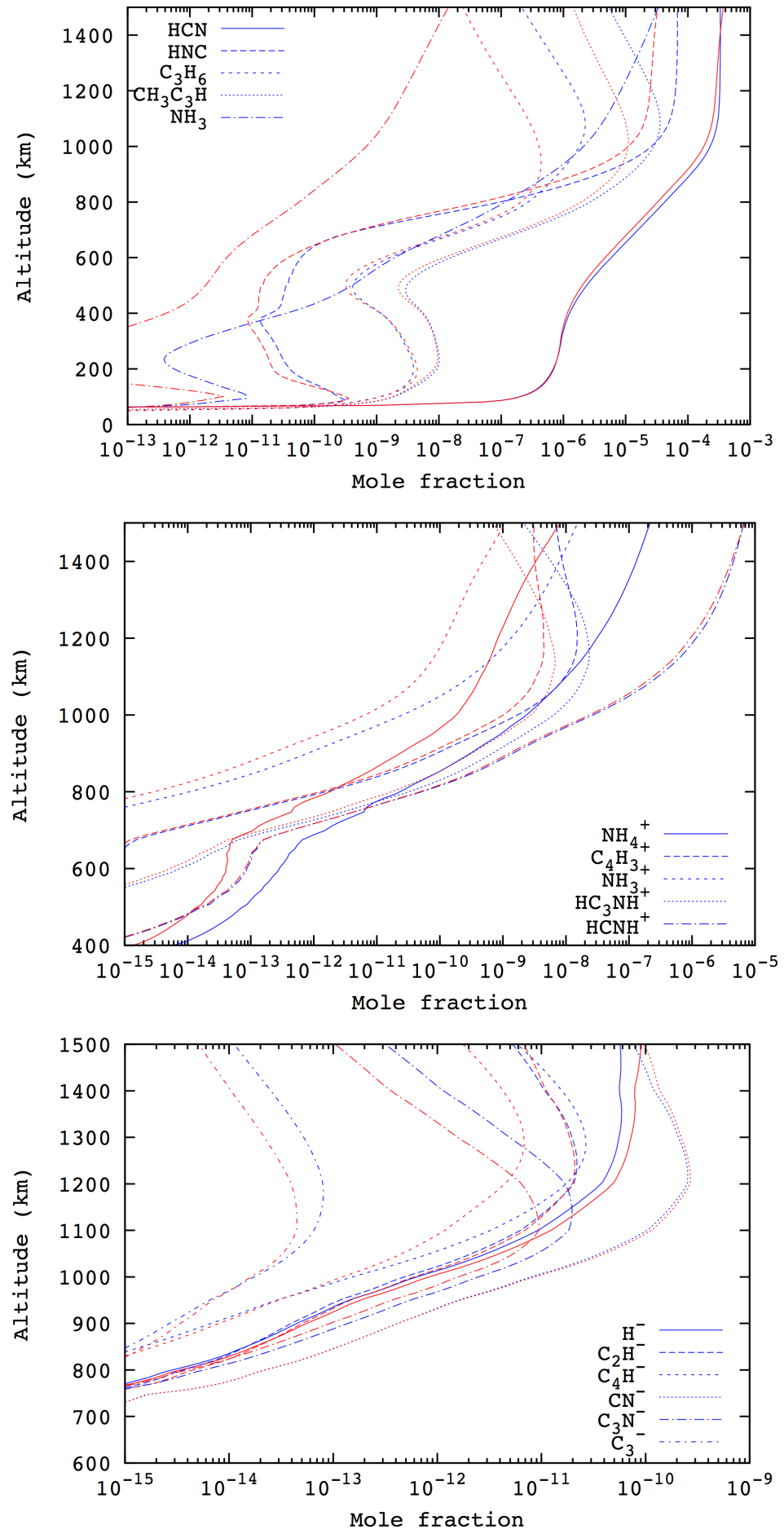

Fig. 25. Mole fraction profiles of some typical species obtained with the nominal (coupled) model (in blue) and the decoupled model (in red). See text for explanation. 
sensitive to some poorly constrained processes.

\subsubsection{Hydrogen cyanide (HNC)}

The neutral production of HNC was studied in depth in Hébrard et al. (2012) and Loison et al. (2015). In the present model, due to the coupling between neutral and ion chemistries, the relative abundance of HNC is greater than in Loison et al. (2015), reaching a value of $710^{-5}$ above $1200 \mathrm{~km}$ (see Figure 26). Our present HNC profile is in good agreement with the Herschel/HIFI observations of Moreno et al. (2012). In Hébrard et al. (2012), the main source of $\mathrm{HNC}$ was the $\mathrm{H}+\mathrm{H}_{2} \mathrm{CN} \rightarrow \mathrm{H}_{2}+\mathrm{HNC}$ reaction. This reaction involves a submerged transition state for which the energy is not well known and depends on the theoretical method used to calculate it. As the main products of the $\mathrm{H}+\mathrm{H}_{2} \mathrm{CN}$ reaction are $\mathrm{H}_{2}+\mathrm{HCN}$, we cannot use the experimental value to constrain $\mathrm{HNC}$ production. We keep this reaction in our nominal model but we performed a test where the $\mathrm{H}+\mathrm{H}_{2} \mathrm{CN}$ reaction produces only $\mathrm{H}_{2}+\mathrm{HCN}$. The result is shown on Figure 26. This test still leads to a good agreement with the observations. In our present model ion chemistry produces almost enough $\mathrm{HNC}$ through the $\mathrm{DR}$ of $\mathrm{HCNH}^{+}$. It should be noted that in the ionosphere the main $\mathrm{HNC}$ loss reaction is $\mathrm{HNC}+\mathrm{HCNH}^{+} \rightarrow \mathrm{HNCH}^{+}+\mathrm{HCN}$, the reaction $\mathrm{HNC}+\mathrm{H} \rightarrow \mathrm{HCN}+\mathrm{H}$ being the most efficient loss process below $900 \mathrm{~km}$.

As with many nitriles, HNC is sensitive to the chemistry induced by Galactic Cosmic Rays (GCRs) in the lower stratosphere of Titan. HNC is also a compound with a very high uncertainty in the stratosphere. The detection, or at least the determination of an upper limit for $\mathrm{HNC}$ in the lower atmosphere could give a valuable opportunity to constrain GCRs in the model and the chemistry that they induce.

\subsubsection{Ammonia $\left(\mathrm{NH}_{3}\right)$}

Our mole fraction profile of $\mathrm{NH}_{3}$ is in agreement with the upper limit derived from the Herschel sub-millimeter observations of Teanby et al. (2013) but our model underestimates its abundance in the ionosphere compared to the value inferred by Cui et al. (2009) (see Figure 27). Compared to the 1Dneutral model of Loison et al. (2015), the coupling between neutrals and ions increases the production of $\mathrm{NH}_{3}$ by a factor of 1000 in the ionosphere but the present abundance is still a factor of 10-100 lower than the value derived by Cui et al. (2009). In addition, we are unable to explain the strong decrease of $\mathrm{NH}_{3}$ density with altitude (corresponding to a slight decrease of $\mathrm{NH}_{3}$ mole fraction with altitude) suggested by INMS data. $\mathrm{NH}_{4}^{+}$detection has often been presented as a validation of the presence of $\mathrm{NH}_{3}$ in Titan's atmosphere. However, according to our model, good agreement between the $\mathrm{NH}_{4}^{+}$model 


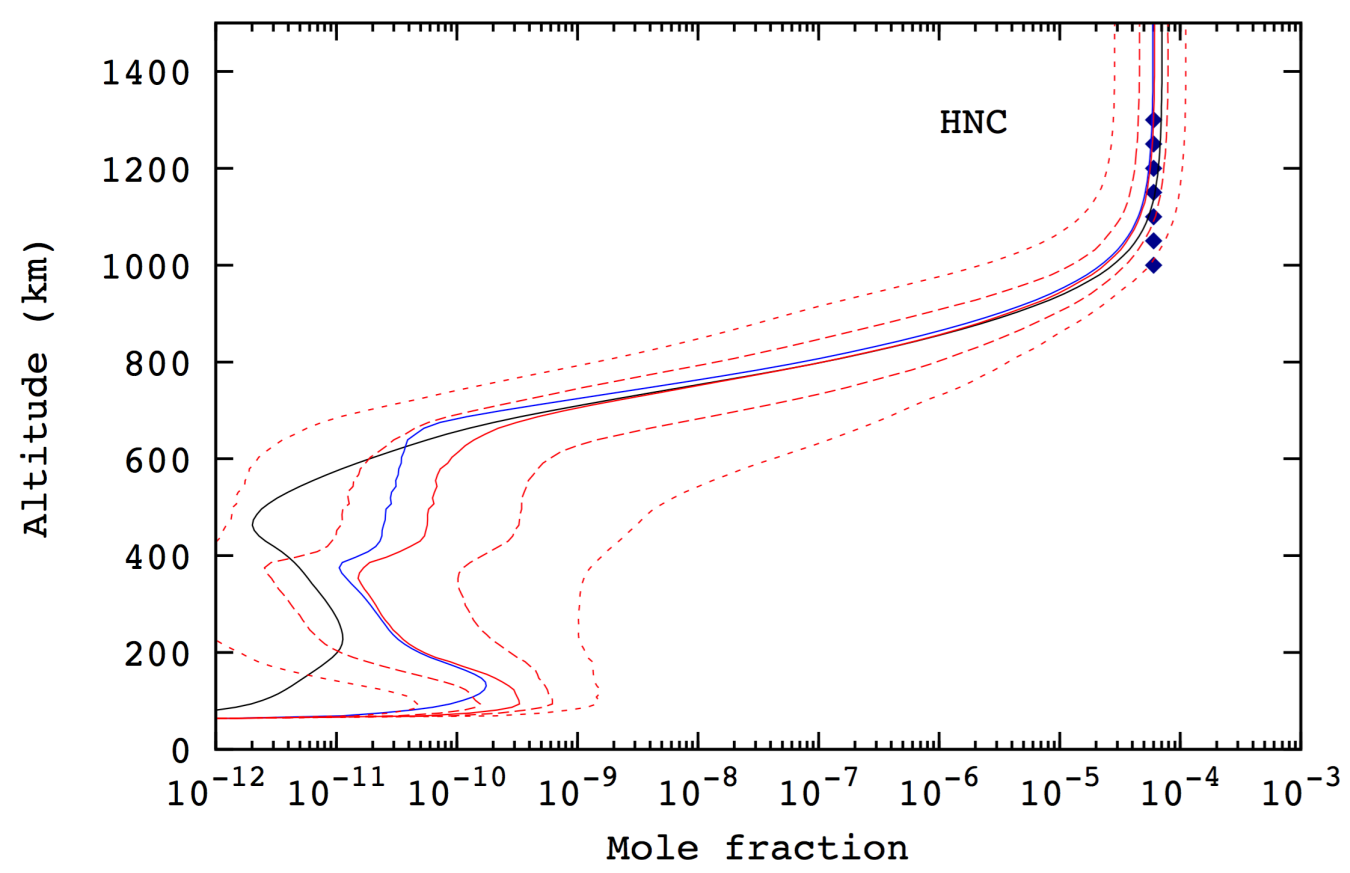

Fig. 26. Mole fraction profile of HNC (in red) and comparison with Moreno et al. (2012) (dark blue points). Solid line: Mean profile. Dashed lines and dotted lines give the intervals containing respectively $50 \%$ and $90 \%$ of the abundance profiles. In black: profile obtained when the source of dissociation by GCR is turned off. In blue: profile obtained by removing the reaction $\mathrm{H}+\mathrm{H}_{2} \mathrm{CN} \rightarrow \mathrm{H}_{2}+\mathrm{HNC}$.

density and INMS data leads to a $\mathrm{NH}_{3}$ density much smaller than the INMS data. Our simulations for $\mathrm{NH}_{4}^{+}$and $\mathrm{NH}_{3}$ densities are similar to the ones found in the model of Yelle et al. (2010). The overproduction of $\mathrm{NH}_{4}^{+}$in our model probably comes from the $\mathrm{NH}_{2}+\mathrm{HCNH}^{+} \rightarrow \mathrm{NH}_{3}^{+}+\mathrm{HCN}$ and $\mathrm{NH}_{2}+\mathrm{C}_{2} \mathrm{H}_{5}^{+}$ $\rightarrow \mathrm{NH}_{3}^{+}+\mathrm{C}_{2} \mathrm{H}_{4}$ reactions. The rate constants and products used in our model for these processes are deduced from PA values and the reactions may not lead to proton transfer. To estimate the effect of these two reactions we performed a test with these reactions switched off. The results are shown by the dashed lines in Figure 27. We notice better agreement with $\mathrm{NH}_{4}^{+}$measurements but we should keep in mind the large uncertainties on reactions producing $\mathrm{NH}_{4}^{+}$ and $\mathrm{NH}_{3}$, particularly the DR reaction of $\mathrm{CH}_{2} \mathrm{NH}_{2}^{+}$. We also notice the strong correlation between $\mathrm{NH}_{4}^{+}$and $\mathrm{NH}_{3}$ dominated by proton transfer $\left(\mathrm{NH}_{3}+\right.$ $\mathrm{HCNH}^{+}$for instance) and $\mathrm{DR}$ of $\mathrm{NH}_{4}^{+}$. Cui et al. (2009) and Magee et al. (2009) stated that the source of $\mathrm{NH}_{3}$ seen by INMS was a topic of debate. Cui et al. (2009) noticed that a significant fraction of $\mathrm{NH}_{3}$ might have been formed on the chamber walls from $\mathrm{N}$ and $\mathrm{H}$ radicals in the ambient atmosphere and Magee et al. (2009) argued that small amounts of $\mathrm{NH}_{3}$ may reach the INMS antechamber from spent hydrazine fuel. The results of our model seem to support the conclusion that most of the $\mathrm{NH}_{3}$ detected by INMS does not come from Titan's atmospheric chemistry. 


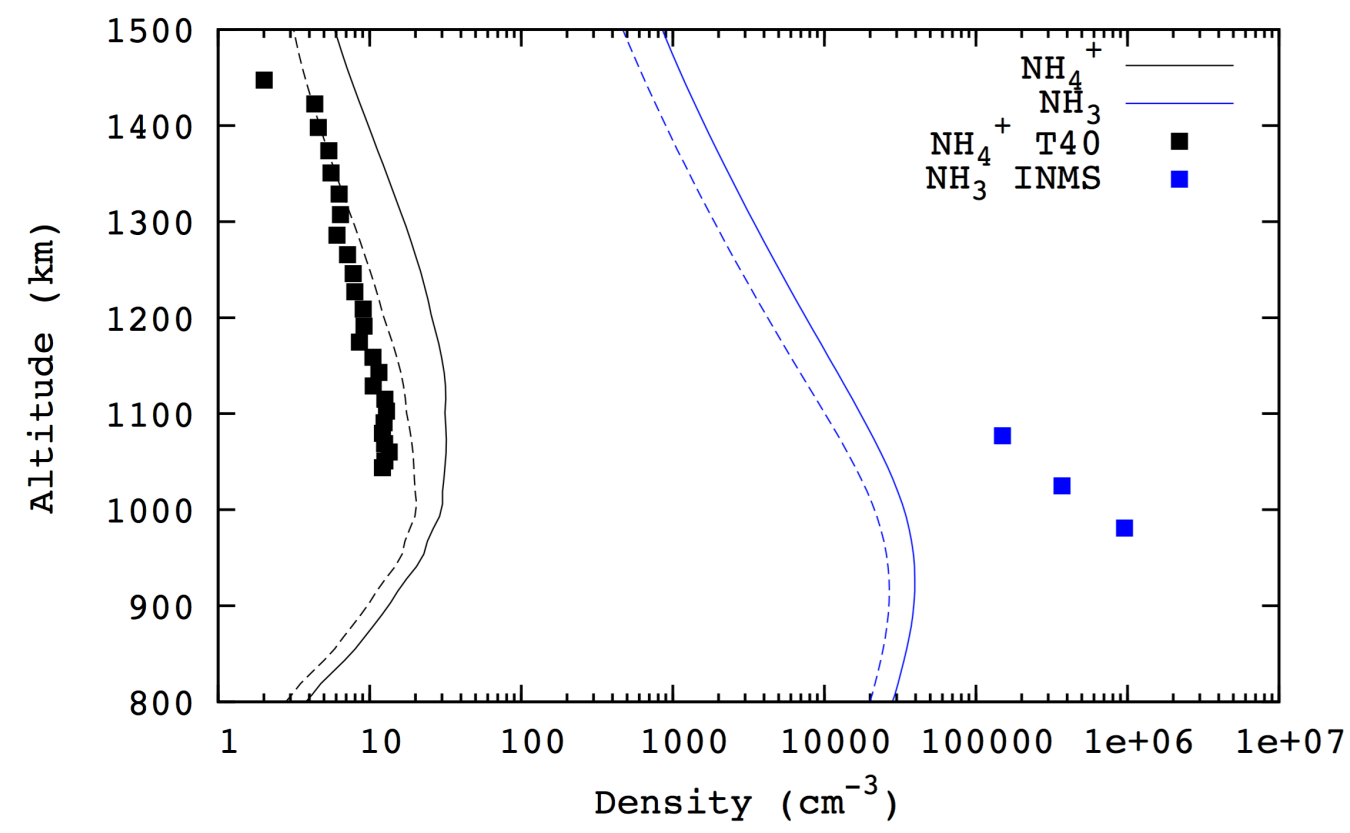

Fig. 27. Density profiles of $\mathrm{NH}_{3}$ (blue) and $\mathrm{NH}_{4}^{+}$(black). Solid lines correspond to the nominal model. Dashed lines correspond to a specific sensitivity analysis (see text). Our model has been used in dayside mode (the solar flux is not divided by a factor of 2 to account for night side). $\mathrm{NH}_{3}$ : INMS data from Cui et al. (2009). $\mathrm{NH}_{4}^{+}$: INMS-T40 data from Westlake et al. (2012). These data have been corrected following the analysis by Teolis et al. (2015). See text for uncertainties on model results.

\subsubsection{Other critical compounds: $\mathrm{C}_{3}, \mathrm{C}_{2} \mathrm{H}_{4}, \mathrm{HC}_{3} \mathrm{~N}, \mathrm{C}_{2} \mathrm{H}_{5} \mathrm{CN}$}

The introduction of ion chemistry in our model leads to a better description for most of the species but with the exception of $\mathrm{NH}_{3}$, does not lead to substantial improvement for critical cases. The calculated abundance of $\mathrm{C}_{3}$ is high even with the introduction of ion chemistry (see Hébrard et al. (2013) for the description of $\mathrm{C}_{3}$ chemistry), $\mathrm{C}_{3}$ being almost as abundant as $\mathrm{C}_{3} \mathrm{H}_{4}$ in the ionosphere. The increase of $\mathrm{C}_{2} \mathrm{H}_{4}$ below $200 \mathrm{~km}$ is not reproduced by our model and nitriles in general are still slightly over-produced; this effect being more pronounced for $\mathrm{HC}_{3} \mathrm{~N}$ and $\mathrm{C}_{2} \mathrm{H}_{5} \mathrm{CN}$. It should be noted that our neutral chemical scheme for $\mathrm{CH}_{3} \mathrm{C}_{3} \mathrm{~N}$ production leads to relatively good agreement with the $\mathrm{CH}_{3} \mathrm{C}_{3} \mathrm{NH}^{+}$abundance derived from INMS spectra. This is clearly an indication of the importance of $\mathrm{C}_{2} \mathrm{~N}$ reactions (the $\mathrm{C}_{2} \mathrm{~N}+\mathrm{C}_{2} \mathrm{H}_{4}$ reaction is the source of $\mathrm{CH}_{3} \mathrm{C}_{3} \mathrm{~N}$ in our model), which should be studied in more detail since there are very few studies on the reactions of $\mathrm{C}_{2} \mathrm{~N}$ (Loison and Hickson, 2015; Stubbing et al., 2015; Zhu et al., 2003; Wang et al., 2006). 


\subsubsection{Electron sticking on aerosols}

In our model we do not consider electron sticking on aerosols and anion densities are always much lower than the electron density. Then, DR reactions are always much more efficient than anion + cation reactions. According to Lavvas et al. (2013), this might be not true for altitudes below $1100 \mathrm{~km}$. In the model developed by Lavvas et al. (2013) there is a very efficient aerosol formation pathway through anion + cation reactions. The authors consider that anion + cation reactions mainly result in radiative associations which lead to an increase in molecule size. The authors consider that the molecule formed by this radiative association can readily accept an electron leading to an anion which reacts with another cation, continuing the chain of reactions up to very high masses. However, considering the fact that various bimolecular exit channels are energetically accessible in such reactions, radiative association is likely to be a negligible channel for small and intermediate systems. Moreover, considering the work of Shuman et al. $(2010,2012,2014)$ the first step of anion + cation reactions (for monoatomic cations) should be charge transfer by a harpoon type mechanism when the coulombic attraction is sufficient, leading to neutralisation of the cation and the anion before collision occurs. Then, there should be the formation of radicals with large kinetic energies (the radicals coming from the cations being highly energized due to their neutralization). This process would mainly involve $\mathrm{CN}, \mathrm{C}_{3} \mathrm{~N}, \mathrm{HCNH}, \mathrm{HC}_{3} \mathrm{NH}$ and $\mathrm{C}_{2} \mathrm{H}_{5}$ in Titan's atmospheric conditions (since our model predicts that $\mathrm{CN}^{-}$and $\mathrm{C}_{3} \mathrm{~N}^{-}$ are the main anions and $\mathrm{HCNH}^{+}, \mathrm{HC}_{3} \mathrm{NH}^{+}$and $\mathrm{C}_{2} \mathrm{H}_{5}^{+}$are the main cations). As the two radicals have a high relative velocity, acquired when they were charged, they will collide, which may result in some mass increase. However, the radicals arising from cation neutralization (like $\mathrm{HCNH}, \mathrm{HC}_{3} \mathrm{NH}, \mathrm{C}_{2} \mathrm{H}_{5}$ ) are likely to be unstable and in highly excited rovibrational levels which will easily dissociate. Then, most of the anion + cation reactions should lead mainly to small species $\left(\mathrm{CN}, \mathrm{C}_{3} \mathrm{~N}, \mathrm{HCN}, \mathrm{C}_{2} \mathrm{H}_{4}, \mathrm{HC}_{3} \mathrm{~N}\right)$. If the first step is proton transfer, instead of electron transfer, it leads to similar conclusions. Then the good agreement between the Lavvas et al. (2013) model and the CAPS-ELS measurement may be fortuitous and the abundance of charged aerosols might be overestimated. Moreover, when we normalize the CAPS-ELS anions spectra to our model, using anions in the mass range between 20 to 60, we predict a total anion density around $100 \mathrm{~cm}^{-3}$ at $1015 \mathrm{~km}$ which is much smaller than the observed electron density (around $4000 \mathrm{~cm}^{-3}$ at this altitude). This is also much smaller than the total anion density of Wellbrock et al. (2013) (maximum total density of $948 \mathrm{~cm}^{-3}$ at $1004 \mathrm{~km}$ ) and also much smaller than the value reported by Ågren et al. (2012) who observed total negative ion densities in the range between $1000 \mathrm{~cm}^{-3}$ up to more than $10000 \mathrm{~cm}^{-3}$ at altitudes below $900 \mathrm{~km}$ using a Langmuir probe. It should be noted however that the CAPS Micro Channel Plate efficiency for anions is unknown and has been taken to be 0.05 in Wellbrock et al. (2013). Modeling of the Langmuir

probe results by Ågren et al. (2012) shows an average mass for positive ions 
equal to $260 \mathrm{amu}$, much greater than observations (Westlake et al., 2014). It is clear that the nature of the negative carrier is highly uncertain and further work is clearly needed to clarify this point. In our model, most of the negative charge is carried by electrons in the upper atmosphere, and then DR reactions of cations are more efficient than cation + anion reactions. The situation at low altitude is less ambiguous. Indeed, there is little doubt that at low altitude most of the negative charge is carried by aerosols. We performed a test with a fixed aerosols concentration taken from Barth and Toon (2003), allowing electrons to stick to the aerosol particles with a probability equal to 1 and a collision cross section that varies as a function of the size of the aerosols. Then below $200 \mathrm{~km}$ the electron density becomes very low and cations react exclusively with charged aerosols. However, this mechanism has little effect at low altitude as neutral chemistry and photodissociation involve in general much higher fluxes.

\section{Conclusion}

We have developed a new photochemical model of Titan's stratosphere and ionosphere with the following main characteristics:

- This1D model couples positive and negative ions with neutral species, i.e. the set of continuity equations is solved for all species simultaneously.

- We studied the atmosphere from the ground up to $1500 \mathrm{~km}$, to constrain the eddy diffusion coefficient profile with several neutral species and to check the validity of the model results over the whole atmosphere.

- Neutral hydrocarbon chemistry has been updated up to $\mathrm{C}_{4} \mathrm{H}_{x}$ species with a special focus on $\mathrm{C}_{4} \mathrm{H}_{10}$.

- The neutral chemistry is derived from Loison et al. (2015). It couples hydrocarbons, nitrogen and oxygen species. It has been reduced to limit the size of the ionic chemical network and consequently to limit the computational time.

- We based our positive ion chemistry on several previous studies with some added modifications to account for the specificity of our neutral chemical network.

- The negative ion chemistry, based on the Vuitton et al. (2009) model, has been updated. This update introduces significant modifications to the chemical model.

- We introduce the high resolution $\mathrm{N}_{2}$ cross section and a high resolution solar spectrum.

- We compute the electron production rate profiles created by the input of magnetospheric electrons and galactic cosmic rays with an updated model.

- We performed for the first time an uncertainty propagation study in a fully coupled ion-neutral model in order to determine how uncertainties on rate 
constants of both neutral and ionic reactions influence the model results and to pinpoint the key reactions responsible for this behaviour.

The main results of this study are the following:

- We confirm the need to study neutrals and ions in a coupled model and we show in particular to what extent some species are affected by the absence of this coupling.

- We confirm the importance of taking into account the high resolution $\mathrm{N}_{2}$ absorption cross sections. Due to the complex coupling between neutrals and ions, the effect on their abundances is both species and altitude dependent (and thus model dependent).

- We find a very good agreement between our model results and observations in both the stratosphere and in the ionosphere for most neutral compounds.

- The inclusion of ion chemistry does not fix the problem of the overestimation of some nitrile abundances in the stratosphere.

- We confirm the large predicted abundance of $\mathrm{C}_{3}$ in the ionosphere of Titan.

- We predict that $\mathrm{C}_{4} \mathrm{H}_{10}$ (sum of the two isomers) could be as abundant as $\mathrm{C}_{3} \mathrm{H}_{8}$ in the stratosphere of Titan.

- Our model supports the hypothesis that the ammonia detected by the INMS instrument is not a product of Titan's atmospheric chemistry.

- The synthetic mass spectrum obtained with our global-mean model results is in good agreement with an average INMS mass spectrum considering the uncertainties on both model results and observations.

- Our model results are also in good agreement with specific flybys in the dayside.

- The interpretation of INMS mass spectra for masses $14,31,41$ is not straightforward since our model shows that for each of these peaks, two species may contribute differently depending on the rate constants of some key reactions. Detailed studies on these key reactions are required to resolve these ambiguities.

- We have updated and improved the production of negative ions. Despite this improvement we still produce much fewer anions than observed by Wellbrock et al. (2013) and Ågren et al. (2012).

- All these results taken together suggest that our chemical model (for both neutral and ions) provides a very good approximation of Titan's atmospheric chemistry as a whole.

- We have identified the key reactions that should be studied in priority to lower model uncertainties. We found that some critical key reactions are important for many compounds including both neutrals and ions.

- To continue to improve the chemical scheme of Titan's atmosphere, it is important to perform a more precise assessment of the uncertainty factors for some rate constants. In particular, a better evaluation of the uncertainty factors for photolysis rates (including photodissociation and photoionization) requires extended studies. 


\section{Supplementary material}

\section{A List of reactions}

List of reactions with rate constants and references used in the present model.

\section{B Integrated column rates}

For each reaction included in the model, the integrated column rate scaled to the surface (in $\mathrm{cm}^{-2} \mathrm{~s}^{-1}$ ) and the mean altitude (in $\mathrm{km}$ ) of the production are given (see Krasnopolsky 2009 for formula).

\section{Acknowledgements}

We would like to thank A.N. Heays for providing us the high resolution absorption cross section of $\mathrm{N}_{2}$ and O. Shebanits for their Cassini RPWS-LP data on the electron density profiles. GG was supported by NASA Astrobiology Institute Grant NNX15AE05G and by the NASA HIDEE program.

\section{References}

K. Ågren, J.-E. Wahlund, R. Modolo, D. Lummerzheim, M. Galand, I. MüllerWodarg, P. Canu, W. S. Kurth, T. E. Cravens, R. V. Yelle, J. H. Waite, Jr., A. J. Coates, G. R. Lewis, D. T. Young, C. Bertucci, and M. K. Dougherty. On magnetospheric electron impact ionisation and dynamics in Titan's ramside and polar ionosphere - a Cassini case study. Annales Geophysicae, 25: 2359-2369, 2007. doi: 10.5194/angeo-25-2359-2007.

K. Ågren, J.-E. Wahlund, P. Garnier, R. Modolo, J. Cui, M. Galand, and I. Müller-Wodarg. On the ionospheric structure of Titan. Planetary and Space Science, 57:1821-1827, 2009. doi: 10.1016/j.pss.2009.04.012.

K. Ågren, N. J. T. Edberg, and J.-E. Wahlund. Detection of negative ions in the deep ionosphere of Titan during the Cassini T70 flyby. Geophysical Research Letters, 39:L10201, 2012. doi: 10.1029/2012GL051714.

N. G. Adams and D. Smith. Reactions of hydrocarbon ions with hydrogen and methane at $300 \mathrm{~K}$. Chemical Physics Letters, 47(2):383-387, 1977. doi: 10.1016/0009-2614(77)80043-2. 
V. G. Anicich. Evaluated Bimolecular Ion-Molecule Gas Phase Kinetics of Positive Ions for Use in Modeling Planetary Atmospheres, Cometary Comae and Interstellar Clouds. J. Phys. Chem. Ref. Data, 22:1469-1569, 1993.

V. G. Anicich. An index of the literature for bimolecular gas phase cationmolecule reaction kinetics. JPL Publication 2003, 03-19 NASA., 2003.

V. G. Anicich, P. F. Wilson, and M. J. McEwan. An ICR Study of IonMolecules Reactions Relevant to Titan's Atmosphere: An Investigation of Binary Hydrocarbon Mixtures up to 1 Micron. Journal of the American Society for Mass Spectrometry, 17(4):544-561, 2006.

G. D. Badhwar and P. M. O'Neill. An improved model of galactic cosmic radiation for space exploration missions. Nucl. Tracks Radiat. Meas., 20(3): 403-410, July 1992. ISSN 1359-0189. doi: 10.1016/1359-0189(92)90024-P.

Nadia Balucani, Francesca Leonori, and Piergiorgio Casavecchia. Combined Crossed Beam and Theoretical Studies of the $\mathrm{N}\left({ }^{2} \mathrm{D}\right)+\mathrm{C}_{2} \mathrm{H}_{4}$ Reaction and Implications for Atmospheric Models of Titan. J. Phys. Chem. A, 116: 10467-10479, 2012.

M. Banaszkiewicz, L. M. Lara, R. Rodrigo, J. J. López-Moreno, and G. J. Molina-Cuberos. A Coupled Model of Titan's Atmosphere and Ionosphere. Icarus, 147:386-404, October 2000. doi: 10.1006/icar.2000.6448.

E. L. Barth and O. B. Toon. Microphysical modeling of ethane ice clouds in Titan's atmosphere. Icarus, 162:94-113, March 2003. doi: 10.1016/S00191035(02)00067-2.

A. Bergeat and J.-C. Loison. Reaction of carbon atoms, $\mathrm{C}\left(2 \mathrm{p}^{2},{ }^{3} \mathrm{P}\right)$ with $\mathrm{C}_{2} \mathrm{H}_{2}, \mathrm{C}_{2} \mathrm{H}_{4}$ and $\mathrm{C}_{6} \mathrm{H}_{6}$ : Overall rate constant and relative atomic hydrogen production. Phys. Chem. Chem. Phys., 3:2038-2042, 2001.

N. Carrasco and P. Pernot. Modeling of branching ratio uncertainty in chemical networks by Dirichlet distributions. Journal of Physical Chemistry A, 111:3507-3512, May 2007. doi: 10.1021/jp067306y.

N. Carrasco, O. Dutuit, R. Thissen, M. Banaszkiewicz, and P. Pernot. Uncertainty analysis of bimolecular reactions in Titan ionosphere chemistry model. Planetary and Space Science, 55:141-157, January 2007a. doi: 10.1016/j.pss.2006.06.004.

N. Carrasco, E. Hébrard, M. Banaszkiewicz, M. Dobrijevic, and P. Pernot. Influence of neutral transport on ion chemistry uncertainties in Titan ionosphere. Icarus, 192:519-526, December 2007b. doi: 10.1016/j.icarus.2007.08.016.

N. Carrasco, C. Alcaraz, O. Dutuit, S. Plessis, R. Thissen, V. Vuitton, R. Yelle, and P. Pernot. Sensitivity of a Titan ionospheric model to the ion-molecule reaction parameters. Planetary and Space Science, 56:1644-1657, November 2008. doi: 10.1016/j.pss.2008.04.007.

D. Chastaing, S. D. Le Picard, I. R. Sims, and I. W. M. Smith. Rate coefficients for the reactions of $\mathrm{C}\left({ }^{3} \mathrm{P}_{J}\right)$ atoms with $\mathrm{C}_{2} \mathrm{H}_{2}, \mathrm{C}_{2} \mathrm{H}_{4}, \mathrm{CH}_{3} \mathrm{CCH}$ and $\mathrm{H}_{2} \mathrm{CCCH}_{2}$ at temperatures down to 15 K. Astron. Astrophys., 365:241-247, 2001.

F.Z. Chen and C.Y.R. Wu. Temperature-dependent photoabsorption cross sections in the VUV-UV region. I. Methane and ethane. J. Quant. Spectrosc. 
Ra., 85(2):195-209, 2004.

M. A. Cordiner, M. Y. Palmer, C. A. Nixon, P. G. J. Irwin, N. A. Teanby, S. B. Charnley, M. J. Mumma, Z. Kisiel, J. Serigano, Y.-J. Kuan, Y.-L. Chuang, and K.-S. Wang. Ethyl Cyanide On Titan: Spectroscopic Detection and Mapping Using Alma. The Astrophysical Journal Letters, 800:L14, February 2015. doi: 10.1088/2041-8205/800/1/L14.

M. Costes, P. Halvick, K. M. Hickson, N. Daugey, and C. Naulin. Nonthreshold, threshold, and nonadiabatic behavior of the key interstellar $\mathrm{C}$ $+\mathrm{C}_{2} \mathrm{H}_{2}$ reaction. Astrophys. J., 703(2):1179-1187, 2009.

A. Coustenis, G. Bampasidis, R. K. Achterberg, P. Lavvas, D. E. Jennings, C. A. Nixon, N. A. Teanby, S. Vinatier, F. M. Flasar, R. C. Carlson, G. Orton, P. N. Romani, E. A. Guandique, and S. Stamogiorgos. Evolution of the Stratospheric Temperature and Chemical Composition over One Titanian Year. The Astrophysical Journal, 779:177, December 2013. doi: 10.1088/0004-637X/779/2/177.

T. E. Cravens, I. P. Robertson, J. H. Waite, R. V. Yelle, W. T. Kasprzak, C. N. Keller, S. A. Ledvina, H. B. Niemann, J. G. Luhmann, R. L. McNutt, W.-H. Ip, V. De La Haye, I. Mueller-Wodarg, J.-E. Wahlund, V. G. Anicich, and V. Vuitton. Composition of Titan's ionosphere. Geophysical Research Letters, 33:L07105, April 2006. doi: 10.1029/2005GL025575.

J. Cui, R. V. Yelle, V. Vuitton, J. H. Waite, W. T. Kasprzak, D. A. Gell, H. B. Niemann, I. C. F. Müller-Wodarg, N. Borggren, G. G. Fletcher, E. L. Patrick, E. Raaen, and B. A. Magee. Analysis of Titan's neutral upper atmosphere from Cassini Ion Neutral Mass Spectrometer measurements. Icarus, 200:581-615, April 2009. doi: 10.1016/j.icarus.2008.12.005.

W. Curdt, P. Brekke, U. Feldman, K. Wilhelm, B. N. Dwivedi, U. Schühle, and P. Lemaire. The SUMER spectral atlas of solar-disk features. Astronomy and Astrophysics, 375:591-613, August 2001. doi: 10.1051/00046361:20010364.

W. Curdt, E. Landi, and U. Feldman. The SUMER spectral atlas of solar coronal features. Astronomy and Astrophysics, 427:1045-1054, December 2004. doi: 10.1051/0004-6361:20041278.

V. De La Haye, J. H. Waite, T. E. Cravens, I. P. Robertson, and S. Lebonnois. Coupled ion and neutral rotating model of Titan's upper atmosphere. Icarus, 197:110-136, September 2008. doi: 10.1016/j.icarus.2008.03.022.

L. Desorgher, E. O. Flückiger, M. Gurtner, M. R. Moser, and R. Bütikofer. ATMOCOSMICS: A Geant4 code for computing the interaction of cosmic rays with the Earth's atmosphere. International Journal of Modern Physics A, 20(29):6802-6804, November 2005. ISSN 0217-751X, 1793-656X. doi: 10.1142/S0217751X05030132. Cited by 0080.

M. Dobrijevic, E. Hébrard, J. C. Loison, and K. M. Hickson. Coupling of oxygen, nitrogen, and hydrocarbon species in the photochemistry of Titan's atmosphere. Icarus, 228:324-346, January 2014. doi: 10.1016/j.icarus.2013.10.015.

M. Fournier, J.C. Guillemin, and I.R. Sims. Low temperature kinetics of $\mathrm{C}_{3} \mathrm{~N}$ 
radical reactions. In preparation., 2015.

M Galand, A. J. Coates, T. E. Cravens, and J. E. Wahlund. Chapter 11 - Titan's Ionosphere. In Titan: Interior, Surface, Atmosphere, and Space Environment. Cambridge Univ. Press., 2014.

T. D. Gilmore and T. A. Field. Absolute cross sections for dissociative electron attachment to HCCCN. Journal of Physics B: Atomic, Molecular and Optical Physics, 48(3):035201, 2015.

K. Graupner, T. L. Merrigan, T. A. Field, T. G. A. Youngs, and P. C. Marr. Dissociative electron attachment to HCCCN. New Journal of Physics, 8(7): 117, 2006.

G. Gronoff, J. Lilensten, L. Desorgher, and E. Flückiger. Ionization processes in the atmosphere of Titan. I. Ionization in the whole atmosphere. Astronomy and Astrophysics, 506:955-964, November 2009a.

G. Gronoff, J. Lilensten, and R. Modolo. Ionization processes in the atmosphere of Titan. II. Electron precipitation along magnetic field lines. Astronomy and Astrophysics, 506:965-970, November 2009b.

G. Gronoff, C. Mertens, J. Lilensten, L. Desorgher, E. Flckiger, and P. Velinov. Ionization processes in the atmosphere of Titan. III. Ionization by high-Z nuclei cosmic rays. Astronomy and Astrophysics, 529:143, May 2011.

G. Gronoff, C. Simon Wedlund, C. J. Mertens, M. Barthélemy, R. J. Lillis, and O. Witasse. Computing uncertainties in ionosphere-airglow models: II. The Martian airglow. Journal of Geophysical Research (Space Physics), 117: A05309, May 2012. doi: 10.1029/2011JA017308.

G. Gronoff, C. Simon Wedlund, C. J. Mertens, and R. J. Lillis. Computing uncertainties in ionosphere-airglow models: I. Electron flux and species production uncertainties for Mars. Journal of Geophysical Research (Space Physics), 117:04306, April 2012.

G. Gronoff, R. B. Norman, and C. J. Mertens. Computation of cosmic ray ionization and dose at Mars. I: A comparison of HZETRN and Planetocosmics for proton and alpha particles. Advances in Space Research, 55:1799-1805, April 2015. doi: 10.1016/j.asr.2015.01.028.

R. Guadagnini, G. C. Schatz, and S. P. Walch. Ab initio and RRKM studies of the reactions of $\mathrm{C}, \mathrm{CH}$ and ${ }^{1} \mathrm{CH}_{2}$ with acetylene. J. Phys. Chem. A, 102: 5857-5866, 1998.

M. Hamberg, E. Vigren, R.D. Thomas, V. Zhaunerchyk, M. Zhang, S. Trippel, M. Kaminska, I. Kashperka, M. af Ugglas, A. Kllberg, A. Simonsson, A. Paal, J. Semaniak, M. Larsson, and W.D. Geppert. Experimental studies of the dissociative recombination processes for the C6D6+ and C6D7+ ions. EAS Publications Series, 46:241-249, 2011.

E. Hébrard, M. Dobrijevic, Y. Bénilan, and F. Raulin. Photochemical kinetics uncertainties in modeling Titan's atmosphere: a review. J. Photochem. Photobiol. C - Photochem. Rev., 7:211-230, 2006.

E. Hébrard, M. Dobrijevic, Y. Bénilan, and F. Raulin. Photochemical kinetics uncertainties in modeling Titan's atmosphere: First consequences. Planet. Space Sci., 55:1470-1489, 2007. doi: 10.1016/j.pss.2007.04.006. 
E. Hébrard, M. Dobrijevic, J. C. Loison, A. Bergeat, and K. M. Hickson. Neutral production of hydrogen isocyanide (HNC) and hydrogen cyanide (HCN) in Titan's upper atmosphere. Astronomy and Astrophysics, 541: A21, May 2012. doi: 10.1051/0004-6361/201218837.

E. Hébrard, M. Dobrijevic, Jean?Christophe Loison, A. Bergeat, K.M. Hickson, and Caralp F. Photochemistry of $\mathrm{C}_{3} \mathrm{H}_{p}$ hydrocarbons in Titan's stratosphere revisited. Astronomy and Astrophysics, 2013. doi: http://dx.doi.org/10.1051/0004-6361/201220686.

E. Hébrard, M. Dobrijevic, P. Pernot, N. Carrasco, A. Bergeat, K. M. Hickson, A. Canosa, S. D. Le Picard, and I. R. Sims. How Measurements of Rate Coefficients at Low Temperature Increase the Predictivity of Photochemical Models of Titan's Atmosphere. Journal of Physical Chemistry, 113(42): 11227-11237, 2009. ISSN 1089-5639. doi: 10.1021/jp905524e.

E. Herbst and Y. Osamura. Calculations on the Formation Rates and Mechanisms for $\mathrm{C}_{n} \mathrm{H}$ Anions in Interstellar and Circumstellar Media. The Astrophysical Journal, 679:1670-1679, June 2008. doi: 10.1086/587803.

K. M. Hickson, J. C. Loison, T. Cavalié, E. Hébrard, and M. Dobrijevic. The evolution of infalling sulfur species in Titan's atmosphere. Astronomy and Astrophysics, 572:A58, December 2014. doi: 10.1051/0004-6361/201424703.

E. P. L. Hunter and S. G. Lias. Evaluated Gas Phase Basicities and Proton Affinities of Molecules: An Update. J. Phys. Chem. Ref. Data, 27(3):413$656,1998$.

M. Inoue. Ions négatifs formés dans le cyanogène et l'acide cyanhydrique . J. Chim. Phys., 63:1061-1071, 1966.

C. N. Keller, V. G. Anicich, and T. E. Cravens. Model of Titans ionosphere with detailed hydrocarbon ion chemistry. Planetary and Space Science, 46: 1157-1174, October 1998. doi: 10.1016/S0032-0633(98)00053-1.

V. A. Krasnopolsky. Chemical composition of Titan's atmosphere and ionosphere: Observations and the photochemical model. Icarus, 236:83-91, July 2014. doi: 10.1016/j.icarus.2014.03.041.

P. Lavvas, M. Galand, R. V. Yelle, A. N. Heays, B. R. Lewis, G. R. Lewis, and A. J. Coates. Energy deposition and primary chemical products in Titan's upper atmosphere. Icarus, 213:233-251, May 2011. doi: 10.1016/j.icarus.2011.03.001.

P. Lavvas, R. V. Yelle, T. Koskinen, A. Bazin, V. Vuitton, E. Vigren, M. Galand, A. Wellbrock, A. J. Coates, J. E. Wahlund, F. J. Crary, and D. Snowden. Aerosol growth in Titan ionosphere. Proceedings of the National Academy of Sciences, 110(8):2729-2734, 2013.

J. C. Loison and K. M. Hickson. Ab Initio study of the C $+\mathrm{HNC}, \mathrm{N}+\mathrm{C}_{2} \mathrm{H}$, $\mathrm{H}+\mathrm{C}_{2} \mathrm{~N}$ and $\mathrm{H}+\mathrm{CNC}$ reactions. Chem. Phys. Lett., 2015.

J. C. Loison, E. Hébrard, M. Dobrijevic, K. M. Hickson, F. Caralp, V. Hue, G. Gronoff, O. Venot, and Y. Bénilan. The neutral photochemistry of nitriles, amines and imines in the atmosphere of Titan. Icarus, 247:218-247, February 2015. doi: 10.1016/j.icarus.2014.09.039.

A. Luspay-Kuti, K. E. Mandt, S. Plessis, and T. K. Greathouse. Effects 
of Nitrogen Photoabsorption Cross Section Resolution on Minor Species Vertical Profiles in Titan's Upper Atmosphere. The Astrophysical Journal Letters, 801:L14, March 2015. doi: 10.1088/2041-8205/801/1/L14.

B. A. Magee, J. H. Waite, K. E. Mandt, J. Westlake, J. Bell, and D. A. Gell. INMS-derived composition of Titan's upper atmosphere: Analysis methods and model comparison. Planet. Space Sci., 57:1895-1916, December 2009. doi: $10.1016 /$ j.pss.2009.06.016.

K. E. Mandt, D. A. Gell, M. Perry, J. Hunter Waite, Jr., F. A. Crary, D. Young, B. A. Magee, J. H. Westlake, T. Cravens, W. Kasprzak, G. Miller, J.-E. Wahlund, K. Ågren, N. J. T. Edberg, A. N. Heays, B. R. Lewis, S. T. Gibson, V. de la Haye, and M.-C. Liang. Ion densities and composition of Titan's upper atmosphere derived from the Cassini Ion Neutral Mass Spectrometer: Analysis methods and comparison of measured ion densities to photochemical model simulations. Journal of Geophysical Research (Planets), 117(E16):10006, October 2012. doi: 10.1029/2012JE004139.

A. Marten, T. Hidayat, Y. Biraud, and R. Moreno. New Millimeter Heterodyne Observations of Titan: Vertical Distributions of Nitriles $\mathrm{HCN}, \mathrm{HC}{ }_{3} \mathrm{~N}, \mathrm{CH}$ ${ }_{3} \mathrm{CN}$, and the Isotopic Ratio ${ }^{15} \mathrm{~N} /{ }^{14} \mathrm{~N}$ in Its Atmosphere. Icarus, 158:532544, August 2002. doi: 10.1006/icar.2002.6897.

O. May, J. Fedor, B. C. Ibanescu, and M. Allan. Absolute cross sections for dissociative electron attachment to acetylene and diacetylene. Physical Review A, 77(4):040701, 2008.

O. May, D. Kubala, and M. Allan. Absolute cross sections for dissociative electron attachment to HCN and DCN. Physical Review A, 82(1):010701, 2010.

A. M. Mebel, V. V. Kislov, and M. Hayashi. Prediction of product branching ratios in the $\mathrm{C}\left({ }^{3} \mathrm{P}\right)+\mathrm{C}_{2} \mathrm{H}_{2} \rightarrow \mathrm{l}^{-} \mathrm{C}_{3} \mathrm{H}+\mathrm{H} / \mathrm{c}-\mathrm{C}_{3} \mathrm{H}+\mathrm{H} / \mathrm{C}_{3}+\mathrm{H}_{2}$ reaction using ab initio coupled clusters calculations extrapolated to the complete basis set combined with Rice-Ramsperger-Kassel-Marcus and radiationless transition theories. J. Chem. Phys., 126(20):204310, 2007.

T. J. Millar, C. Walsh, M. A. Cordiner, R. Ni Chuimin, and Herbst Eric. Hydrocarbon Anions in Interstellar Clouds and Circumstellar Envelopes. The Astrophysical Journal Letters, 662(2):L87, 2007.

D. B. Milligan, C. G. Freeman, R. G. A. R. Maclagan, M. J. McEwan, P. F. Wilson, and V. G. Anicich. Termolecular ion-molecule reactions in Titan atmosphere. II: the structure of the association adducts of $\mathrm{HCNH}^{+}$with $\mathrm{C}_{2} \mathrm{H}_{2}$ and $\mathrm{C}_{2} \mathrm{H}_{4}$. Journal of the American Society for Mass Spectrometry, 12(5):557-564, 2001.

R. Moreno, E. Lellouch, L. M. Lara, H. Feuchtgruber, M. Rengel, P. Hartogh, and R. Courtin. The abundance, vertical distribution and origin of $\mathrm{H}_{2} \mathrm{O}$ in Titan's atmosphere: Herschel observations and photochemical modelling. Icarus, 221:753-767, November 2012. doi: 10.1016/j.icarus.2012.09.006.

C. A. Nixon, D. E. Jennings, B. Bézard, S. Vinatier, N. A. Teanby, K. Sung, T. M. Ansty, P. G. J. Irwin, N. Gorius, V. Cottini, A. Coustenis, and F. M. Flasar. Detection of Propene in Titan's Stratosphere. The Astrophysical 
Journal Letters, 776:L14, October 2013. doi: 10.1088/2041-8205/776/1/L14.

R. B. Norman, G. Gronoff, and C. J. Mertens. Influence of dust loading on atmospheric ionizing radiation on Mars. Journal of Geophysical Research: Space Physics, 2014. ISSN 2169-9402. doi: 10.1002/2013JA019351. URL http://onlinelibrary.wiley.com/doi/10.1002/2013JA019351/abstract.

Z. Peng, M. Dobrijevic, E. Hébrard, N. Carrasco, and P. Pernot. Photochemical modeling of Titan atmosphere at the "10 percent uncertainty horizon". Faraday discussions, 147:137-153, 2010.

S. Plessis, N. Carrasco, and P. Pernot. Knowledge-based probabilistic representations of branching ratios in chemical networks: The case of dissociative recombinations. The Journal of Chemical Physics, 133(13):134110-21, 2010.

S. Plessis, N. Carrasco, M. Dobrijevic, and P. Pernot. Production of neutral species in Titan's ionosphere through dissociative recombination of ions. Icarus, 219:254-266, May 2012. doi: 10.1016/j.icarus.2012.02.032.

P. Rawat, V. S. Prabhudesai, M. A. Rahman, N. B. Ram, and E. Krishnakumar. Absolute cross sections for dissociative electron attachment to $\mathrm{NH}_{3}$ and $\mathrm{CH}_{4}$. International Journal of Mass Spectrometry, 277:96-102, 2008.

D. Reiter and R. K. Janev. Hydrocarbon Collision Cross Sections for Magnetic Fusion: The Methane, Ethane and Propane Families. Contributions to Plasma Physics, 50(10):986-1013, 2010.

M. S. Richard, T. E. Cravens, I. P. Robertson, J. H. Waite, J.-E. Wahlund, F. J. Crary, and A. J. Coates. Energetics of Titan's ionosphere: Model comparisons with Cassini data. Journal of Geophysical Research (Space Physics), 116:A09310, September 2011. doi: 10.1029/2011JA016603.

M. S. Richard, T. E. Cravens, C. Wylie, D. Webb, Q. Chediak, K. Mandt, J. H. Waite, A. Rymer, C. Bertucci, A. Wellbrock, A. Windsor, and A. J. Coates. An empirical approach to modeling ion production rates in $\mathrm{Ti}$ tan's ionosphere II: Ion production rates on the nightside. Journal of Geophysical Research (Space Physics), 120:1281-1298, February 2015a. doi: 10.1002/2014JA020343.

M. S. Richard, T. E. Cravens, C. Wylie, D. Webb, Q. Chediak, R. Perryman, K. Mandt, J. Westlake, J. H. Waite, I. Robertson, B. A. Magee, and N. J. T. Edberg. An empirical approach to modeling ion production rates in Titan's ionosphere I: Ion production rates on the dayside and globally. Journal of Geophysical Research (Space Physics), 120:1264-1280, February 2015b. doi: 10.1002/2013JA019706.

J. C. Rienstra-Kiracofe, G. S. Tschumper, H. F. Schaefer, S. Nandi, and G. B. Ellison. Atomic and Molecular Electron Affinities: Photoelectron Experiments and Theoretical Computations. Chemical Reviews, 102(1):231-282, 2002. doi: 10.1021/cr990044u.

I. P. Robertson, T. E. Cravens, J. H. Waite, R. V. Yelle, V. Vuitton, A. J. Coates, J. E. Wahlund, K. Ågren, K. Mandt, B. Magee, M. S. Richard, and E. Fattig. Structure of Titan's ionosphere: Model comparisons with Cassini data. Planetary and Space Science, 57:1834-1846, 2009. doi: 10.1016/j.pss.2009.07.011. 
N. J. Rogers, M. J. Simpson, R. P. Tuckett, K. F. Dunn, and C. J. Latimer. Vacuum-UV negative photoion spectroscopy of $\mathrm{CH}_{4}$. Molecular Physics, 108 (7-9):895-904, 2010. doi: 10.1080/00268970903535483.

Kei Sato, Kazuaki Misawa, Yasuhide Kobayashi, Miho Matsui, Shigeru Tsunashima, Yuzuru Kurosaki, and Toshiyuki Takayanagi. Measurements of thermal rate constants for the reactions of $\mathrm{N}\left({ }^{2} \mathrm{D}-{ }^{2} \mathrm{P}\right)$ with $\mathrm{C}_{2} \mathrm{H}_{4}$ and $\mathrm{C}_{2} \mathrm{D}_{4}$ between 225 and 292 K. J. Phys. Chem., 103(43):8650-8656, 1999.

T. E. Sharp and J. T. Dowell. Isotope Effects in Dissociative Attachment of Electrons in Methane. The Journal of Chemical Physics, 46(4):1530-1531, 1967.

O. Shebanits, J.-E. Wahlund, K. Mandt, K. Ågren, N. J. T. Edberg, and J. H. Waite. Negative ion densities in the ionosphere of Titan-Cassini RPWS/LP results. Planetary and Space Science, 84:153-162, August 2013. doi: 10.1016/j.pss.2013.05.021.

N. S. Shuman, T. M. Miller, N. Hazari, E. D. Luzik, and A. A. Viggiano. Kinetics following addition of sulfur fluorides to a weakly ionized plasma from 300 to $500 \mathrm{~K}$ : Rate constants and product determinations for ion-ion mutual neutralization and thermal electron attachment to SF5, SF3, and SF2. The Journal of Chemical Physics, 133(23):234304, 2010.

N. S. Shuman, T. M. Miller, and A. A. Viggiano. Kinetics of electron attachment to $\mathrm{OH}$ and $\mathrm{HNO}_{3}$ and mutual neutralization of $\mathrm{Ar}^{+}$with $\mathrm{NO}_{2}^{-}$and $\mathrm{NO}_{3}^{-}$at 300 and $500 \mathrm{~K}$. The Journal of Chemical Physics, 136:124307, 2012.

N. S. Shuman, J. P. Wiens, T. M. Miller, and A. A. Viggiano. Kinetics of ion-ion mutual neutralization: Halide anions with polyatomic cations. The Journal of Chemical Physics, 140(22):224309, 2014.

J. W. Stubbing, G. Vanuzzo, A. Moudens, J. C. Loison, and K. M. Hickson. Gas-Phase Kinetics of the $\mathrm{N}+\mathrm{C}_{2} \mathrm{~N}$ Reaction at Low Temperature. J. Phys. Chem. A, 119(13):3194-3199, 2015. doi: 10.1021/acs.jpca.5b01259.

N. A. Teanby, P. G. J. Irwin, C. A. Nixon, R. Courtin, B. M. Swinyard, R. Moreno, E. Lellouch, M. Rengel, and P. Hartogh. Constraints on Titan's middle atmosphere ammonia abundance from Herschel/SPIRE submillimetre spectra. Planet. Space Sci., 75:136-147, January 2013. doi: 10.1016/j.pss.2012.11.008.

B. D. Teolis, H. B. Niemann, J. H. Waite, D. A. Gell, R. S. Perryman, W. T. Kasprzak, K. E. Mandt, R. V. Yelle, A. Y. Lee, F. J. Pelletier, G. P. Miller, D. T. Young, J. M. Bell, B. A. Magee, E. L. Patrick, J. Grimes, G. G. Fletcher, and V. Vuitton. A Revised Sensitivity Model for Cassini INMS: Results at Titan. Space Science Reviews, 2015. doi: 10.1007/s11214-0140133-8.

G. Thuillier, L. Floyd, T. N. Woods, R. Cebula, E. Hilsenrath, M. Hersé, and D. Labs. Solar irradiance reference spectra for two solar active levels. Advances in Space Research, 34:256-261, January 2004. doi: 10.1016/j.asr.2002.12.004.

E. Vigren, M. Hamberg, V. Zhaunerchyk, M. Kaminska, R. D. Thomas, M. Larsson, T. J. Millar, C. Walsh, and W. D. Geppert. The Dissociative 
Recombination of Protonated Acrylonitrile, $\mathrm{CH}_{2} \mathrm{CHCNH}^{+}$, with Implications for the Nitrile Chemistry in Dark Molecular Clouds and the Upper Atmosphere of Titan. The Astrophysical Journal, 695(1):317, 2009.

E. Vigren, M. Hamberg, V. Zhaunerchyk, M. Kaminska, R. D. Thomas, M. Larsson, T. J. Millar, C. Walsh, and W. D. Geppert. Erratum: "The Dissociative Recombination of Protonated Acrylonitrile, $\mathrm{CH}_{2} \mathrm{CHCNH}^{+}$, with Implications for the Nitrile Chemistry in Dark Molecular Clouds and the Upper Atmosphere of Titan" (2009, ApJ, 695, 317). The Astrophysical Journal, 724(2):1571, 2010a.

E. Vigren, M. Hamberg, V. Zhaunerchyk, M. Kaminska, R. D. Thomas, S. Trippel, R. Wester, M. Zhang, I. Kashperka, M. af Ugglas, J. Semaniak, M. Larsson, and W. D. Geppert. Dissociative Recombination of Protonated Propionitrile, $\mathrm{CH}_{3} \mathrm{CH}_{2} \mathrm{CNH}^{+}$: Implications for Titan's Upper Atmosphere. The Astrophysical Journal, 722(1):847, 2010b.

E. Vigren, J. Semaniak, M. Hamberg, V. Zhaunerchyk, M. Kaminska, R. D. Thomas, M. af Ugglas, M. Larsson, and W. D. Geppert. Dissociative recombination of nitrile ions with implications for Titan's upper atmosphere. Planetary and Space Science, 60(1):102-106, 2012a.

E. Vigren, V. Zhaunerchyk, M. Hamberg, M. Kaminska, J. Semaniak, M. af Ugglas, M. Larsson, R. D. Thomas, and W. D. Geppert. Reassessment of the Dissociative Recombination of $\mathrm{N}_{2} \mathrm{H}^{+}$at CRYRING. The Astrophysical Journal, 757(1):34, 2012b.

E. Vigren, M. Galand, R. V. Yelle, J. Cui, J.-E. Wahlund, K. Ågren, P. P. Lavvas, I. C. F. Mueller-Wodarg, D. F. Strobel, V. Vuitton, and A. Bazin. On the thermal electron balance in Titan's sunlit upper atmosphere. Icarus, 223:234-251, March 2013. doi: 10.1016/j.icarus.2012.12.010.

S. Vinatier, B. Bézard, C. A. Nixon, A. Mamoutkine, R. C. Carlson, D. E. Jennings, E. A. Guandique, N. A. Teanby, G. L. Bjoraker, F. Michael Flasar, and V. G. Kunde. Analysis of Cassini/CIRS limb spectra of Titan acquired during the nominal mission. I. Hydrocarbons, nitriles and $\mathrm{CO}$ 2 vertical mixing ratio profiles. Icarus, 205:559-570, February 2010. doi: 10.1016/j.icarus.2009.08.013.

V. Vuitton, R. V. Yelle, and M. J. McEwan. Ion chemistry and N-containing molecules in Titan's upper atmosphere. Icarus, 191:722-742, November 2007. doi: 10.1016/j.icarus.2007.06.023.

V. Vuitton, P. Lavvas, R. V. Yelle, M. Galand, A. Wellbrock, G. R. Lewis, A. J. Coates, and J.-E. Wahlund. Negative ion chemistry in Titan's upper atmosphere. Planet. Space Sci., 57:1558-1572, November 2009. doi: 10.1016/j.pss.2009.04.004.

J. H. Waite, J. Bell, R. Lorenz, R. Achterberg, and F. M. Flasar. A model of variability in Titan's atmospheric structure. Planet. Space Sci., 86:45-56, September 2013. doi: 10.1016/j.pss.2013.05.018.

J. Wang, Y. Ding, and C. Sun. Cyanomethylidyne: A Reactive Carbyne Radical. ChemPhysChem, 7(3):710-722, 2006.

A. Wellbrock, A. J. Coates, G. H. Jones, G. R. Lewis, and J. H. Waite. Cassini 
CAPS-ELS observations of negative ions in Titan's ionosphere: Trends of density with altitude. Geophysical Research Letters, 40:4481-4485, September 2013. doi: 10.1002/grl.50751.

J. H. Westlake, J. H. Waite, Jr., K. E. Mandt, N. Carrasco, J. M. Bell, B. A. Magee, and J.-E. Wahlund. Titan's ionospheric composition and structure: Photochemical modeling of Cassini INMS data. Journal of Geophysical Research (Planets), 117:E01003, January 2012. doi: 10.1029/2011JE003883.

J. H. Westlake, J. H. Waite, N. Carrasco, M. Richard, and T. Cravens. The role of ion-molecule reactions in the growth of heavy ions in Titan's ionosphere. Journal of Geophysical Research (Space Physics), 119:5951-5963, July 2014. doi: 10.1002/2014JA020208.

E.H. Wilson and S.K. Atreya. Current state of modeling the photochemistry of Titan's mutually dependent atmosphere and ionosphere. J. Geophys. Res. - Planets, 109(E6):E06002, 2004.

R. V. Yelle, V. Vuitton, P. Lavvas, S. J. Klippenstein, M. A. Smith, S. M. Horst, and J. Cui. Formation of $\mathrm{NH}_{3}$ and $\mathrm{CH}_{2} \mathrm{NH}$ in Titan's upper atmosphere. Faraday Discuss., 147:31-49, 2010.

Z. Zhu, Z. Zhang, C. Huang, L. Pei, C. Chen, and Y. Chen. Kinetics of CCN Radical Reactions with a Series of Normal Alkanes. J. Phys. Chem. A., 107 (48):10288-10291, 2003. doi: 10.1021/jp030763j. 